\title{
Data report: consolidation characteristics of sediments along a shelf-slope transect from IODP Expedition 317, Canterbury Basin, New Zealand'
}

\author{
Daniel A. Hepp ${ }^{2}$ and Daniel Otto ${ }^{2,3}$
}

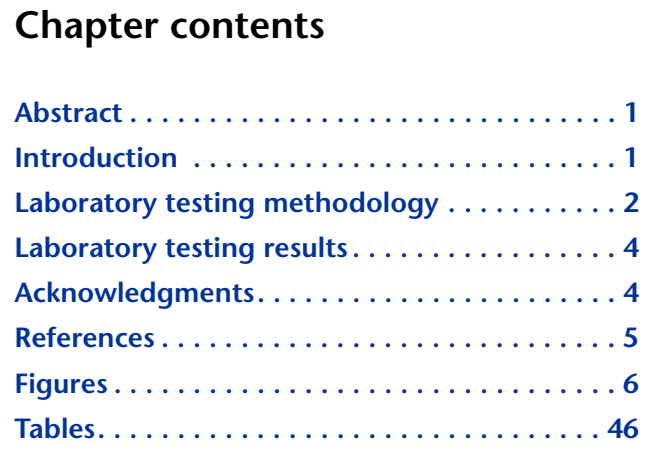

${ }^{1}$ Hepp, D.A., and Otto, D., 2013. Data report: consolidation characteristics of sediments along a shelf-slope transect from IODP Expedition 317, Canterbury Basin, New Zealand. In Fulthorpe, C.S., Hoyanagi, K., Blum, P., and the Expedition 317 Scientists, Proc. IODP, 317: Tokyo (Integrated Ocean Drilling Program Management International, Inc.).

doi:10.2204/iodp.proc.317.203.2013

2MARUM-Center for Marine Environmental Sciences and Faculty of Geosciences, University of Bremen, Leobener Strasse, 28359 Bremen,

Germany. Correspondence author: dhepp@marum.de ${ }^{3}$ GEO-ENGINEERING.org GmbH, Am Fallturm 5, 28359 Bremen, Germany.

\begin{abstract}
We performed uniaxial consolidation tests on 41 whole-round samples from four sites along a shelf-slope transect (Integrated Ocean Drilling Program [IODP] Sites U1351-U1354) that were collected during Expedition 317. Each sample was loaded in 9-15 loading and unloading steps, with each step taking $\sim 24 \mathrm{~h}$. The preconsolidation stress was estimated using a graphical procedure. However, this method has limitations because it requires that the transition from the reloading curve to the virgin compression curve is well defined on the semilogarithmic plot of void ratio versus vertical effective stress. The sediments are mostly strongly overconsolidated. In the uppermost $25 \mathrm{~m}$, the maximum past effective overburden stress correlates very well among each site. Below this depth, the maximum past effective overburden stress tends to higher values at sites more distal to the slope (Sites U1353 and U1354) than at sites proximal to the slope (Sites U1351 and U1352).
\end{abstract}

\section{Introduction}

During Integrated Ocean Drilling Program (IODP) Expedition 317, four sites were drilled along a mid-shelf to upper slope transect in the Canterbury Basin (New Zealand) (Fig. F1). The Canterbury Basin was targeted to study the complex interaction of tectonic and erosional processes with glacioeustatic change, which results in a high-frequency sedimentary record of depositional cyclicity from the late Miocene to recent (see the "Expedition 317 summary" chapter [Expedition 317 Scientists, 2011]).

A total of 19 seismostratigraphic sequence boundaries were recognized, but the interpretation of these erosional unconformities is limited due to time gaps caused by missing sediment that eroded at sequence boundaries. However, a nearly continuous sedimentary record is crucial for age-depth estimation, correlation of lithologic sequences among sites, and 2-D backstripping, among others. In intervals where "missing strata" are indicated, underestimation of sedimentation rates and thicknesses of lithologic sequences is unavoidable. This restricts the potential for interpretation of the sedimentary processes that control continental margin sedimentary cycles on the basis of a reconstructed initial sedimentary record. 
One approach to bridging these gaps in the sedimentary record is the reconstruction of missing strata using the reaction of clayey sediments to changing overburden stresses. The consolidation characteristics of clayey sediments are determined by the maximum effective overburden stress that they have experienced since their deposition. This allows us to constrain the former overburden and ultimately the thicknesses of missing strata from geotechnical tests, specifically from uniaxial consolidation tests performed using oedometers. In the course of IODP expeditions, recent consolidation tests were successfully deployed to investigate the compression behavior, with respect to evaluating the stability of continental slopes (Long et al., 2008) or to understanding the role of lithologies within subduction zones (Dugan and Daigle, 2011; Guo et al., 2011; Hüpers and Kopf, 2012; Saffer et al., 2011). In this study, we present the results of the uniaxial consolidation tests to evaluate sediment dynamics on a tectonic and glacioeustatic controlled shelf.

\section{Laboratory testing methodology}

\section{Sample handling and preparation}

All three standard coring systems, the advanced piston corer (APC), the extended core barrel (XCB), and the rotary core barrel (RCB), were used during Expedition 317. The whole-round samples used in this study were recovered using the APC and XCB coring systems only.

Because it was not possible to locate the unconformities within the cores before completion of shipboard measurements, the samples for uniaxial consolidation tests were taken according to the following scheme. The first hole (Hole A) drilled at each site was dedicated to whole-round sampling for microbiology, geochemistry, and geotechnical studies, and we obtained $10 \mathrm{~cm}$ long whole-round samples for uniaxial consolidation tests from the lower end of each core. From Holes B and C at each site we collected $6 \mathrm{~cm}$ long whole-round samples from the lower ends of approximately every fifth core. Core catchers, cores from Holes $\mathrm{B}$ and $\mathrm{C}$ that duplicated the section cored in Hole A, cores filled with pure sand, obviously disturbed cores, or cores with poor or very poor recovery were not sampled.

To avoid any additional stress on the samples or fracturing prior to the experiments and to maintain natural saturation, the whole-round samples were not extruded but cut off while still in the core liners, capped, sealed in wax, and shrink-wrapped. The samples were kept in refrigerated storage at $\sim 4^{\circ} \mathrm{C}$ both on the ship and on shore.
For the experiments, each sample was carefully removed from its wax-sealed liner and subsampled with a sharp cutter and a cutting shoe. Remaining material was capped, sealed in wax, and stored under refrigeration again for potential additional measurements.

\section{Sample descriptions}

All samples measured were visually undisturbed and showed no obvious deformation or inhomogeneity. The grain size of the samples ranges from clay to silty clay. Some samples contained few shell fragments ranging in size from the sand to coarse sand fraction. One exception, Sample 317-U1351B-104X-3, 100$106 \mathrm{~cm}$ (912.8-912.86 meters below seafloor [mbsf]), contained mainly silty and fine-grained sand and many shell fragments. As a result, this sample was too fragile; it crumbled into pieces during sample preparation and was not tested.

\section{Index properties}

Water content $\left(w_{c}\right)$ and bulk density $\left(\rho_{\mathrm{b}}\right)$ were measured on the test specimens during the onshore consolidation tests by oven-drying the samples. Water content was calculated by taking the difference in the weight of the sample before and after oven-drying and dividing this difference by the oven-dried weight. Bulk density was calculated by dividing the wet weight of the sample by the volume of the specimen. We compared the bulk density measured on our specimens with the shipboard measurements of moisture and density (MAD). The laboratory-derived wet bulk density is very scattered and underestimates density relative to the MAD wet bulk density by a factor of $\sim 1.08$ (Fig. F2). For Holes U1352A and U1354A, no shipboard MAD data are available, so we used the laboratory-derived bulk density only.

\section{Uniaxial consolidation testing}

The uniaxial consolidation tests were performed in the geotechnical laboratory of MARUM-Center for Marine Environmental Sciences (Bremen, Germany). We conducted incremental loading consolidation tests in a fixed-ring oedometer system following the general standard for unaxial consolidation tests specified by the Deutsches Institut für Normung (German Institute for Standardization) (DIN, 1999). The nomenclature and symbols used in this study are summarized in Table T1.

Specimens were prepared from the centers of wholeround samples parallel to the longitudinal axis of the core. To avoid failure of the grain structure, which would have a negative effect on preconsolidation stress, each sample was trimmed carefully by hand 
with a cutter and then placed in a tightly fitting stainless steel specimen ring. The specimen ring was used to maintain a condition of zero lateral strain. The ring has an inner diameter $(d)$ of $5.05 \mathrm{~cm}$ (area $\left.[A]=20 \mathrm{~cm}^{2}\right)$ and a height $\left(h_{\mathrm{i}}\right)$ of $1.48 \mathrm{~cm}$. A smaller ring size with $d$ of $3.57 \mathrm{~cm}\left(A=10 \mathrm{~cm}^{2}\right)$ and $h_{\mathrm{i}}$ of 14.8 $\mathrm{mm}$ was used if it was not possible to prepare intact samples for the larger ring size. This was the case for five samples (Table T2). However, the unfavorable diameter/height ratio of the small ring size may result in unwanted edge effects of friction resistance. Immediately after trimming the sample into the specimen ring, the wet weight of each sample was determined.

Loading of the specimen was applied through a mechanical lever arm capable of a maximum vertical stress of $18,000 \mathrm{kPa}$ for an area of $20 \mathrm{~cm}^{2}$. Nine incremental loading steps were needed for samples from the upper $100 \mathrm{~m}$ and $12-15$ steps were needed for samples from core depths below $100 \mathrm{mbsf}$. At the beginning of each experiment, the specimen was saturated with demineralized water in the oedometer cell for $24 \mathrm{~h}$ with applied initial vertical stress of 6.13 $\mathrm{kPa}$. The use of demineralized water, which does not correspond chemically to the natural pore water of the samples, did not obviously affect the displacement behavior of the sample, and no change in height of the sample was observed under normal pressure conditions.

For each loading phase, the initial applied vertical stress $\left(\sigma_{\text {vi }}^{\prime}\right)$ was doubled to a maximum vertical stress $\left(\sigma_{\mathrm{vm}}^{\prime}\right)$ of up to $4,905 \mathrm{kPa}$ for samples from core depths above $100 \mathrm{mbsf}$ or $34,320 \mathrm{kPa}$ for samples from core depths below 100 mbsf. We allowed $24 \mathrm{~h}$ for each loading step until the applied vertical stress was nearly equal to the vertical effective stress $\left(\sigma_{v}^{\prime}\right)$. The highest loading rates were applied on specimens from the deepest intervals to ensure that the effective stress applied to the specimen would exceed the preconsolidation stress. For the unloading phase, we reduced the applied vertical stress by $1 / 4$ every $24 \mathrm{~h}$. The associated change in height $(h)$ was measured continuously with a linear variable differential transformer mounted on the top of the consolidation cell and digitally recorded through an analog-to-digital converter.

The change in void ratio (e) during the test was calculated following the approach presented by (Blum, 1997):

$$
e=\left(V_{\mathrm{b}} \times 2.65-w_{\mathrm{d}}\right) / w_{\mathrm{d}}
$$

where

$$
V_{\mathrm{b}}=\text { bulk volume of the specimen (in cubic cen- }
$$
timeters) given by the height of the sample at the end of each loading phase and the specimen ring area,

$2.65=$ assumed grain density $\left(\right.$ in $\left.\mathrm{g} / \mathrm{cm}^{3}\right)$, and

$w_{\mathrm{d}}=$ dry weight of the sample after the test by oven-drying for $24 \mathrm{~h}$ at $60^{\circ} \mathrm{C}$.

We computed the compression index $\left(C_{\mathrm{c}}\right)$ as a function of the change in the void ratio in relation to the vertical effective stress during normal consolidation (Craig, 2004):

$$
C_{\mathrm{c}}=-\left(e_{\mathrm{n}-1}-e_{\mathrm{n}}\right) / \log \left(\sigma_{\mathrm{v} n}^{\prime} / \sigma_{\mathrm{v} n-1}^{\prime}\right) .
$$

This relationship is also shown graphically as the slope of the virgin compression curves (blue line) in the result plots of the uniaxial consolidation tests (Figs. F3-F38; Table T2; see OEDOMETER in "Supplementary material").

Preconsolidation stress $\left(\sigma_{\mathrm{pc}}\right)$ is the apparent maximum vertical effective stress the sediment experienced. $\sigma_{\mathrm{pc}}$ was determined by the graphical method of Casagrande (1936). This method requires that the transition from the reloading curve to the virgin compression curve is well defined on the semilogarithmic plot of void ratio versus vertical effective stress. $\sigma_{p c}$ (green dot in Figs. F3-F38) corresponds to the abscissa of the point of intersection between the backward projected virgin compression line (blue) and the bisecting line (black solid) between the horizontal line (black dashed) and the tangent (black dotted) at the point of maximum curvature of the consolidation curve (red). The Casagrande method potentially underestimates $\sigma_{\mathrm{pc}}$, and preconsolidations $>800 \mathrm{kPa}$ are potentially untrustworthy (Sauer et al., 1993).

The constrained modulus $\left(E_{\mathrm{s}}\right)$ is a specific value for computation of the subsidence behavior of a soil and defines the soil resistance against deformation:

$$
E_{\mathrm{s}}=\left(\Delta \sigma_{\mathrm{v}}^{\prime} / \Delta \varepsilon\right) \times(1-\varepsilon),
$$

where $\varepsilon$ is the strain rate, the change in specimen thickness for each load step in relation to the initial specimen thickness $\left(\Delta h / h_{\mathrm{i}}\right)$.

The consolidation state of the sediments was estimated from the overconsolidation ratio (OCR), which is defined as the ratio of the preconsolidation stress and the vertical hydrostatic effective stress $\left(\sigma_{v h}^{\prime}\right)$ in the following equation:

$$
\mathrm{OCR}=\sigma_{\mathrm{pc}} / \sigma_{\mathrm{vh}}^{\prime},
$$

and $\sigma_{\text {vh }}^{\prime}$ was computed by

$$
\sigma_{v h}^{\prime}=g \times z_{s} \times\left(\rho_{b}-\rho_{p w}\right),
$$


where

$\mathrm{g}=$ acceleration of gravity $\left(9.81 \mathrm{~m} / \mathrm{s}^{2}\right)$,

$Z_{\mathrm{s}}=$ midpoint of the sample depth interval (mbsf),

$\rho_{\mathrm{b}}=$ average bulk density from shipboard MAD measurements close to the relating depth interval or from uniaxial consolidation tests $\left(\mathrm{g} / \mathrm{cm}^{3}\right)$, and

$\rho_{\mathrm{pw}}=$ pore water density $\left(\sim 1 \mathrm{~g} / \mathrm{cm}^{3}\right)$.

For the calculation, it is assumed that only hydrostatic pore pressure exists in the sediments. If OCR = 1 , the tested sample is considered to be normally consolidated; OCR $<1$ indicates underconsolidation, and OCR $>1$ indicates overconsolidation.

\section{Laboratory testing results}

Thirty-six of 41 uniaxial consolidation tests were successfully performed on samples from Sites U1351-U1354. For five of the consolidation tests, the inflection point on the $e$-log could not be clearly defined in the graphical determination. The results are summarized in Table T2. The first section of the table gives sample name and sample depth information. The second section gives information about area of specimen, diameter of specimen, initial height of specimen, the initial pretest void ratio measured on the specimen $\left(e_{\mathrm{i}}\right)$, and the applied maximum load $\left(\sigma^{\prime}{ }_{v m}\right)$. The third section gives the water content, bulk density $\left(\rho_{b}\right)$, weight per unit volume $\left(\rho_{b}-1\right)$, and dry bulk density $\left(\rho_{d}\right)$ derived from oedometer tests and shipboard MAD measurements located closest to the tested sample. The final section gives the void ratio at the intersection point $\left(e_{\mathrm{pc}}\right)$, the vertical effective stress, the maximum past effective overburden stress determined by the graphical method of Casagrande (1936) $\left(\sigma_{\mathrm{pc}}\right)$, the compression index, the constrained modulus at the point of first maximum loading, and the calculated OCR. The results are graphically presented as semilogarithmic plots of void ratio versus vertical effective stress and plots of constrained modulus versus vertical effective stress (Figs. F3-F38).

The maximum past effective overburden stress versus depth is graphically presented for Sites U1351U1354 in Figure F39. As expected, the maximum past effective overburden stress for each site increases with depth. For the uppermost $25 \mathrm{~m}$, the maximum past effective overburden stress correlates well among each site. Below 25 mbsf, the maximum past effective overburden stress tends toward higher values for the shelf sites (U1353 and U1354) than for the slope site (U1352). The outermost shelf site (U1351) shows comparable values to the slope site (U1352).
The compression behavior (values from $C_{\mathrm{c}}$ ) is similar for sediments from all four sites (Table T2). $C_{c}$ ranges from 0.15 to 0.27 for samples from Site U1351. $C_{c}$ ranges from 0.15 to 0.32 for samples from Site U1353. $C_{c}$ ranges from 0.17 to 0.30 for samples from Site U1354. $C_{c}$ for samples from the slope site (U1352) show the widest range from 0.11 to 0.39 .

In general, the soil resistance against deformation $\left(E_{\mathrm{s}}\right)$ is similar for sediments from all four sites and increases with depth (from 19.30 to $510.36 \mathrm{MN} / \mathrm{m}^{2}$ ). $E_{\mathrm{s}}$ ranges from 12.17 to $83.66 \mathrm{MN} / \mathrm{m}^{2}$ for the upper $90 \mathrm{~m}$, with most values ranging between 20 and $60 \mathrm{MN} / \mathrm{m}^{2}$. For depths below $90 \mathrm{mbsf}, E_{\mathrm{s}}$ ranges from 89.53 to $510.36 \mathrm{MN} / \mathrm{m}^{2}$, with most values $>140 \mathrm{MN} / \mathrm{m}^{2}$.

OCR shows that sediments are strongly overconsolidated in the uppermost $80 \mathrm{~m}$ of all sites, with ratios ranging from 0.15 to 3.05 for the shelf edge proximal Sites U1351 and U1352 and ratios ranging from 1.34 to 3.86 for the shelf edge more distal Sites U1353 and U1354. Below $90 \mathrm{~m}$, the sediment seems to be normal to underconsolidated (values ranging from 0.15 to 1). The two uppermost samples from Site U1352 (at 2.89 and $10.09 \mathrm{mbsf}$ ) show noncredible high OCR values of 9.73 and 5.41, respectively.

We used the criteria of Lunne et al. (1997) to evaluate the effect of drilling disturbance on test quality. The results are summarized in Table T3. $\Delta e$ was calculated as the difference between the initial void ratio and the void ratio at the intersection point on the consolidation curve. The degree of sample disturbance is rated on the volume change $\Delta e / e_{\mathrm{i}}$, where ratios $<0.04$ are designated as very good to excellent, ratios from 0.04 to 0.07 are good to fair, ratios from 0.07 to 0.14 are poor, and ratios $>0.14$ are very poor. The tested samples range from fair to very poor (0.06-1.0), whereas deeper samples are generally rated very poor. The semiquantitatively evaluated results with poor to very poor rates contradict the visual observation, which describes the samples as undisturbed and not obviously deformed. Disturbance generally results in a decrease in effective stress relative to the in situ effective stress. Saffer et al. (2012) suggested that possible restructuring of the sediment fabric because of disturbance has an impact on the laboratory stress-strain response, which may not be representative of in situ behavior. The consequences of drilling disturbance while drilling on a shelf of interpretation of these results should be appreciated.

\section{Acknowledgments}

This research used whole-round samples and data provided by the Integrated Ocean Drilling Program (IODP). We thank the laboratory technicians and fel- 
low scientists aboard the R/V JOIDES Resolution for their dedicated assistance during Expedition 317. This research was funded by the Deutsche Forschungsgemeinschft (DFG Project HE5377-1) and through DFG-Research Center/Cluster of Excellence "MARUM-The Ocean in the Earth System." We thank Brandon Dugan and Craig Fulthorpe for their reviews and helpful comments on the manuscript.

\section{References}

Blum, P., 1997. Physical properties handbook: a guide to the shipboard measurement of physical properties of deep-sea cores. ODP Tech. Note, 26. doi:10.2973/ odp.tn.26.1997

Casagrande, A., 1936. The determination of pre-consolidation load and its practical significance. In Casagrande, A., Rutledge, P.C., and Watson, J.D. (Eds.), Proc. 1st Int. Conf. Soil Mech. Found. Eng. Am. Soc. Civ. Eng., 3:60-64.

Craig, R.F., 2004. Craig's Soil Mechanics (7th ed.): London (Taylor \& Francis).

DIN, 1999. Soil, Investigation and Testing: One-Dimensional Compression Test (German Standard DIN 18135-06): Berlin (Deutsches Institut für Normung).

Dugan, B., and Daigle, H., 2011. Data report: permeability, compressibility, stress state, and grain size of shallow sediments from Sites C0004, C0006, C0007, and C0008 of the Nankai accretionary complex. In Kinoshita, M., Tobin, H., Ashi, J., Kimura, G., Lallemant, S., Screaton, E.J., Curewitz, D., Masago, H., Moe, K.T., and the Expedition 314/315/316 Scientists, Proc. IODP, 314/315/316: Tokyo (Integrated Ocean Drilling Program Management International, Inc.). doi:10.2204/ iodp.proc.314315316.208.2011

Expedition 317 Scientists, 2011. Expedition 317 summary. In Fulthorpe, C.S., Hoyanagi, K., Blum, P., and the Expedition 317 Scientists, Proc. IODP, 317: Tokyo (Integrated Ocean Drilling Program Management International, Inc.). doi:10.2204/iodp.proc.317.101.2011

Guo, J., Likos, W.J., Underwood, M.B., Skarbek, R.M., Adamson, N., and Saffer, D., 2011. Data report: consolidation characteristics of sediments from Sites C0002, C0006, and C0007, IODP Expeditions 315 and 316, NanTroSEIZE Stage 1. In Kinoshita, M., Tobin, H., Ashi,
J., Kimura, G., Lallemant, S., Screaton, E.J., Curewitz, D., Masago, H., Moe, K.T., and the Expedition 314/315/316 Scientists, Proc. IODP, 314/315/316: Washington, DC (Integrated Ocean Drilling Program Management International, Inc.). doi:10.2204/

iodp.proc.314315316.213.2011

Hüpers, A., and Kopf, A.J., 2012. Data report: consolidation properties of silty claystones and sandstones sampled seaward of the Nankai Trough subduction zone, IODP Sites C0011 and C0012. In Saito, S., Underwood, M.B., Kubo, Y., and the Expedition 322 Scientists, Proc. IODP, 322: Tokyo (Integrated Ocean Drilling Program Management International, Inc.). doi:10.2204/ iodp.proc.322.203.2012

Long, H., Flemings, P.B., Germaine, J.T., Saffer, D.M., and Dugan, B., 2008. Data report: consolidation characteristics of sediments from IODP Expedition 308, Ursa Basin, Gulf of Mexico. In Flemings, P.B., Behrmann, J.H., John, C.M., and the Expedition 308 Scientists, Proc. IODP, 308: College Station, TX (Integrated Ocean Drilling Program Management International, Inc.). doi:10.2204/ iodp.proc.308.204.2008

Lunne, T., Berre, T., and Strandvik, S., 1997. Sample disturbance effects in soft low plastic Norwegian clay. Publ.Nor. Geotek. Inst., 204:81-102.

Saffer, D., Guo, J., Underwood, M.B., Likos, W., Skarbek, R.M., Song, I., and Gildow, M., 2011. Data report: consolidation, permeability, and fabric of sediments from the Nankai continental slope, IODP Sites C0001, C0008, and C0004. In Kinoshita, M., Tobin, H., Ashi, J., Kimura, G., Lallemant, S., Screaton, E.J., Curewitz, D., Masago, H., Moe, K.T., and the Expedition 314/315/316 Scientists, Proc. IODP, 314/315/316: Washington, DC (Integrated Ocean Drilling Program Management International, Inc.). doi:10.2204/ iodp.proc.314315316.218.2011

Sauer, E.K., Egeland, A.K., and Christiansen, E.A., 1993. Preconsolidation of tills and intertill clays by glacial loading in southern Saskatchewan, Canada. Can. J. Earth Sci., 30(3):420-433. doi:10.1139/e93-031

Initial receipt: 4 September 2012

Acceptance: 22 April 2013

Publication: 15 July 2013

MS 317-203 
Figure F1. A. Map of the Canterbury Basin on eastern margin of South Island, New Zealand, showing location of study area and boreholes (after Expedition 317 Scientists, 2011). ODP = Ocean Drilling Program. (Continued on next page.)

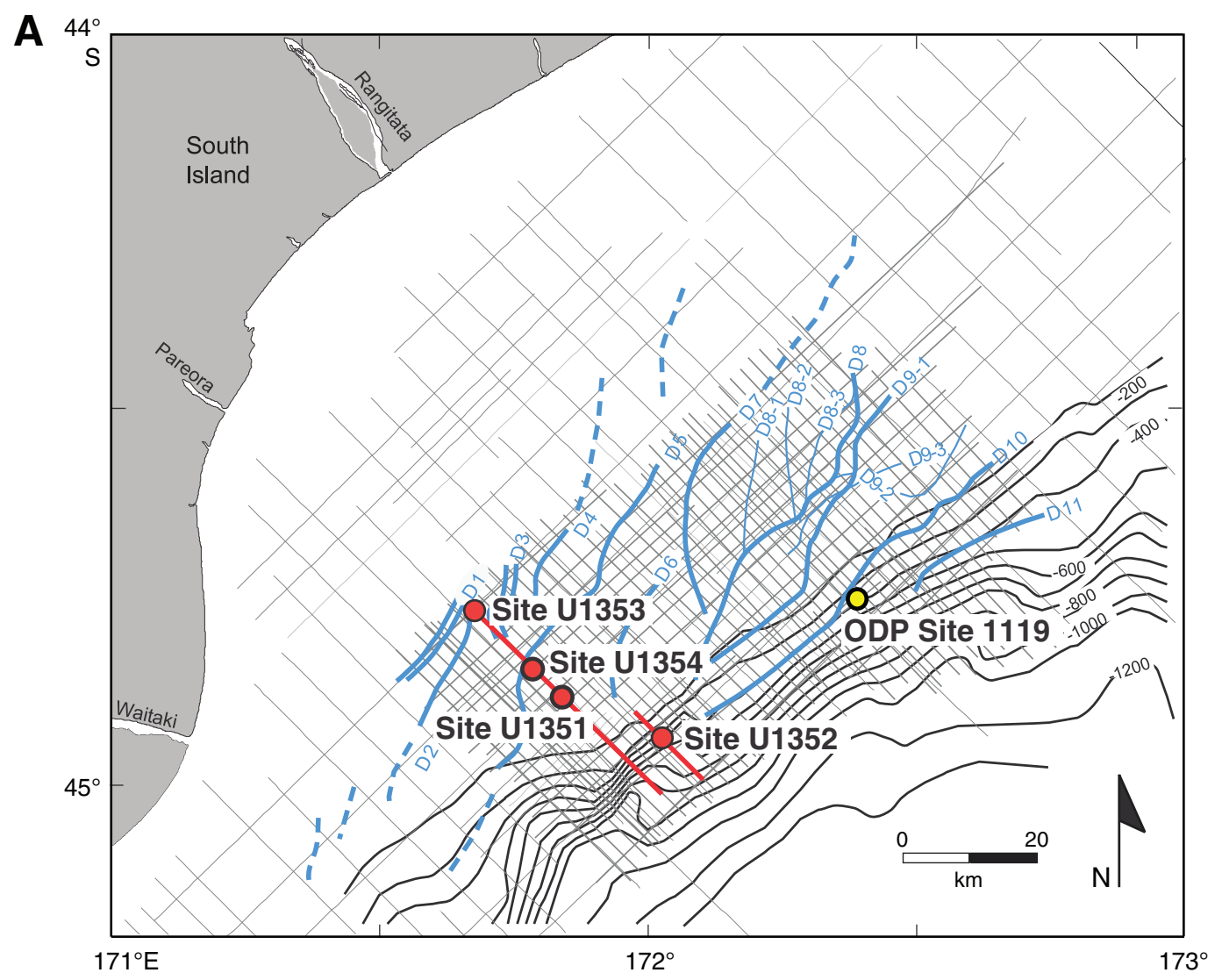


Figure F1 (continued). B. Seismic dip Profile EW00-01-66 across the shelf showing locations of Sites U1351, U1353, and U1354. C. Profile EW0001-60 across the slope showing location of Site U1352 (after Expedition 317 Scientists, 2011). MP = Marshall Paraconformity.
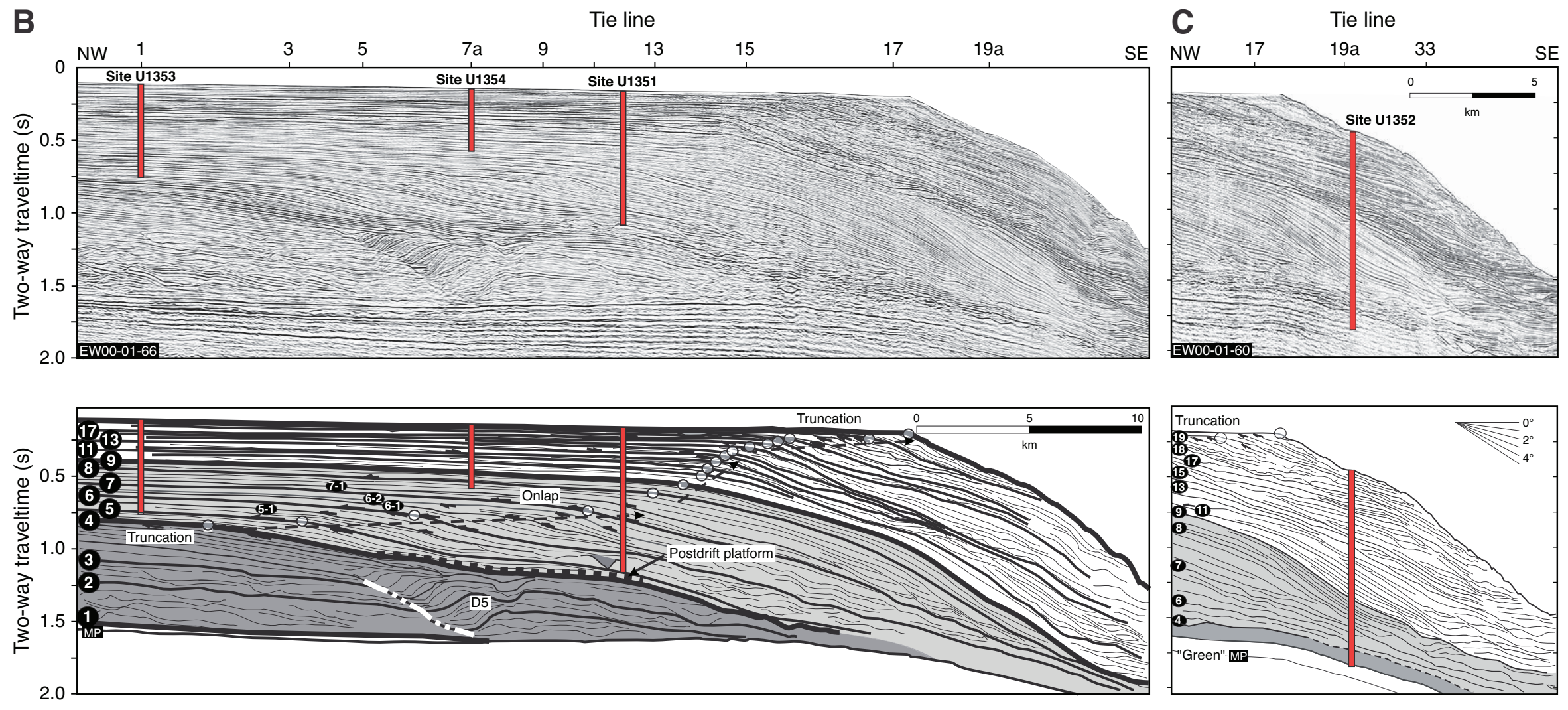
Current erosion
2. Sequence boundary:
$\square \begin{aligned} & \text { Sequences between } \\ & \text { boundaries } \mathrm{U} 1 \text { and } \mathrm{U} 4\end{aligned}$
Sequences between
boundaries U4 and U9
Sequences between
seafloor and boundary U
$\bigcirc$ Shelf edge 
Figure F2. Comparison of bulk density derived from shipboard moisture and density measurements and onshore laboratory measurements on specimens during oedometer tests, Expedition 317.

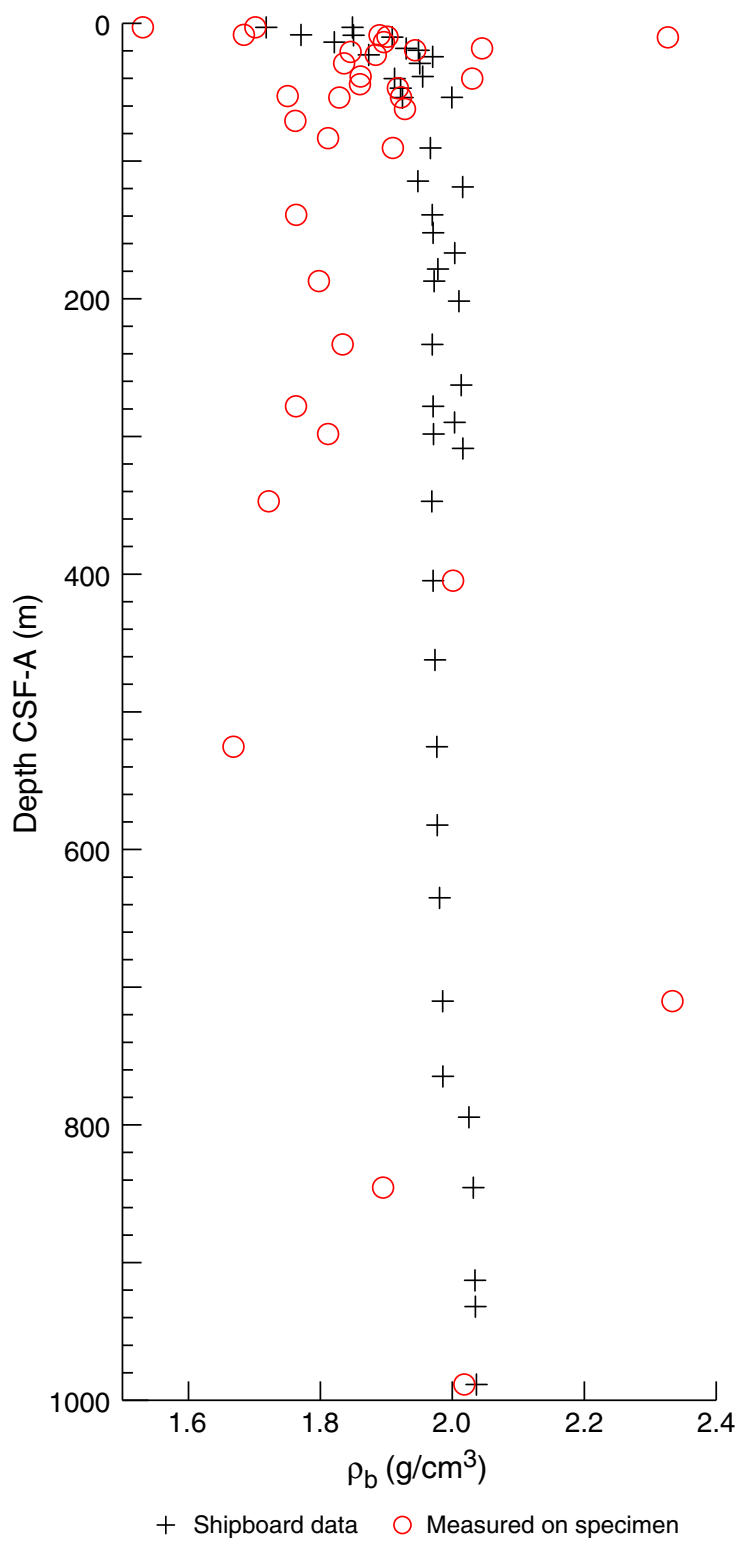


Figure F3. Results of uniaxial consolidation test (interval 317-U1351A-2H-4, 148-150 cm) represented by a semilogarithmic plot of (A) void ratio vs. vertical effective stress and (B) constrained modulus vs. vertical effective stress. Green dot = maximum past effective stress $\left(\sigma_{\mathrm{pc}}\right)$ derived by the graphical method of Casagrande (1936). $\sigma_{\mathrm{pc}}$ corresponds to the abscissa of the point of intersection between the backward projected virgin compression line (blue) and the bisecting line (black solid) between the horizontal line (black dashed) and the tangent (black dotted) at the point of maximum curvature of the consolidation curve (red).
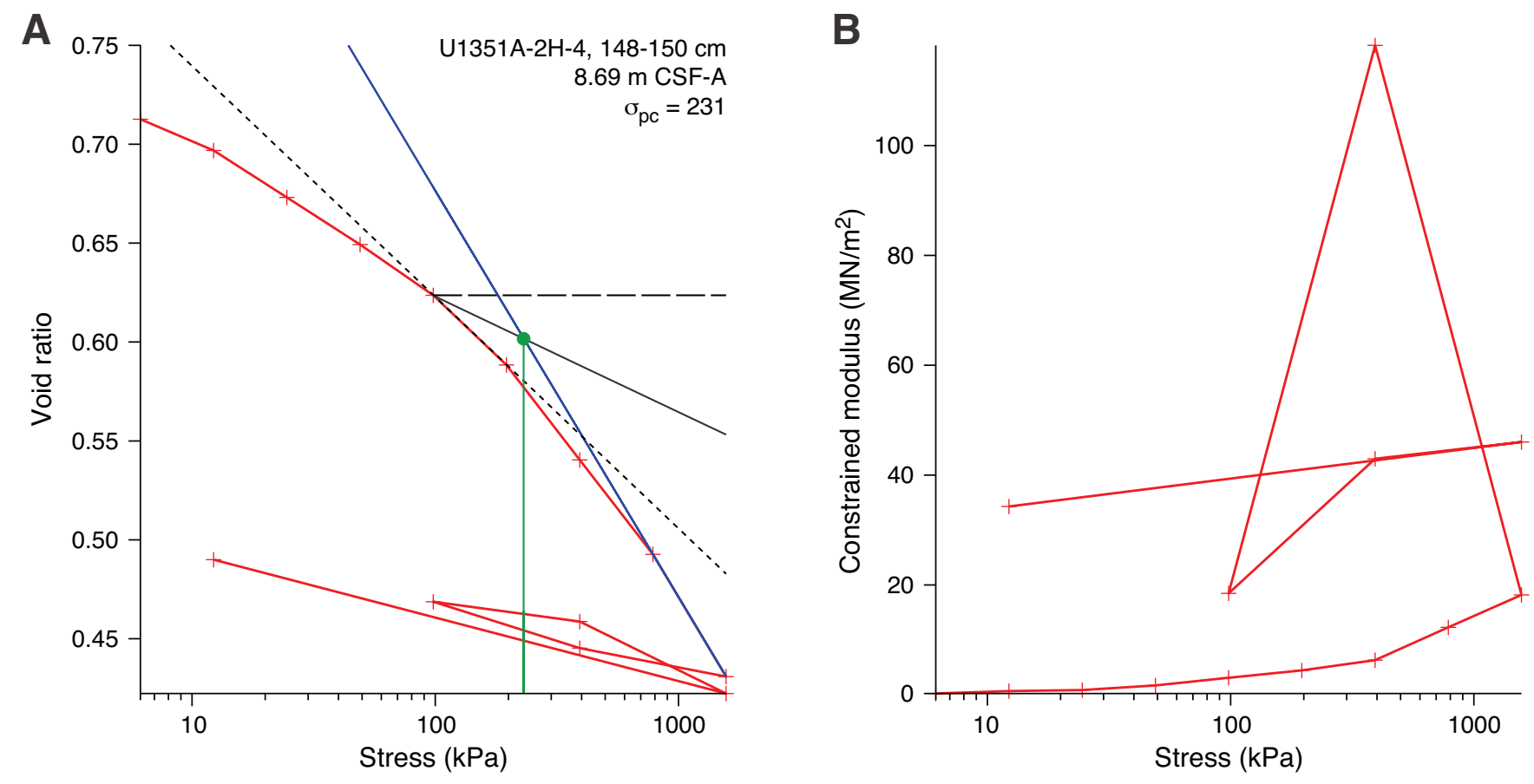
Figure F4. Results of uniaxial consolidation test (interval 317-U1351A-3H-4, 148-150 cm) represented by a semilogarithmic plot of (A) void ratio vs. vertical effective stress and (B) constrained modulus vs. vertical effective stress. Green dot = maximum past effective stress $\left(\sigma_{\mathrm{pc}}\right)$ derived by the graphical method of Casagrande (1936). $\sigma_{\mathrm{pc}}$ corresponds to the abscissa of the point of intersection between the backward projected virgin compression line (blue) and the bisecting line (black solid) between the horizontal line (black dashed) and the tangent (black dotted) at the point of maximum curvature of the consolidation curve (red).
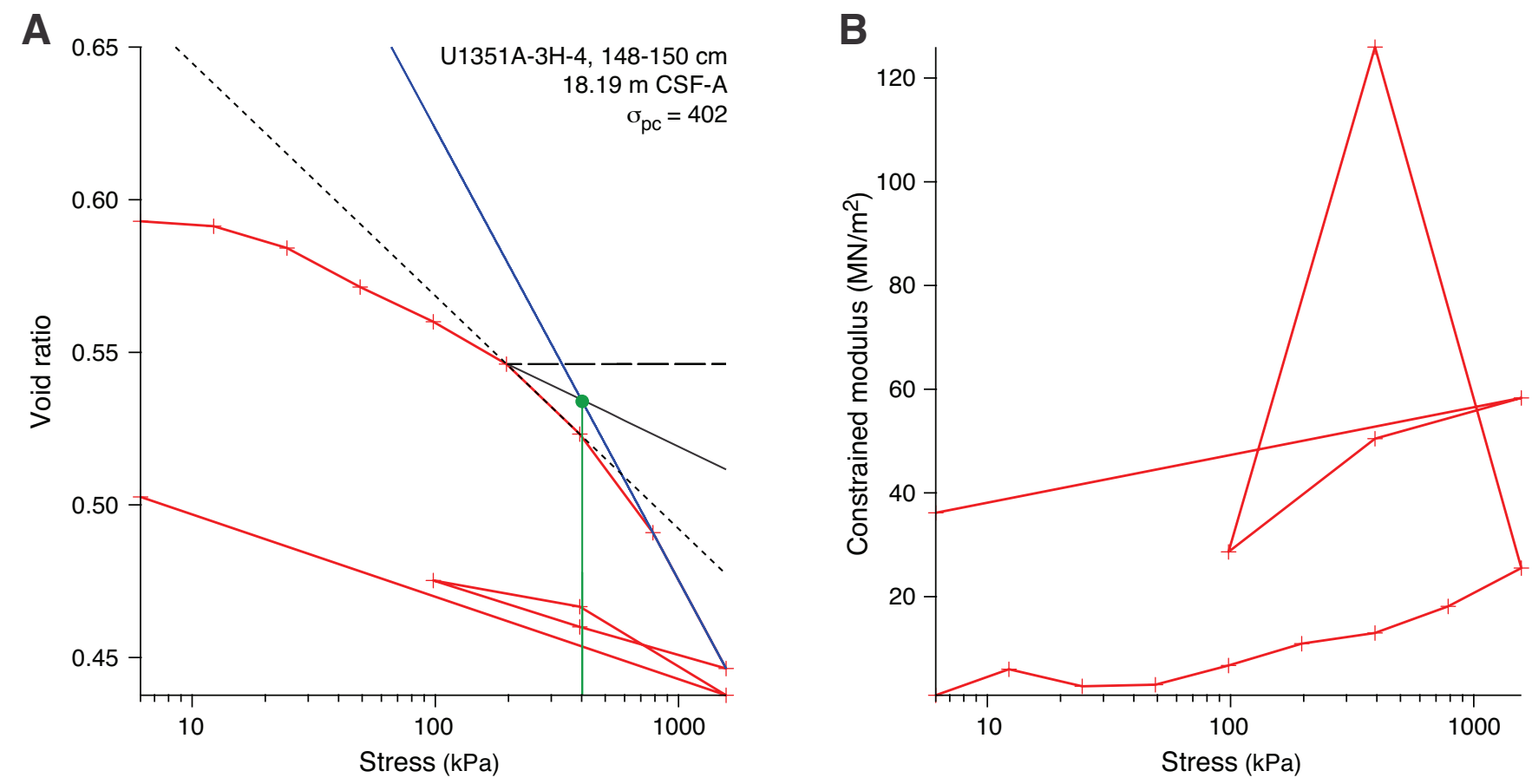
Figure F5. Results of uniaxial consolidation test (interval 317-U1351B-8H-4, 152-154 cm) represented by a semilogarithmic plot of (A) void ratio vs. vertical effective stress and (B) constrained modulus vs. vertical effective stress. Green dot = maximum past effective stress $\left(\sigma_{\mathrm{pc}}\right)$ derived by the graphical method of Casagrande (1936). $\sigma_{\mathrm{pc}}$ corresponds to the abscissa of the point of intersection between the backward projected virgin compression line (blue) and the bisecting line (black solid) between the horizontal line (black dashed) and the tangent (black dotted) at the point of maximum curvature of the consolidation curve (red).
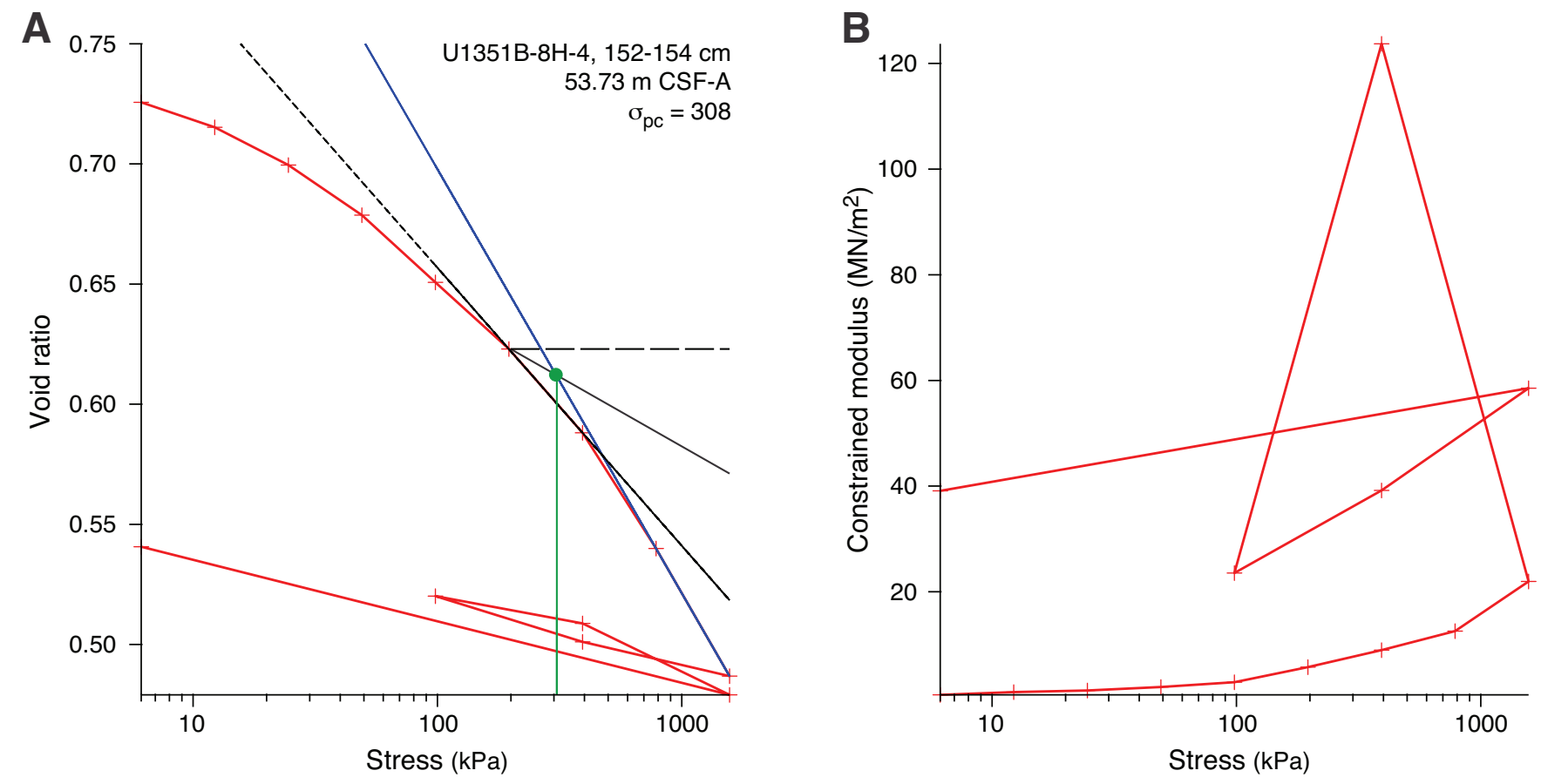
Figure F6. Results of uniaxial consolidation test (interval 317-U1351B-97X-3, 148-150 cm) represented by a semilogarithmic plot of (A) void ratio vs. vertical effective stress and (B) constrained modulus vs. vertical effective stress. Green dot = maximum past effective stress $\left(\sigma_{\mathrm{pc}}\right)$ derived by the graphical method of Casagrande (1936). $\sigma_{\mathrm{pc}}$ corresponds to the abscissa of the point of intersection between the backward projected virgin compression line (blue) and the bisecting line (black solid) between the horizontal line (black dashed) and the tangent (black dotted) at the point of maximum curvature of the consolidation curve (red).
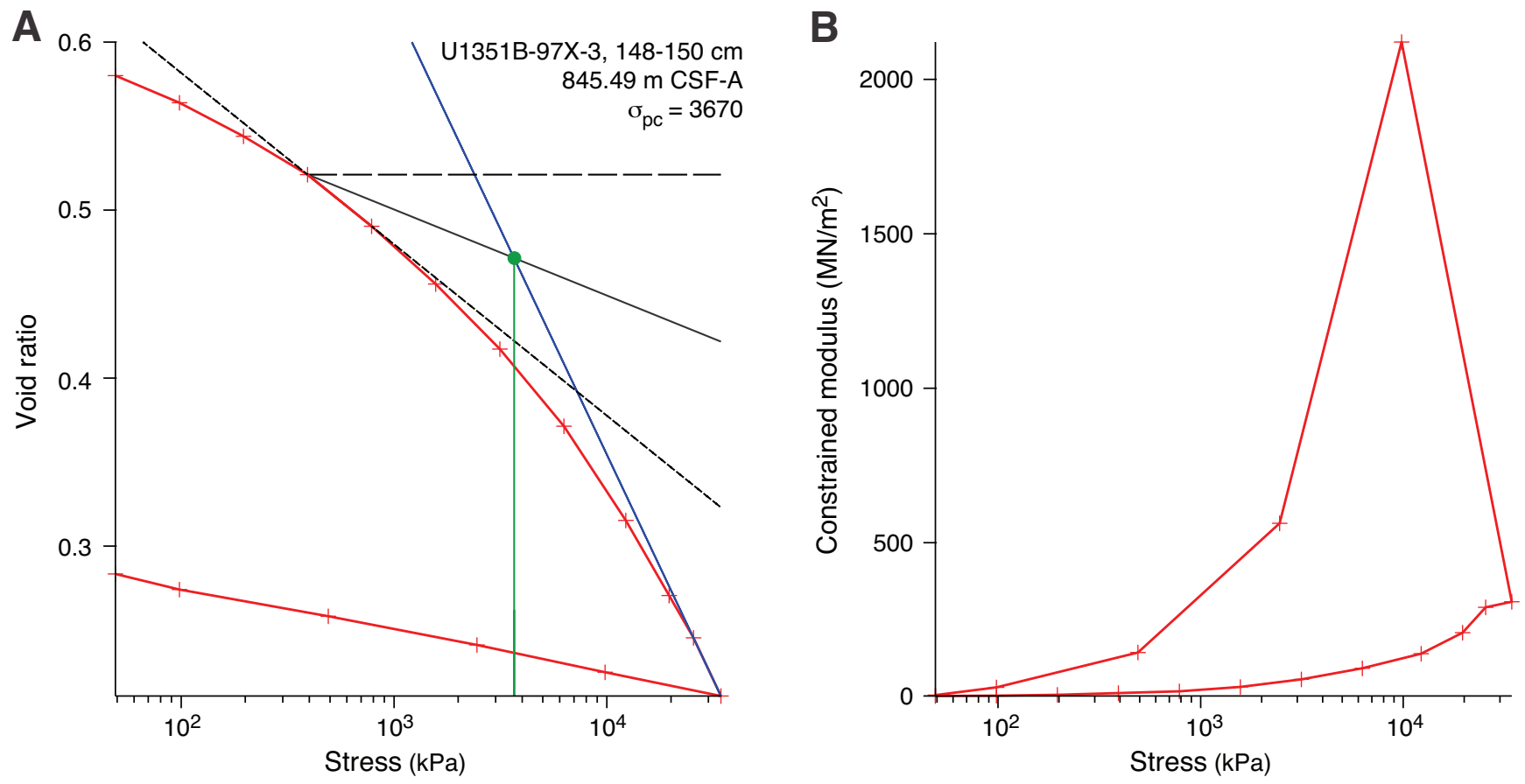
Figure F7. Results of uniaxial consolidation test (interval 317-U1351B-106X-3, 98-100 cm) represented by a semilogarithmic plot of (A) void ratio vs. vertical effective stress and (B) constrained modulus vs. vertical effective stress. Green dot = maximum past effective stress $\left(\sigma_{\mathrm{pc}}\right)$ derived by the graphical method of Casagrande (1936). $\sigma_{\mathrm{pc}}$ corresponds to the abscissa of the point of intersection between the backward projected virgin compression line (blue) and the bisecting line (black solid) between the horizontal line (black dashed) and the tangent (black dotted) at the point of maximum curvature of the consolidation curve (red).
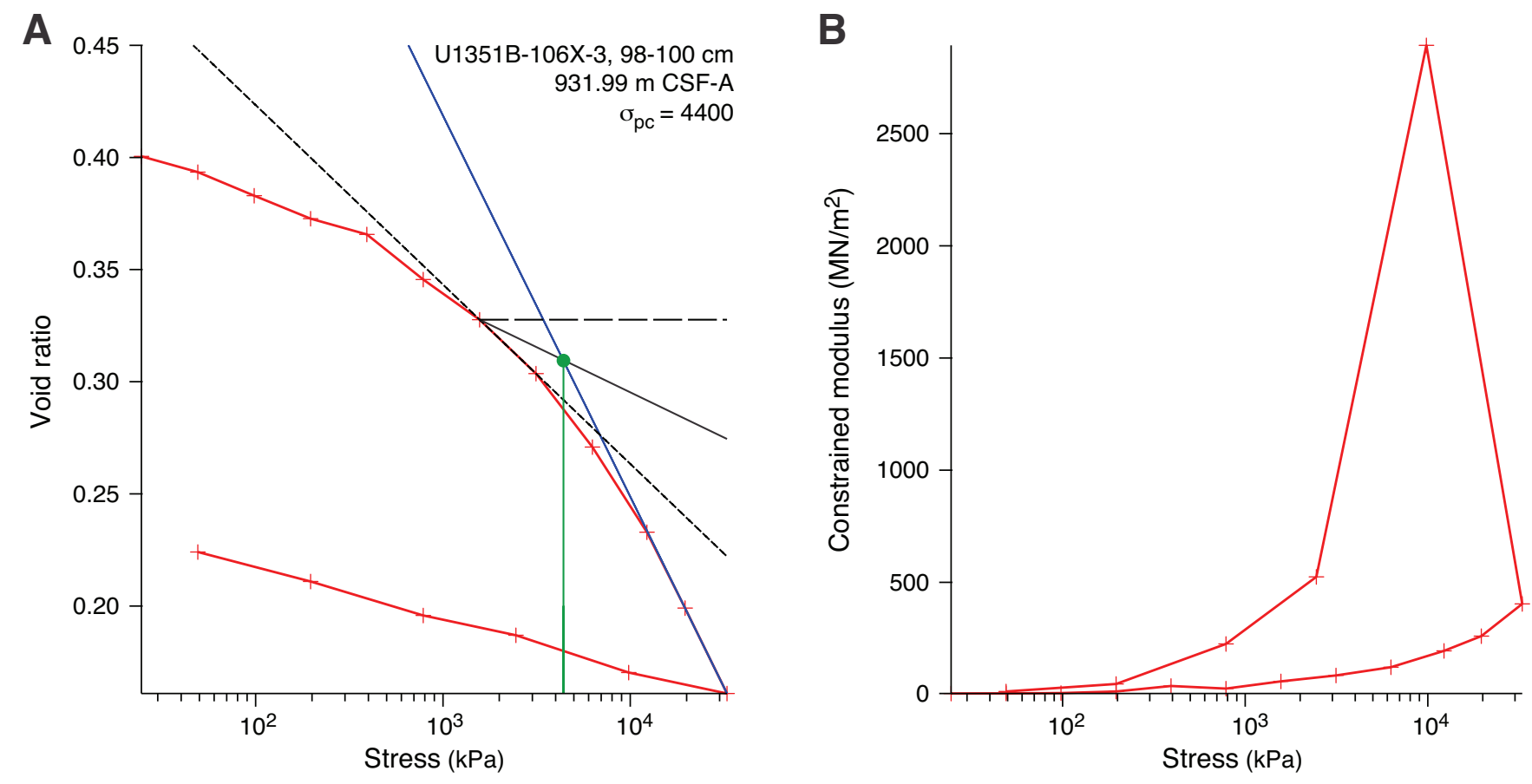
Figure F8. Results of uniaxial consolidation test (interval 317-U1351B-112X-2, 148-150 cm) represented by a semilogarithmic plot of (A) void ratio vs. vertical effective stress and (B) constrained modulus vs. vertical effective stress. Green dot = maximum past effective stress $\left(\sigma_{\mathrm{pc}}\right)$ derived by the graphical method of Casagrande (1936). $\sigma_{\mathrm{pc}}$ corresponds to the abscissa of the point of intersection between the backward projected virgin compression line (blue) and the bisecting line (black solid) between the horizontal line (black dashed) and the tangent (black dotted) at the point of maximum curvature of the consolidation curve (red).
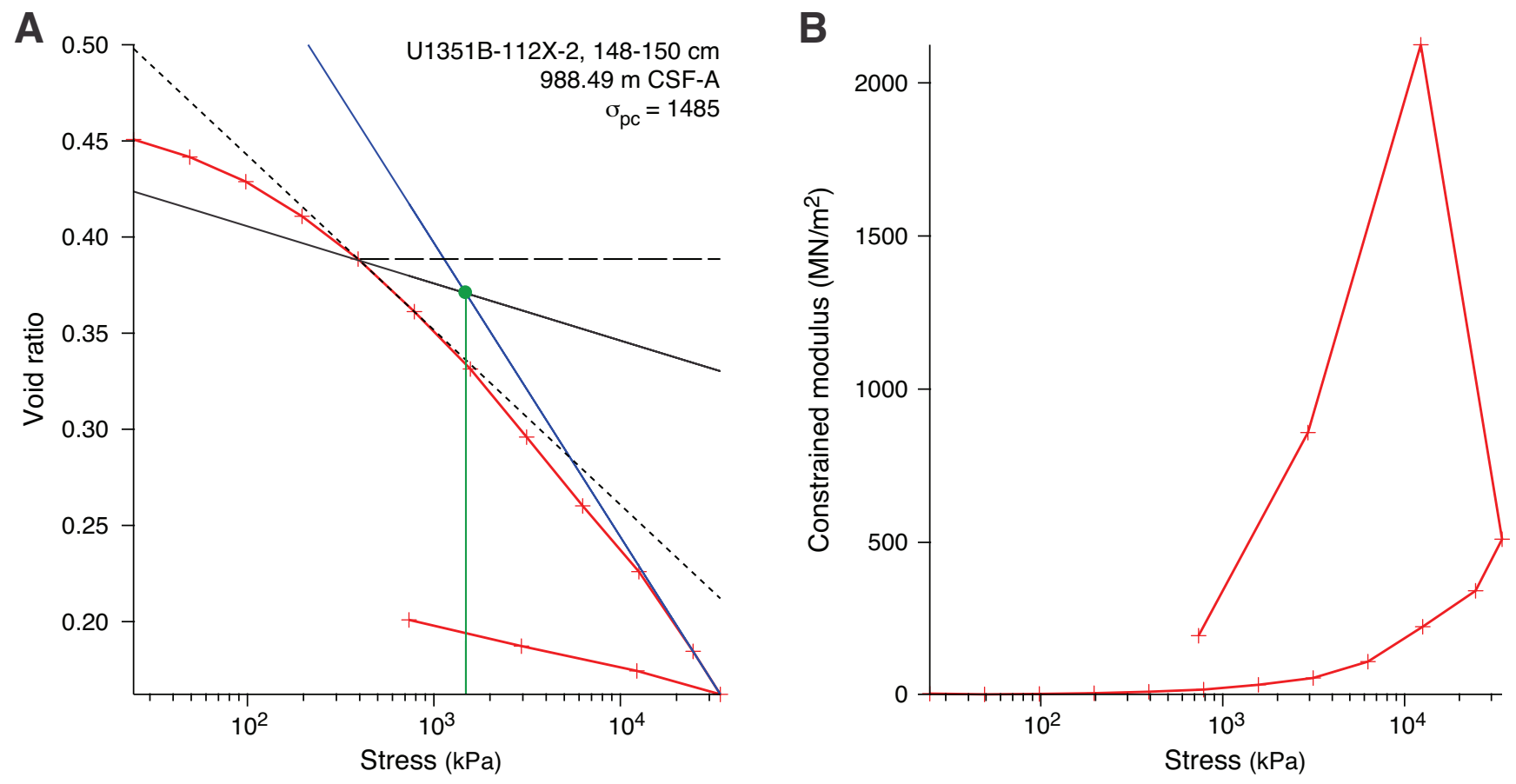
Figure F9. Results of uniaxial consolidation test (interval 317-U1352A-1H-2, 138-140 cm) represented by a semilogarithmic plot of (A) void ratio vs. vertical effective stress and (B) constrained modulus vs. vertical effective stress. Green dot = maximum past effective stress $\left(\sigma_{\mathrm{pc}}\right)$ derived by the graphical method of Casagrande (1936). $\sigma_{\mathrm{pc}}$ corresponds to the abscissa of the point of intersection between the backward projected virgin compression line (blue) and the bisecting line (black solid) between the horizontal line (black dashed) and the tangent (black dotted) at the point of maximum curvature of the consolidation curve (red).
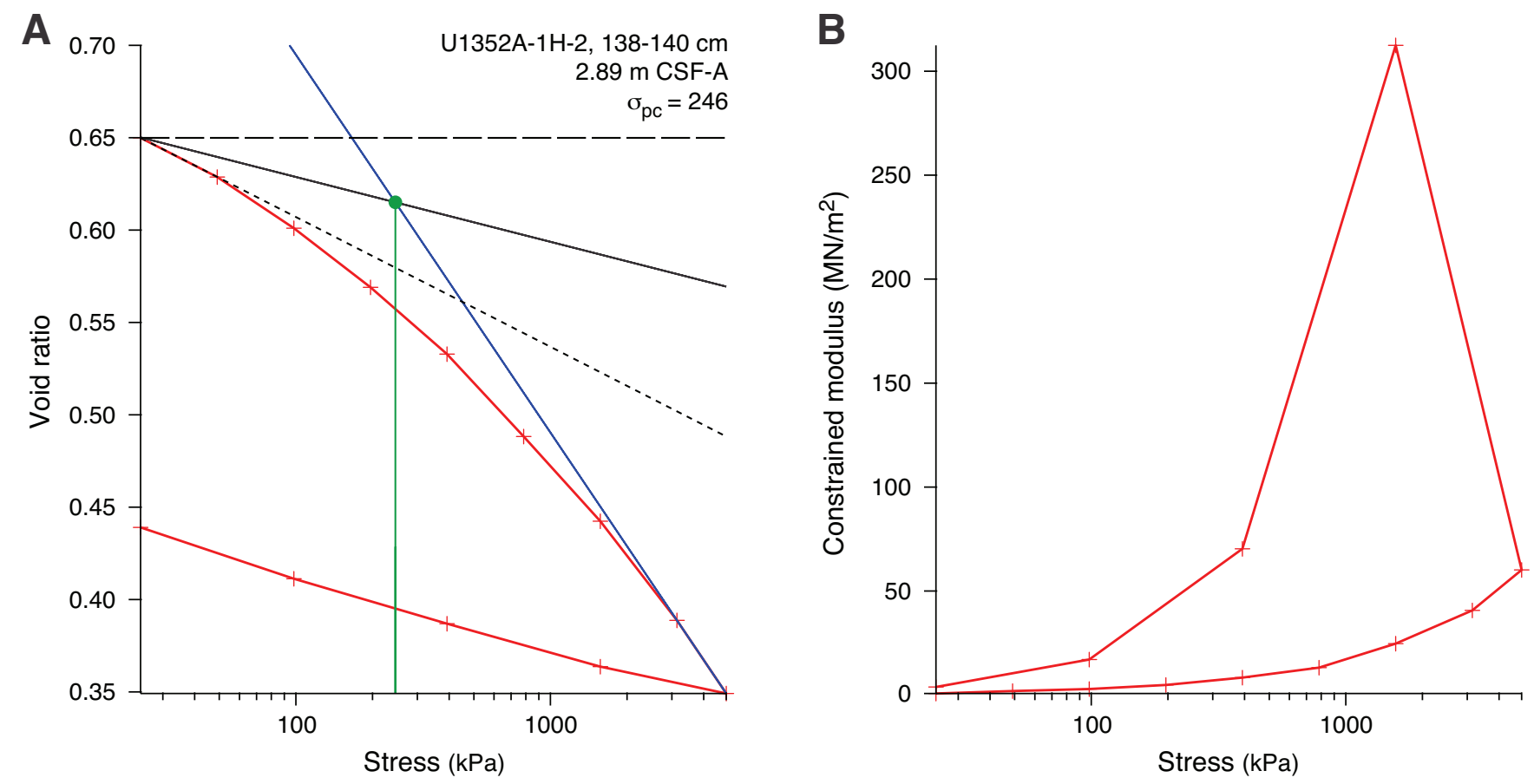
Figure F10. Results of uniaxial consolidation test (interval 317-U1352A-2H-4, 138-140 cm) represented by a semilogarithmic plot of (A) void ratio vs. vertical effective stress and (B) constrained modulus vs. vertical effective stress. Green dot = maximum past effective stress $\left(\sigma_{\mathrm{pc}}\right)$ derived by the graphical method of Casagrande (1936). $\sigma_{\mathrm{pc}}$ corresponds to the abscissa of the point of intersection between the backward projected virgin compression line (blue) and the bisecting line (black solid) between the horizontal line (black dashed) and the tangent (black dotted) at the point of maximum curvature of the consolidation curve (red).
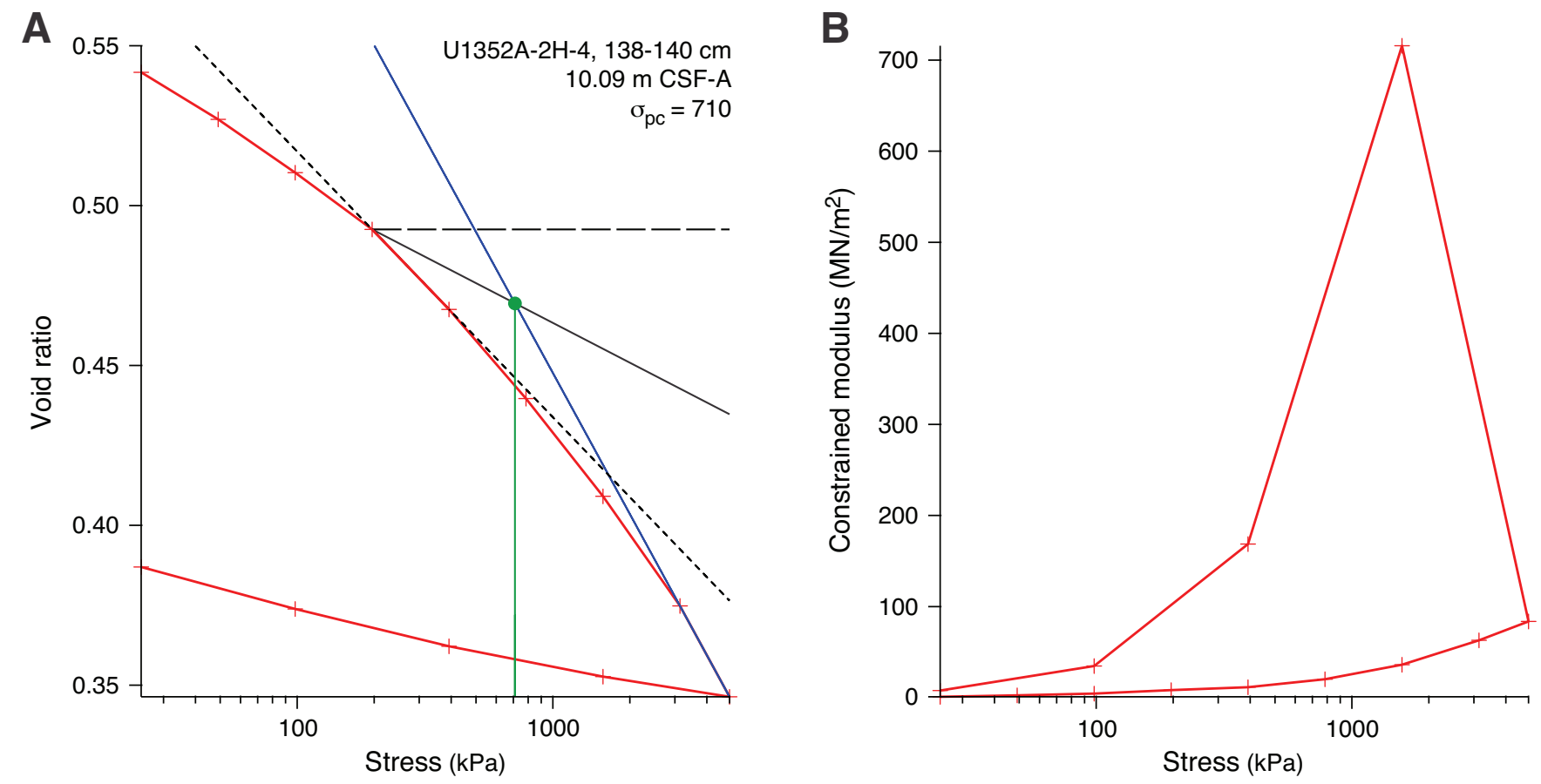
Figure F11. Results of uniaxial consolidation test (interval 317-U1352A-3H-4, 138-140 cm) represented by a semilogarithmic plot of (A) void ratio vs. vertical effective stress and (B) constrained modulus vs. vertical effective stress. Green dot = maximum past effective stress $\left(\sigma_{p c}\right)$ derived by the graphical method of Casagrande (1936). $\sigma_{\mathrm{pc}}$ corresponds to the abscissa of the point of intersection between the backward projected virgin compression line (blue) and the bisecting line (black solid) between the horizontal line (black dashed) and the tangent (black dotted) at the point of maximum curvature of the consolidation curve (red).
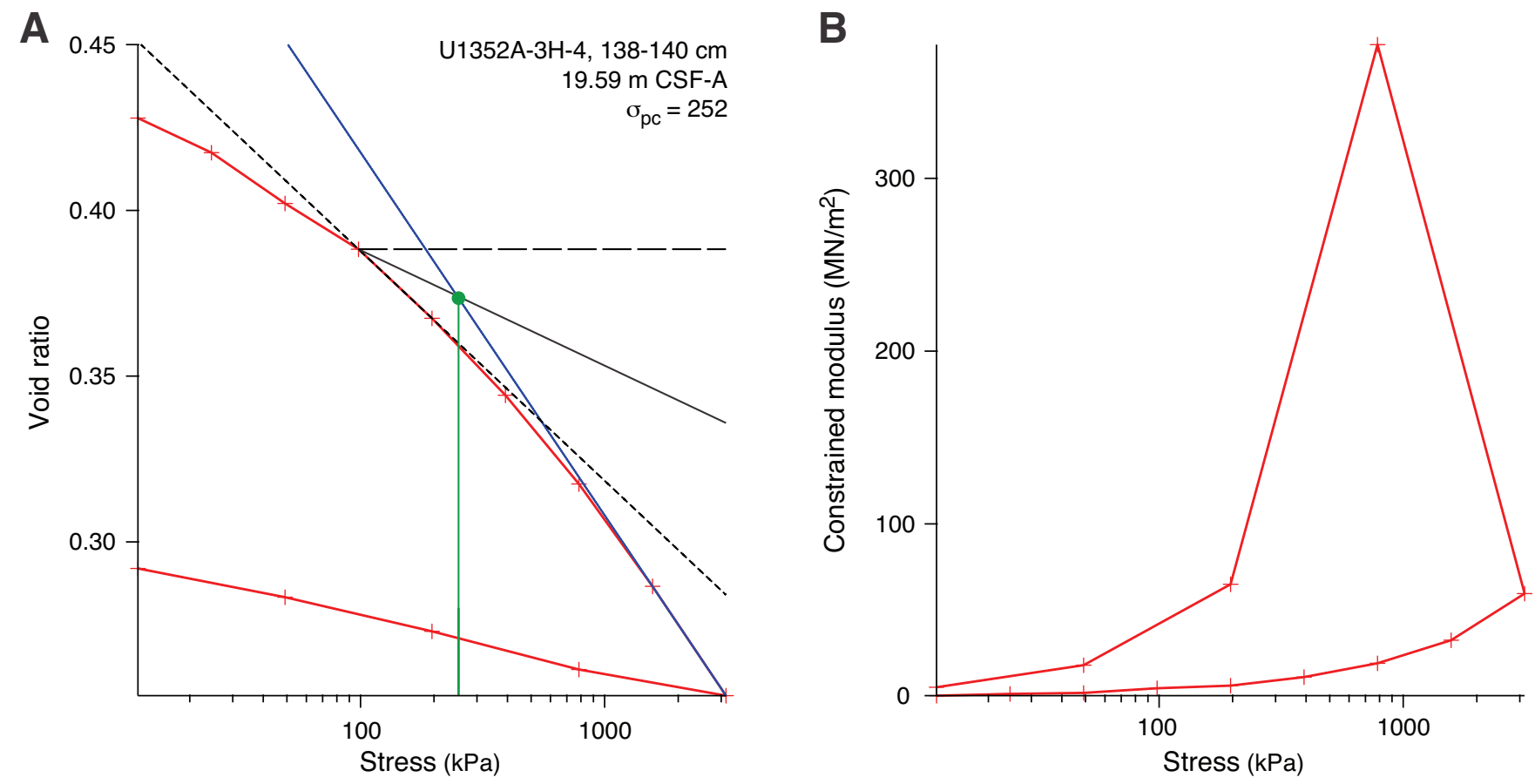
Figure F12. Results of uniaxial consolidation test (interval 317-U1352A-4H-4, 138-140 cm) represented by a semilogarithmic plot of (A) void ratio vs. vertical effective stress and (B) constrained modulus vs. vertical effective stress. Green dot = maximum past effective stress $\left(\sigma_{\mathrm{pc}}\right)$ derived by the graphical method of Casagrande (1936). $\sigma_{\mathrm{pc}}$ corresponds to the abscissa of the point of intersection between the backward projected virgin compression line (blue) and the bisecting line (black solid) between the horizontal line (black dashed) and the tangent (black dotted) at the point of maximum curvature of the consolidation curve (red).
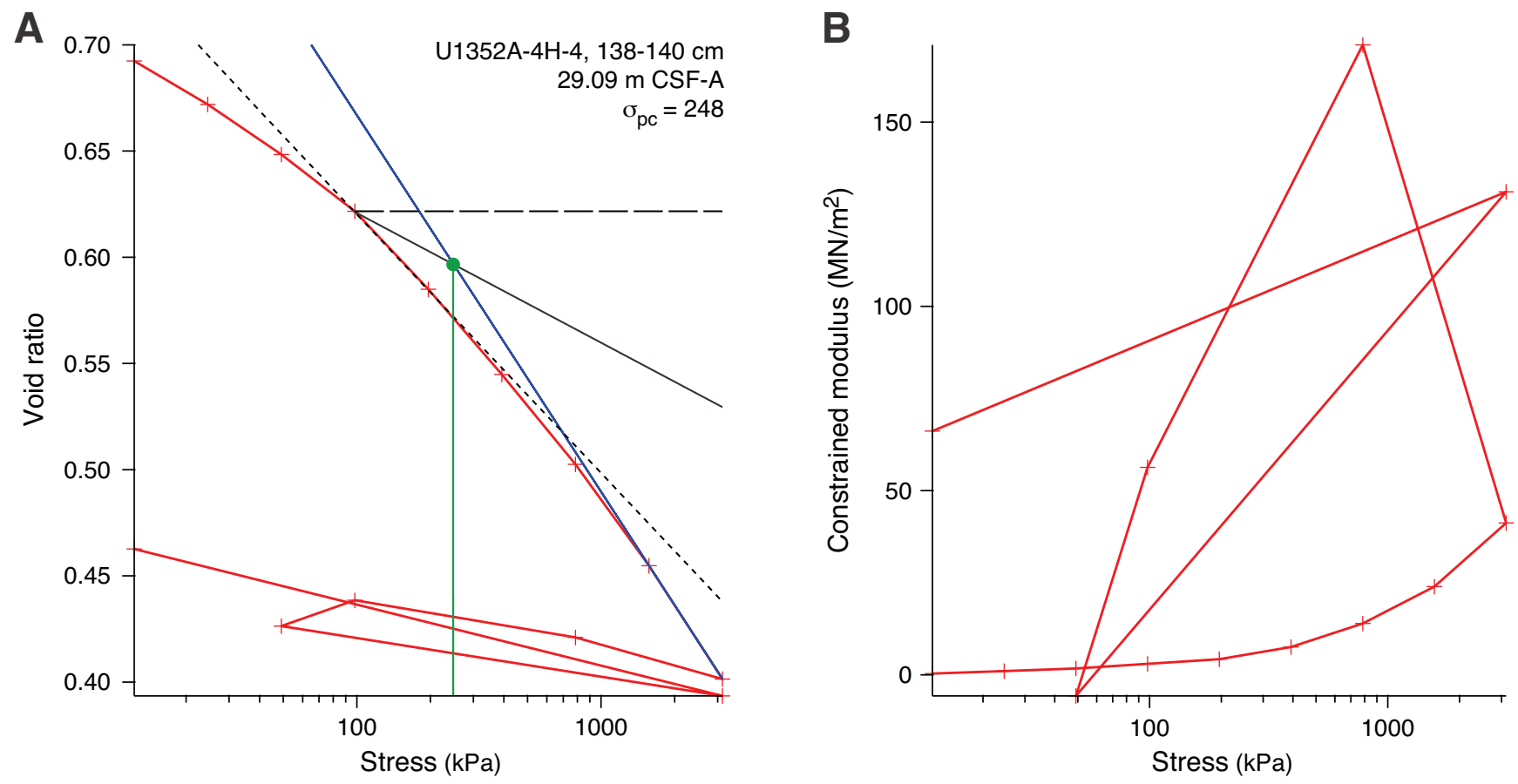
Figure F13. Results of uniaxial consolidation test (interval 317-U1352A-5H-4, 138-140 cm) represented by a semilogarithmic plot of (A) void ratio vs. vertical effective stress and (B) constrained modulus vs. vertical effective stress. Green dot = maximum past effective stress $\left(\sigma_{\mathrm{pc}}\right)$ derived by the graphical method of Casagrande (1936). $\sigma_{\mathrm{pc}}$ corresponds to the abscissa of the point of intersection between the backward projected virgin compression line (blue) and the bisecting line (black solid) between the horizontal line (black dashed) and the tangent (black dotted) at the point of maximum curvature of the consolidation curve (red).
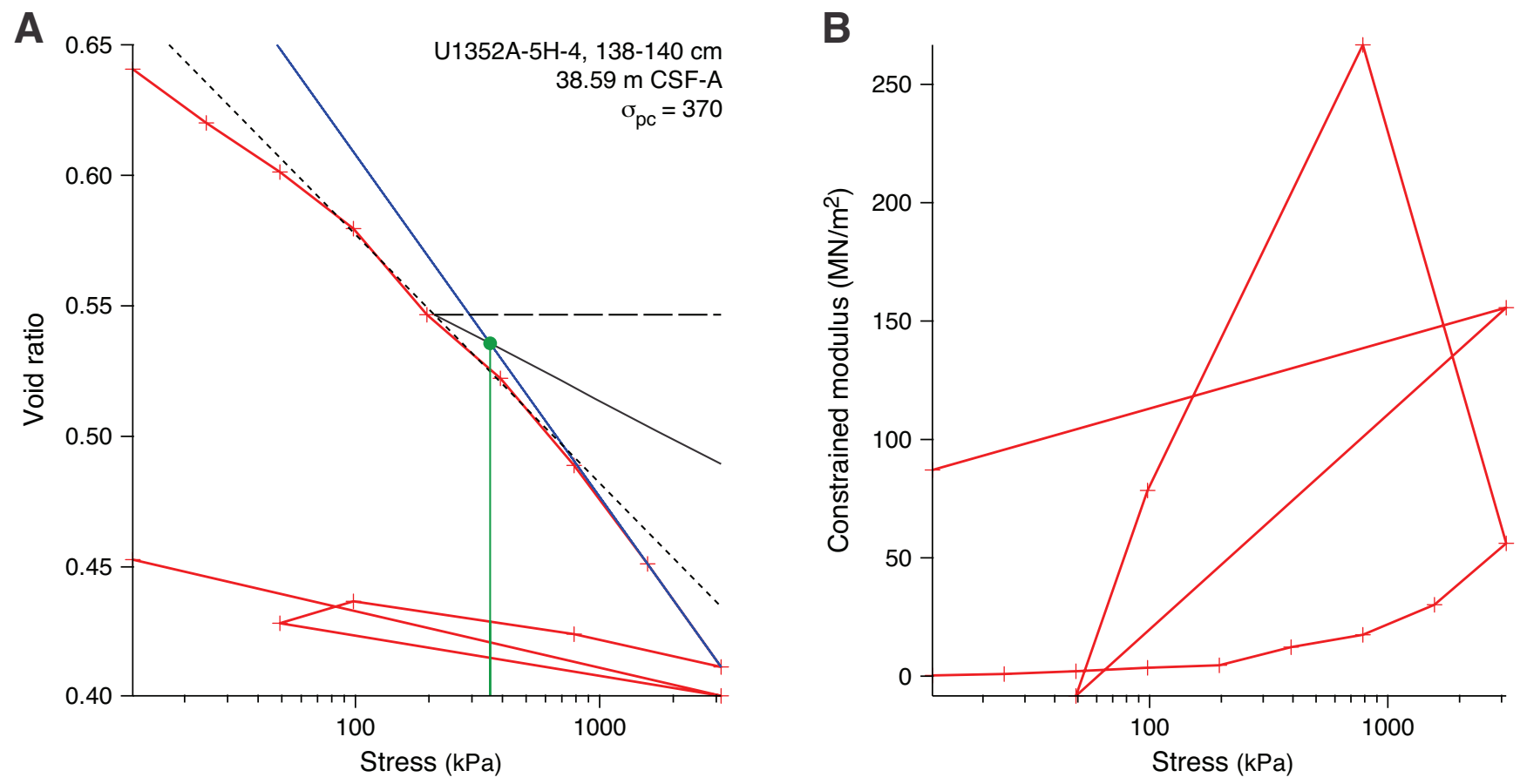
Figure F14. Results of uniaxial consolidation test (interval 317-U1352B-10H-5, 148-150 cm) represented by a semilogarithmic plot of (A) void ratio vs. vertical effective stress and (B) constrained modulus vs. vertical effective stress. Green dot = maximum past effective stress $\left(\sigma_{\mathrm{pc}}\right)$ derived by the graphical method of Casagrande (1936). $\sigma_{\mathrm{pc}}$ corresponds to the abscissa of the point of intersection between the backward projected virgin compression line (blue) and the bisecting line (black solid) between the horizontal line (black dashed) and the tangent (black dotted) at the point of maximum curvature of the consolidation curve (red).
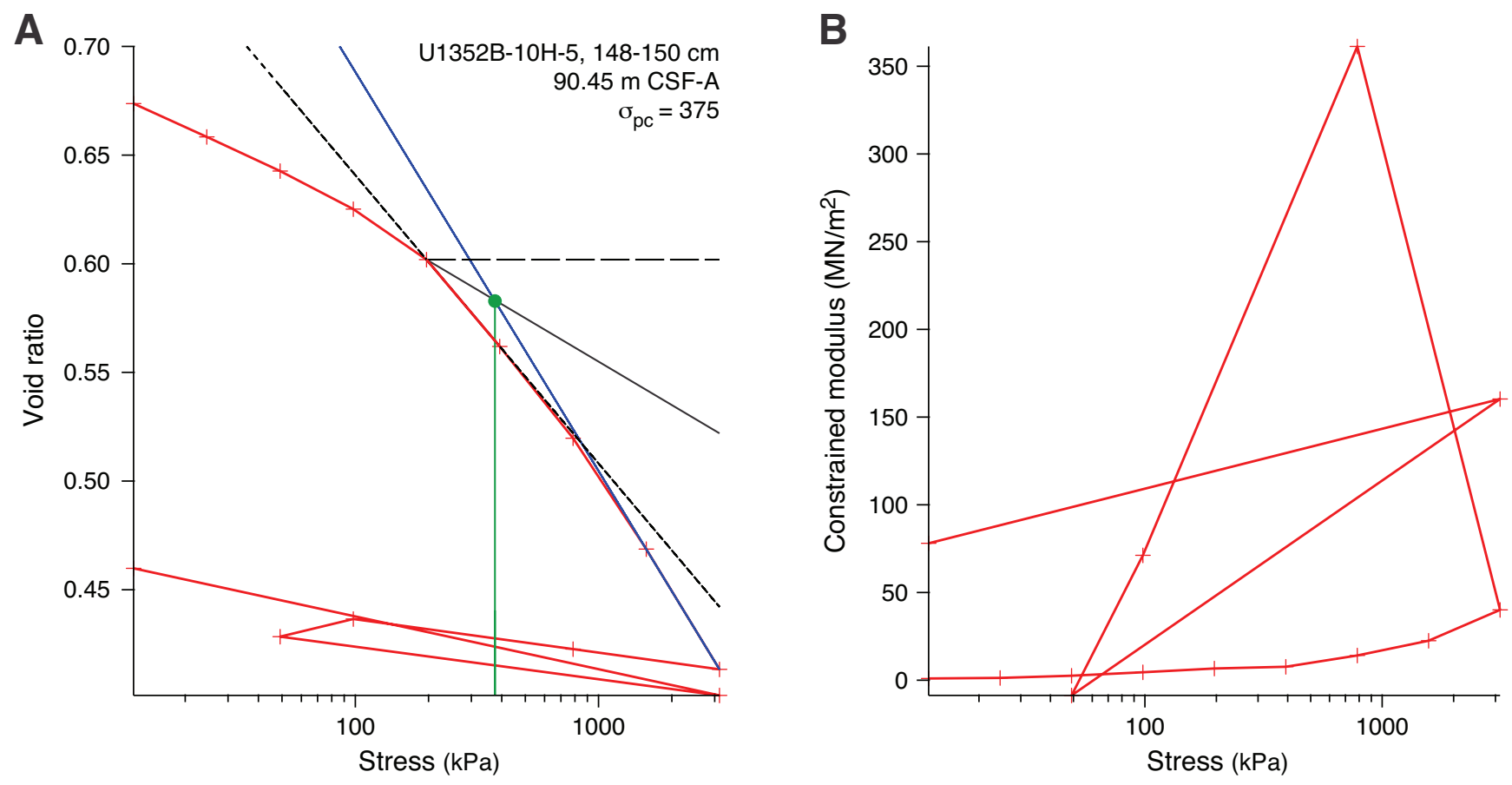
Figure F15. Results of uniaxial consolidation test (interval 317-U1352B-15H-5, 148-150 cm) represented by a semilogarithmic plot of (A) void ratio vs. vertical effective stress and (B) constrained modulus vs. vertical effective stress. Green dot = maximum past effective stress $\left(\sigma_{\mathrm{pc}}\right)$ derived by the graphical method of Casagrande (1936). $\sigma_{\mathrm{pc}}$ corresponds to the abscissa of the point of intersection between the backward projected virgin compression line (blue) and the bisecting line (black solid) between the horizontal line (black dashed) and the tangent (black dotted) at the point of maximum curvature of the consolidation curve (red).
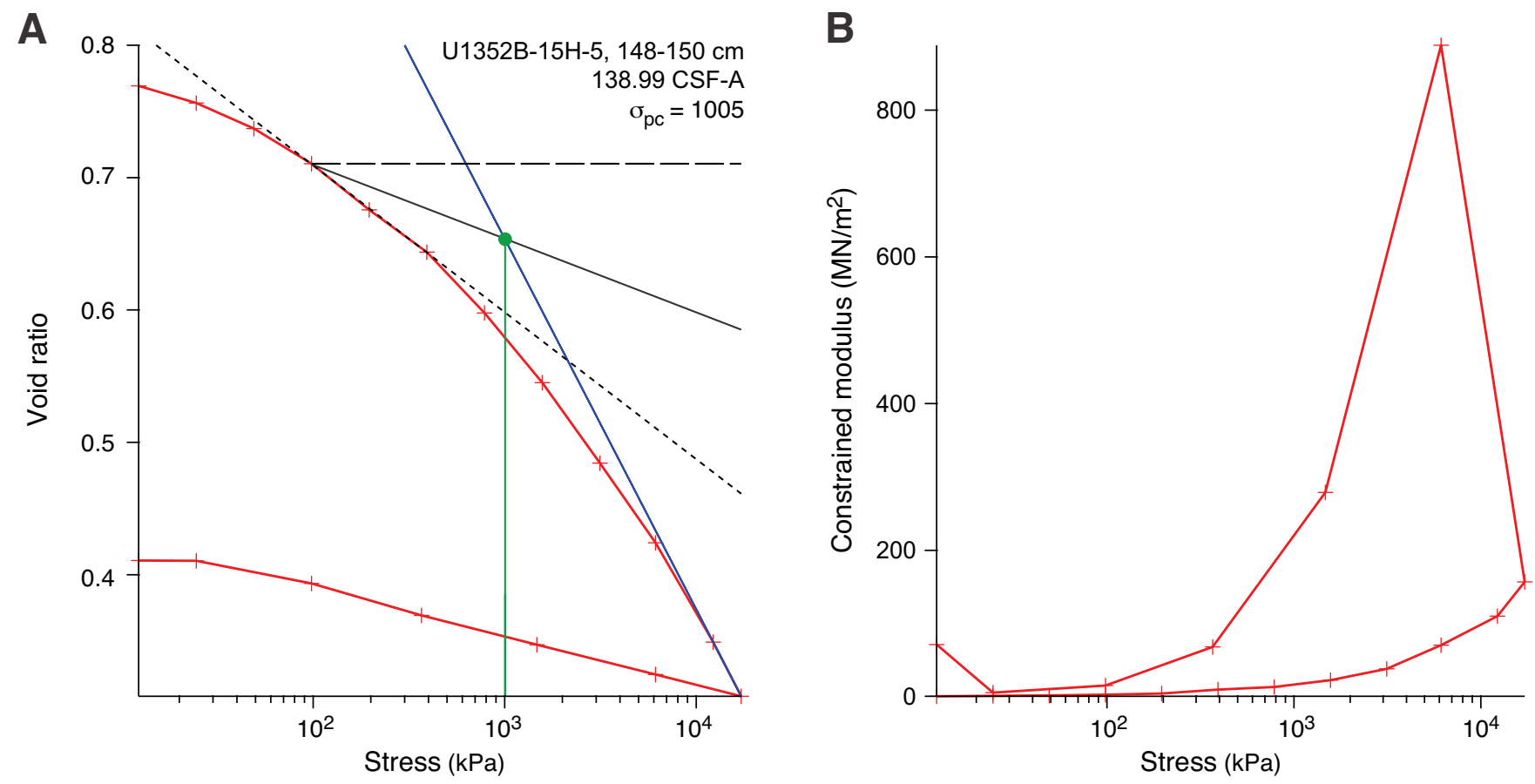
Figure F16. Results of uniaxial consolidation test (interval 317-U1352B-21H-5, 148-150 cm) represented by a semilogarithmic plot of (A) void ratio vs. vertical effective stress and (B) constrained modulus vs. vertical effective stress. Green dot = maximum past effective stress $\left(\sigma_{p c}\right)$ derived by the graphical method of Casagrande (1936). $\sigma_{\mathrm{pc}}$ corresponds to the abscissa of the point of intersection between the backward projected virgin compression line (blue) and the bisecting line (black solid) between the horizontal line (black dashed) and the tangent (black dotted) at the point of maximum curvature of the consolidation curve (red).

A

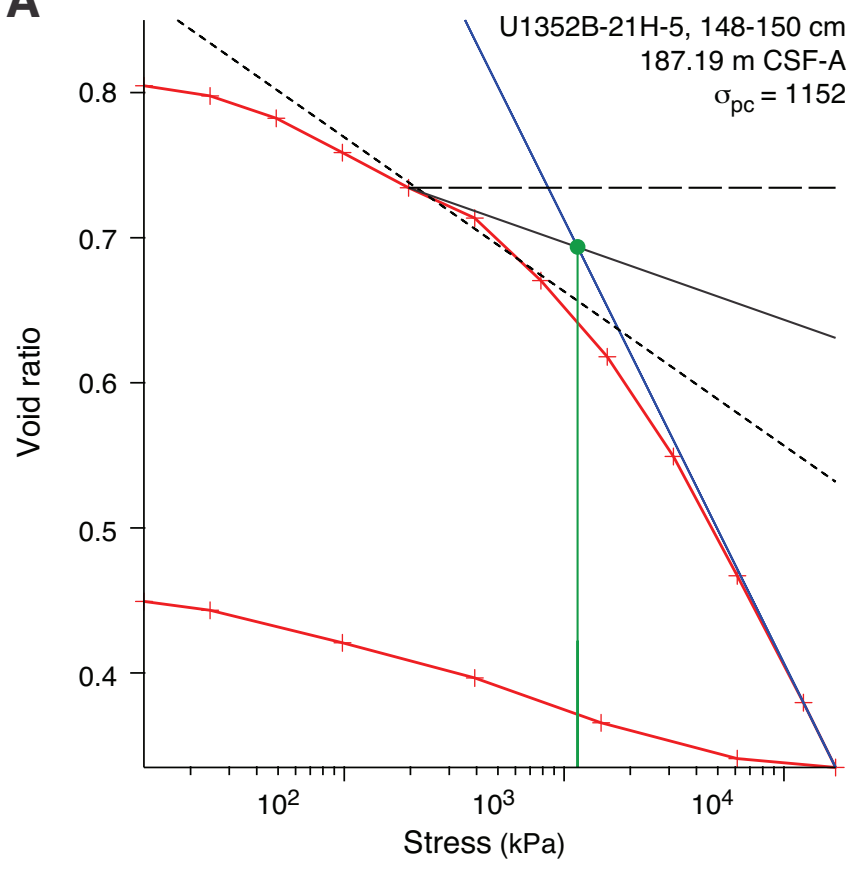

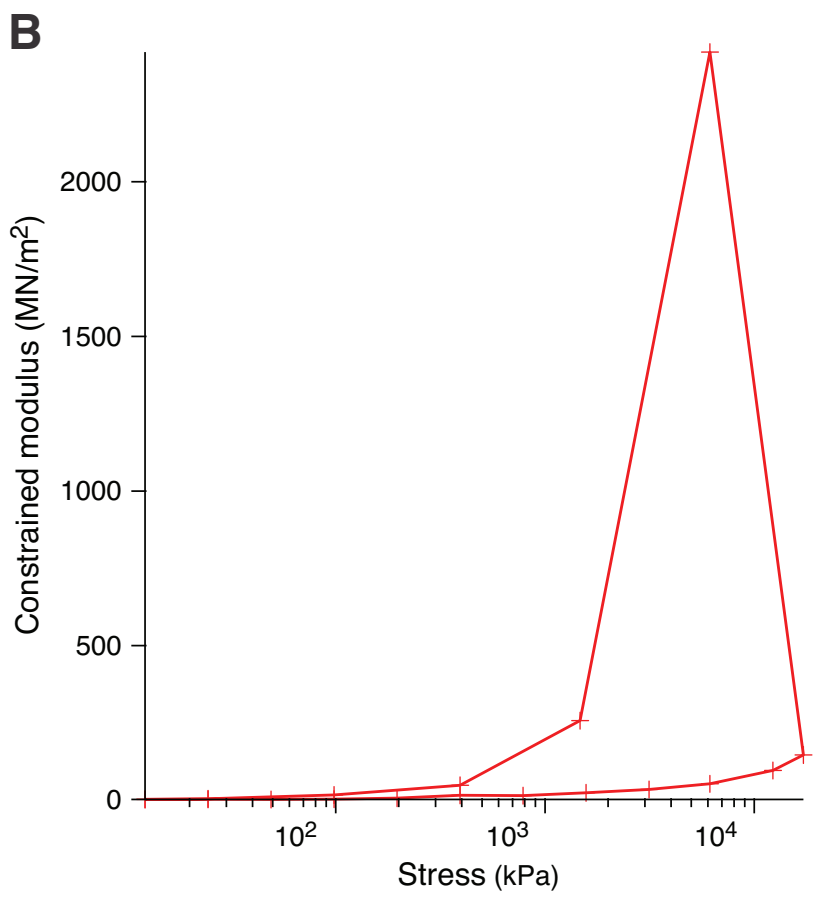


Figure F17. Results of uniaxial consolidation test (interval 317-U1352B-26H-4, 148-150 cm) represented by a semilogarithmic plot of (A) void ratio vs. vertical effective stress and (B) constrained modulus vs. vertical effective stress. Green dot = maximum past effective stress $\left(\sigma_{\mathrm{pc}}\right)$ derived by the graphical method of Casagrande (1936). $\sigma_{\mathrm{pc}}$ corresponds to the abscissa of the point of intersection between the backward projected virgin compression line (blue) and the bisecting line (black solid) between the horizontal line (black dashed) and the tangent (black dotted) at the point of maximum curvature of the consolidation curve (red).
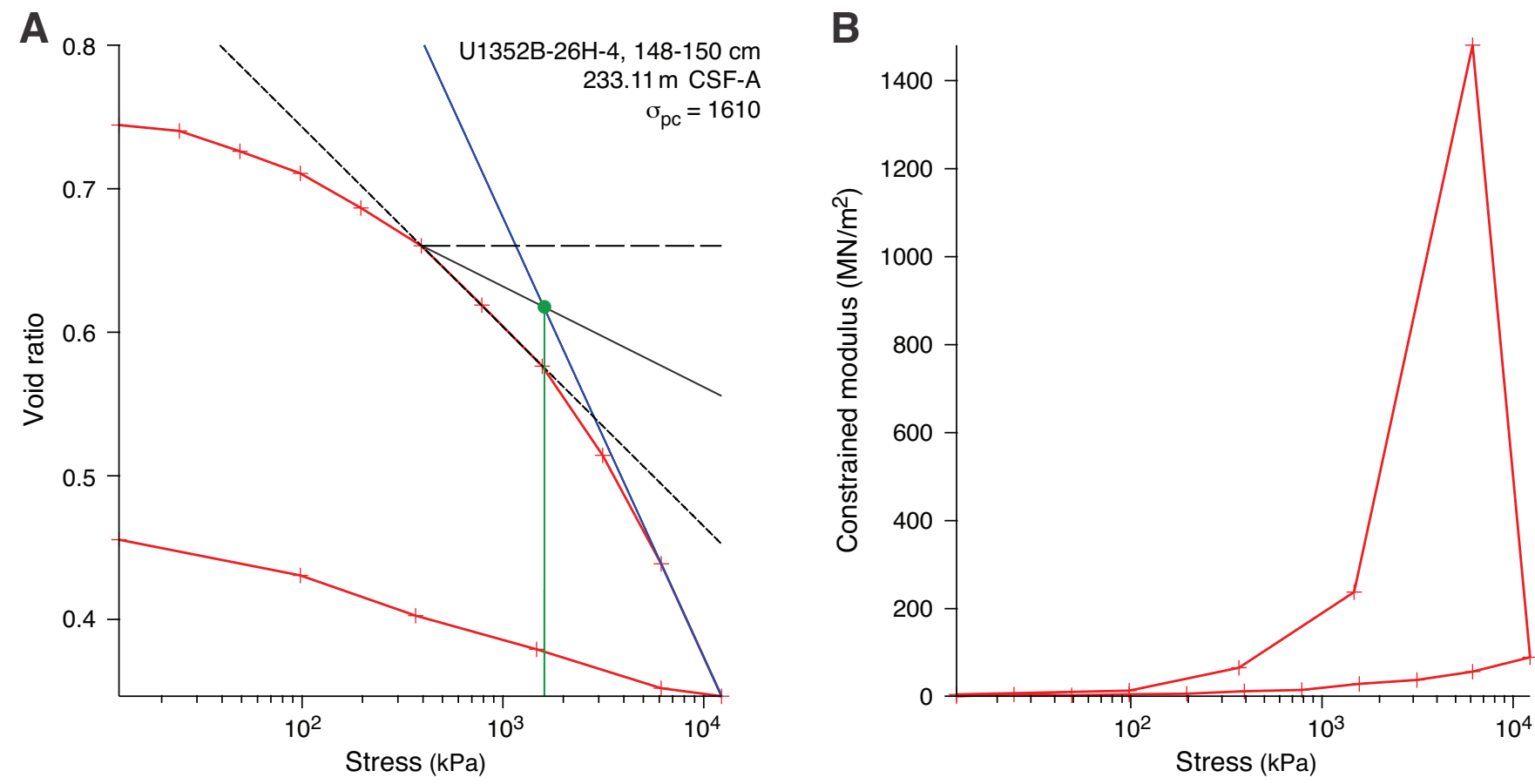
Figure F18. Results of uniaxial consolidation test (interval 317-U1352B-32H-4, 143-145 cm) represented by a semilogarithmic plot of (A) void ratio vs. vertical effective stress and (B) constrained modulus vs. vertical effective stress. Green dot = maximum past effective stress $\left(\sigma_{\mathrm{pc}}\right)$ derived by the graphical method of Casagrande (1936). $\sigma_{\mathrm{pc}}$ corresponds to the abscissa of the point of intersection between the backward projected virgin compression line (blue) and the bisecting line (black solid) between the horizontal line (black dashed) and the tangent (black dotted) at the point of maximum curvature of the consolidation curve (red).
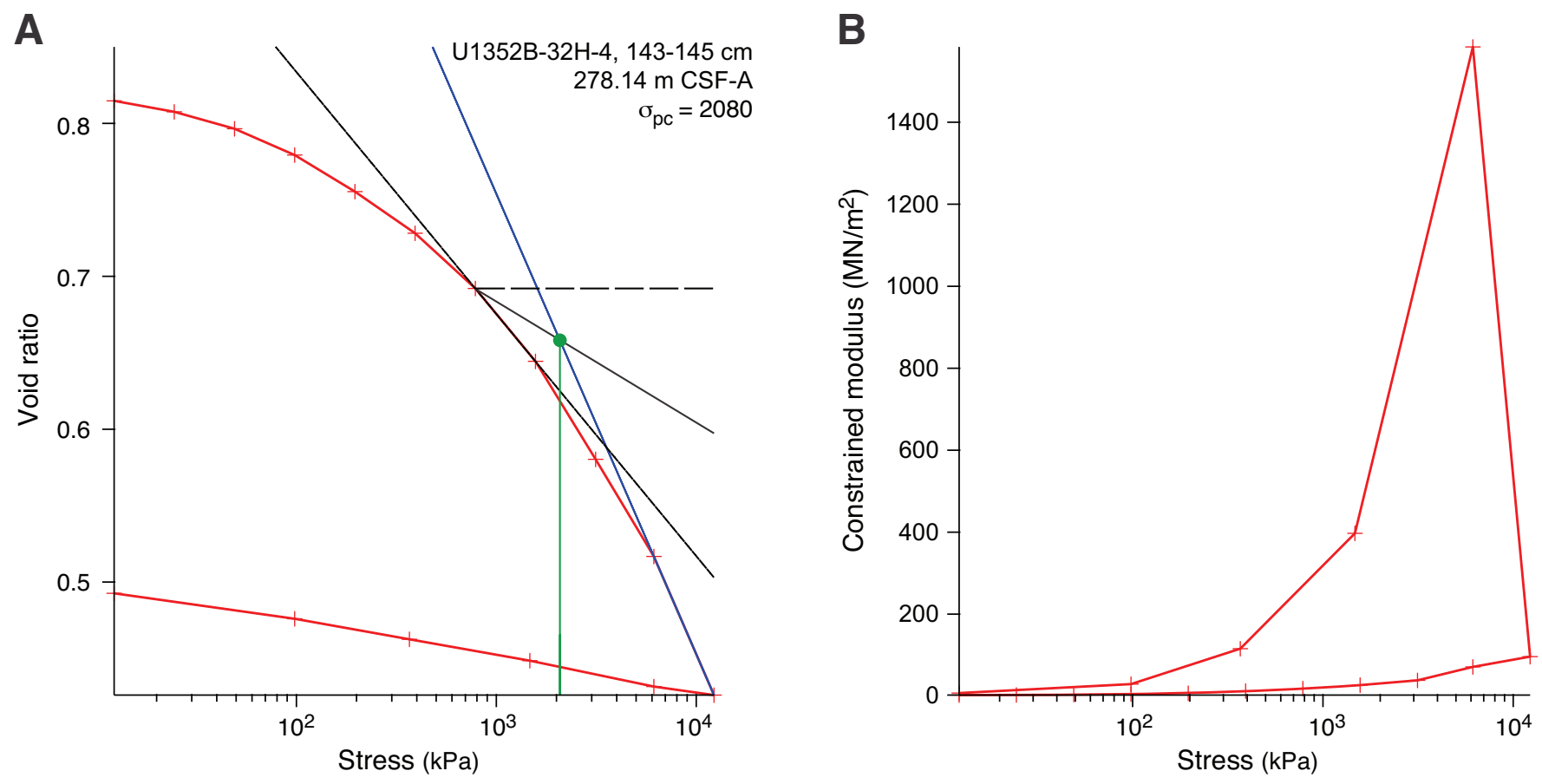
Figure F19. Results of uniaxial consolidation test (interval 317-U1352B-37X-1, 118-120 cm) represented by a semilogarithmic plot of (A) void ratio vs. vertical effective stress and (B) constrained modulus vs. vertical effective stress. Green dot = maximum past effective stress $\left(\sigma_{\mathrm{pc}}\right)$ derived by the graphical method of Casagrande (1936). $\sigma_{p c}$ corresponds to the abscissa of the point of intersection between the backward projected virgin compression line (blue) and the bisecting line (black solid) between the horizontal line (black dashed) and the tangent (black dotted) at the point of maximum curvature of the consolidation curve (red).
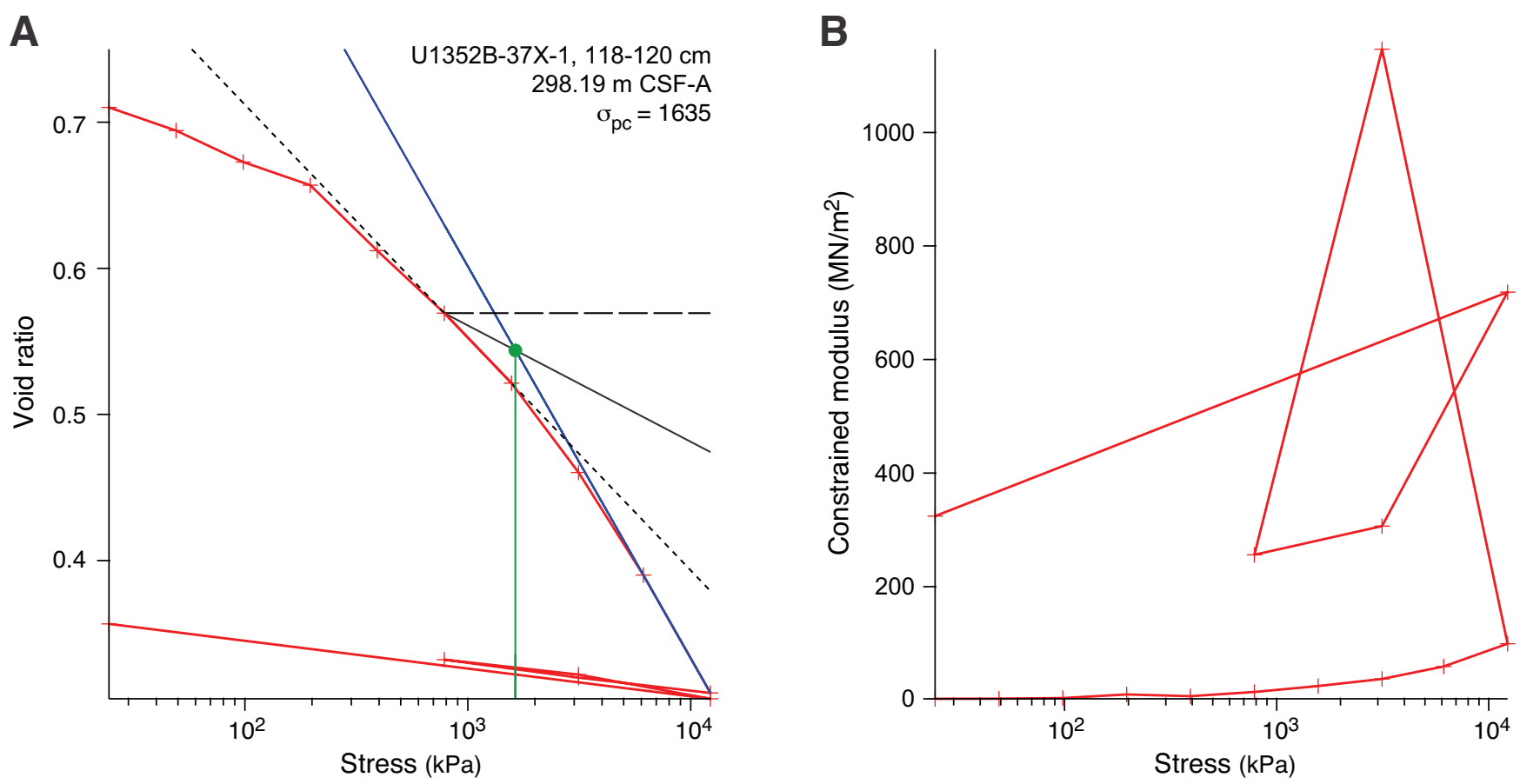
Figure F20. Results of uniaxial consolidation test (interval 317-U1352B-42X-4, 148-150 cm) represented by a semilogarithmic plot of (A) void ratio vs. vertical effective stress and (B) constrained modulus vs. vertical effective stress. Green dot = maximum past effective stress $\left(\sigma_{\mathrm{pc}}\right)$ derived by the graphical method of Casagrande (1936). $\sigma_{p c}$ corresponds to the abscissa of the point of intersection between the backward projected virgin compression line (blue) and the bisecting line (black solid) between the horizontal line (black dashed) and the tangent (black dotted) at the point of maximum curvature of the consolidation curve (red).
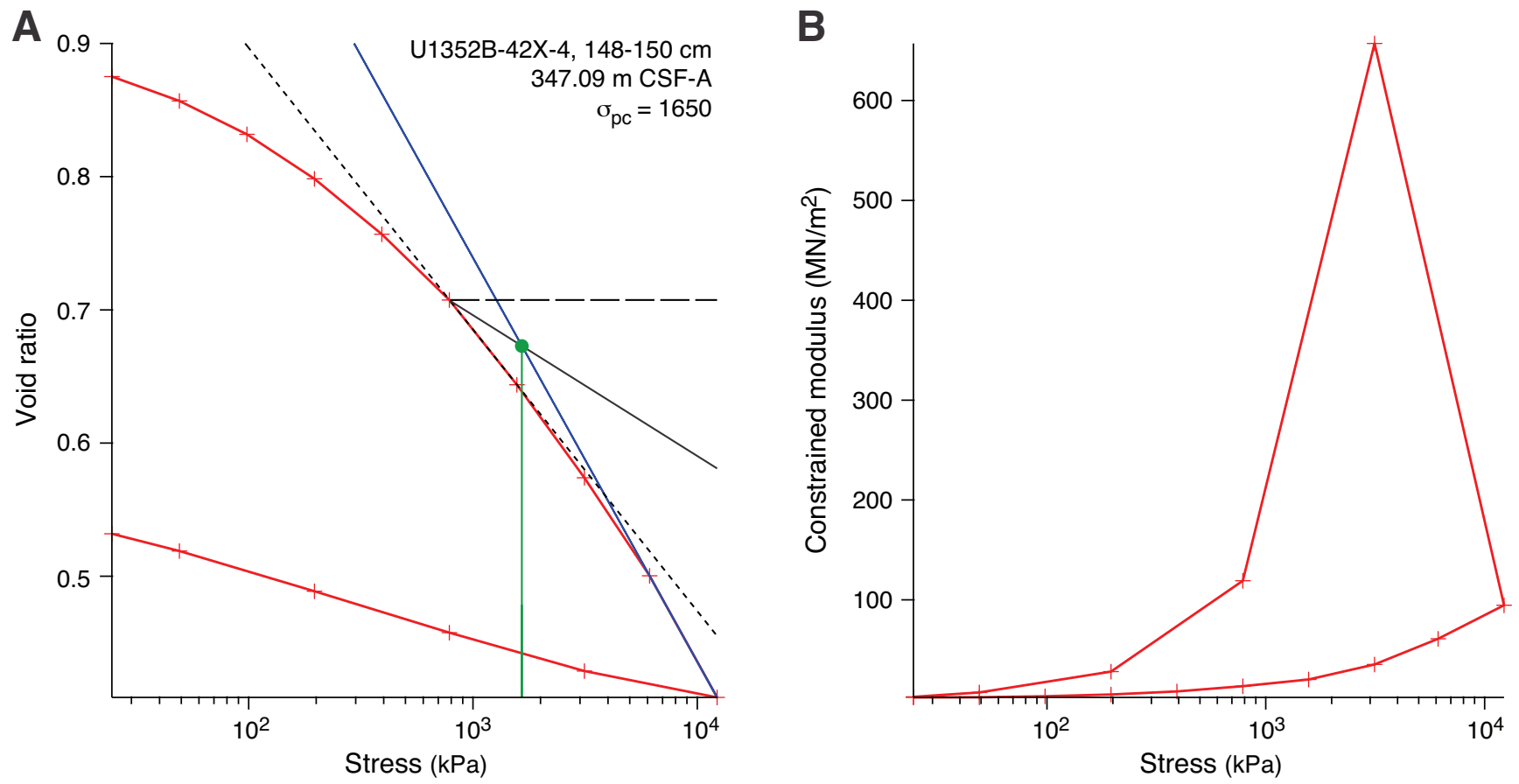
Figure F21. Results of uniaxial consolidation test (interval 317-U1352B-48X-4, 148-150 cm) represented by a semilogarithmic plot of (A) void ratio vs. vertical effective stress and (B) constrained modulus vs. vertical effective stress. Green dot = maximum past effective stress $\left(\sigma_{\mathrm{pc}}\right)$ derived by the graphical method of Casagrande (1936). $\sigma_{\mathrm{pc}}$ corresponds to the abscissa of the point of intersection between the backward projected virgin compression line (blue) and the bisecting line (black solid) between the horizontal line (black dashed) and the tangent (black dotted) at the point of maximum curvature of the consolidation curve (red).
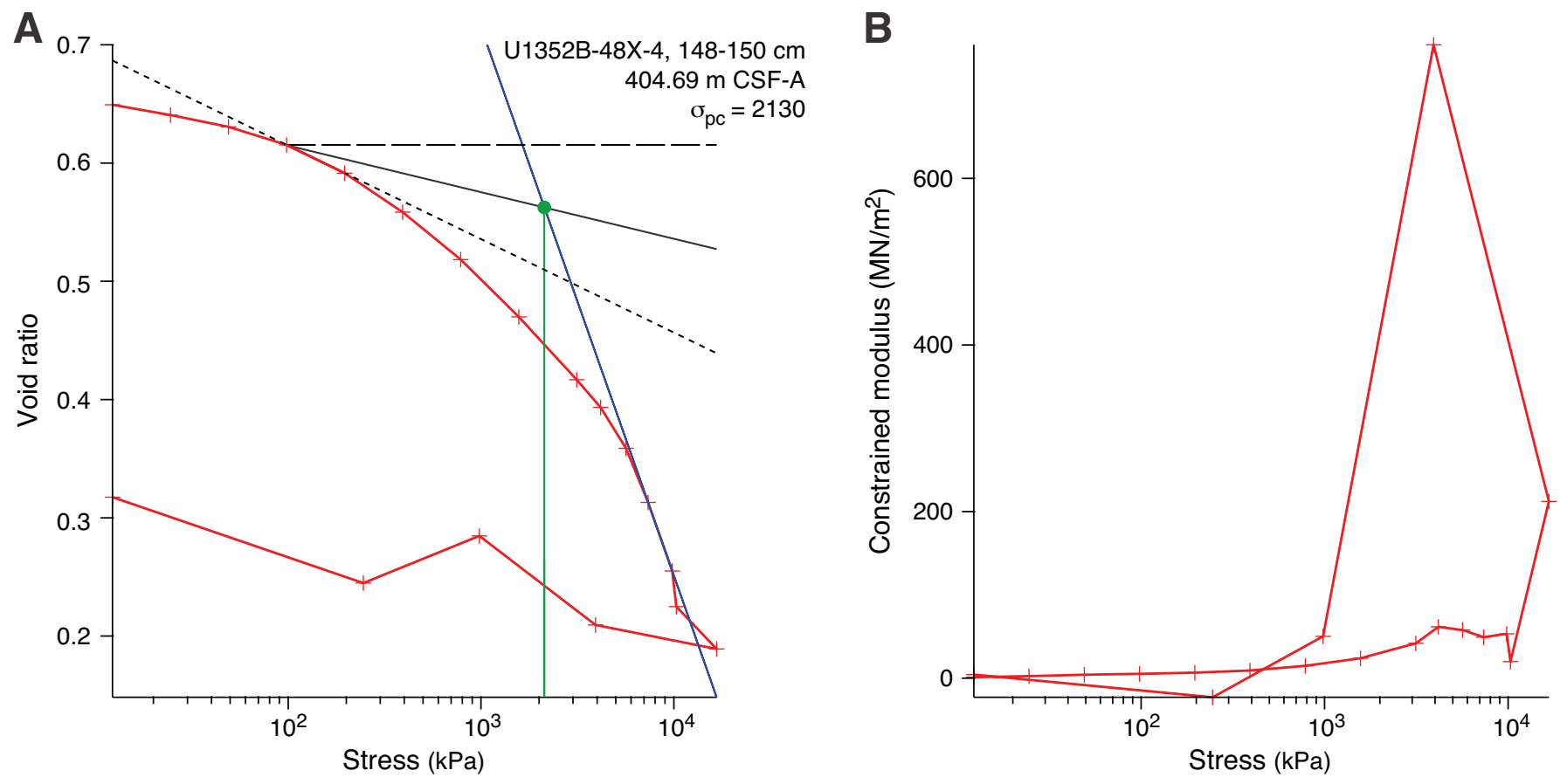
Figure F22. Results of uniaxial consolidation test (interval 317-U1352B-61X-2, 82-84 cm) represented by a semilogarithmic plot of (A) void ratio vs. vertical effective stress and (B) constrained modulus vs. vertical effective stress. Green dot = maximum past effective stress $\left(\sigma_{\mathrm{pc}}\right)$ derived by the graphical method of Casagrande (1936). $\sigma_{\mathrm{pc}}$ corresponds to the abscissa of the point of intersection between the backward projected virgin compression line (blue) and the bisecting line (black solid) between the horizontal line (black dashed) and the tangent (black dotted) at the point of maximum curvature of the consolidation curve (red).
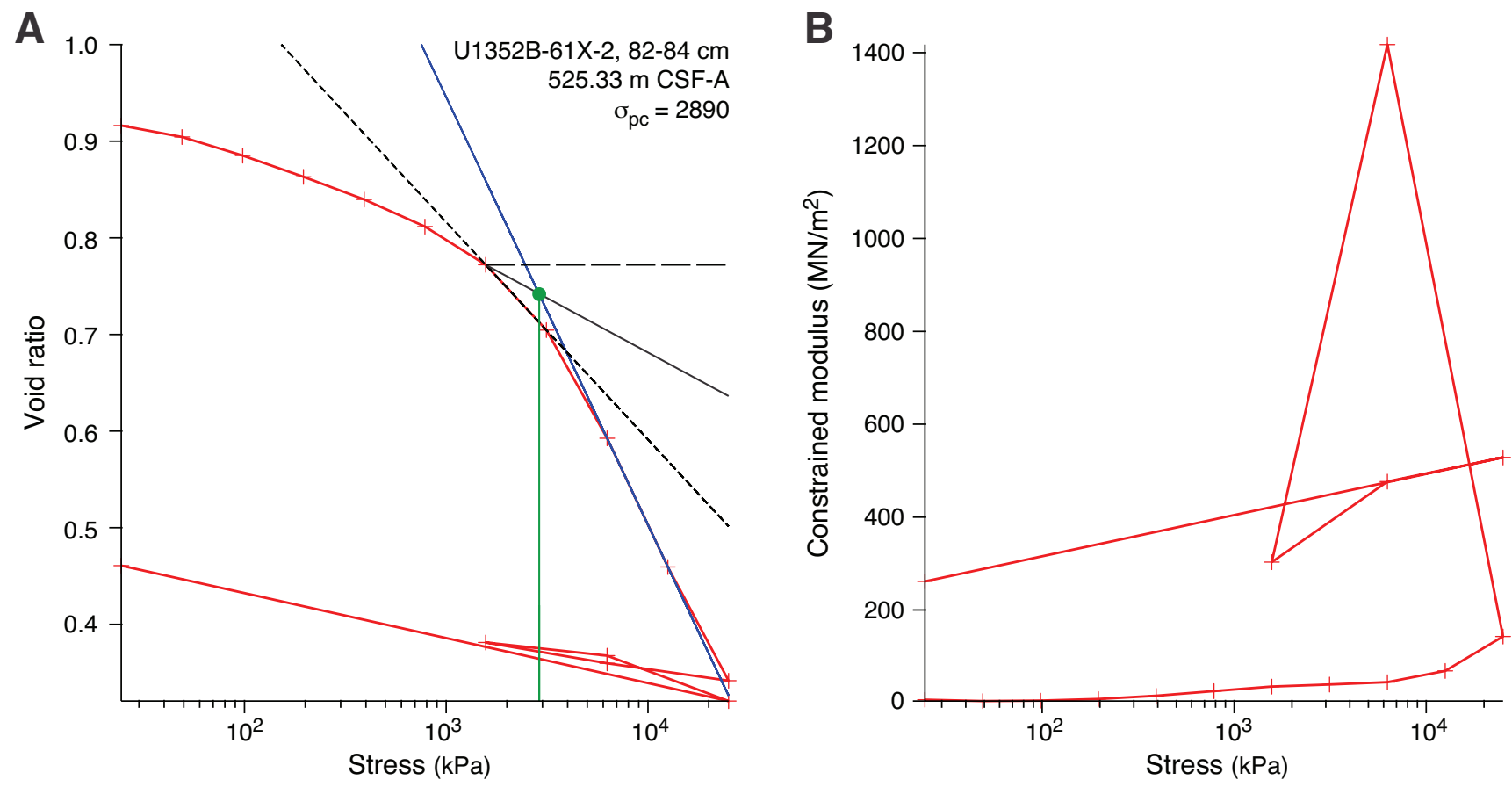
Figure F23. Results of uniaxial consolidation test (interval 317-U1352B-81X-3, 98-100 cm) represented by a semilogarithmic plot of (A) void ratio vs. vertical effective stress and (B) constrained modulus vs. vertical effective stress. Green dot = maximum past effective stress $\left(\sigma_{p c}\right)$ derived by the graphical method of Casagrande (1936). $\sigma_{\mathrm{pc}}$ corresponds to the abscissa of the point of intersection between the backward projected virgin compression line (blue) and the bisecting line (black solid) between the horizontal line (black dashed) and the tangent (black dotted) at the point of maximum curvature of the consolidation curve (red).
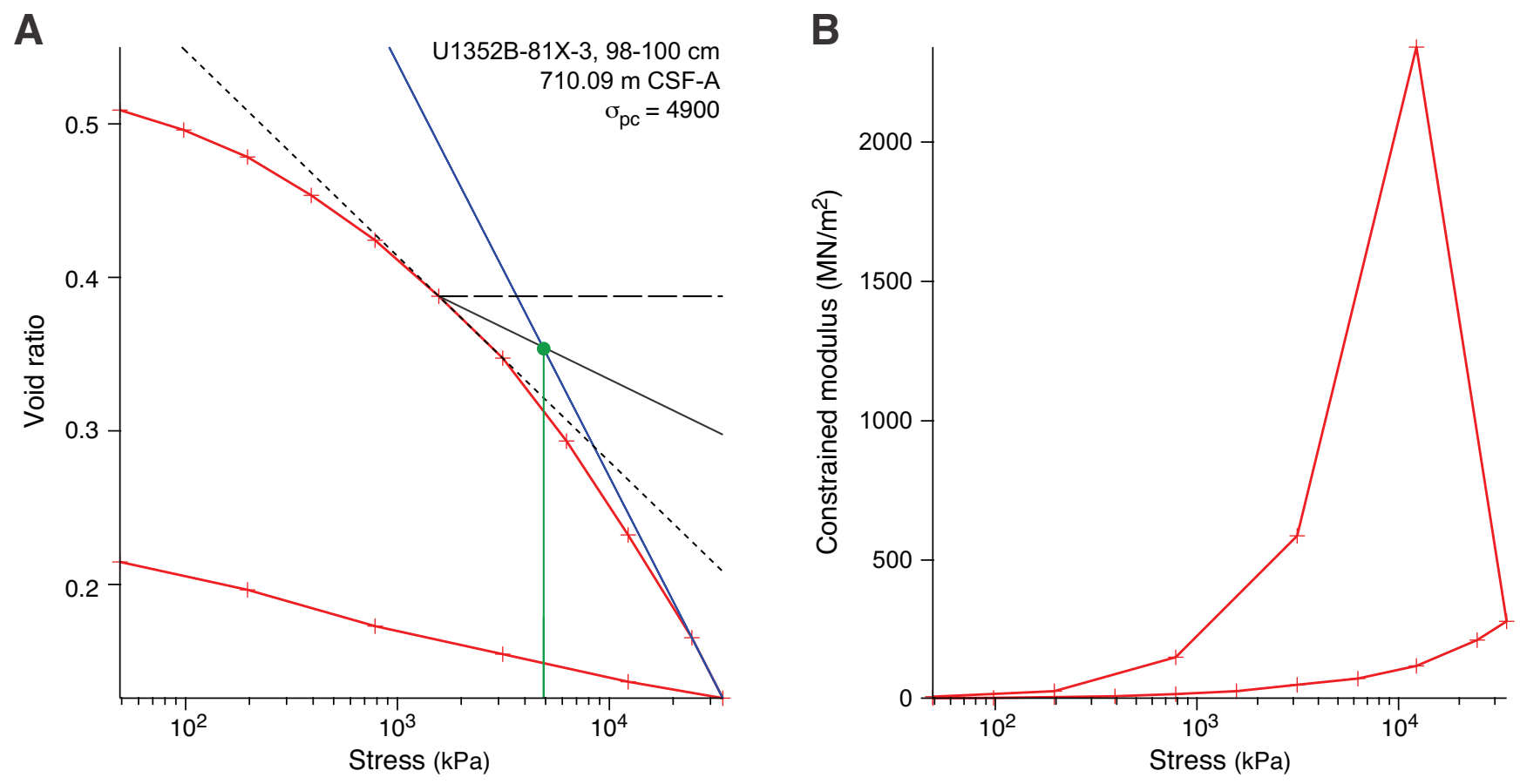
Figure F24. Results of uniaxial consolidation test (interval 317-U1353A-1H-2, 138-140 cm) represented by a semilogarithmic plot of (A) void ratio vs. vertical effective stress and (B) constrained modulus vs. vertical effective stress. Green dot = maximum past effective stress $\left(\sigma_{\mathrm{pc}}\right)$ derived by the graphical method of Casagrande (1936). $\sigma_{\mathrm{pc}}$ corresponds to the abscissa of the point of intersection between the backward projected virgin compression line (blue) and the bisecting line (black solid) between the horizontal line (black dashed) and the tangent (black dotted) at the point of maximum curvature of the consolidation curve (red).
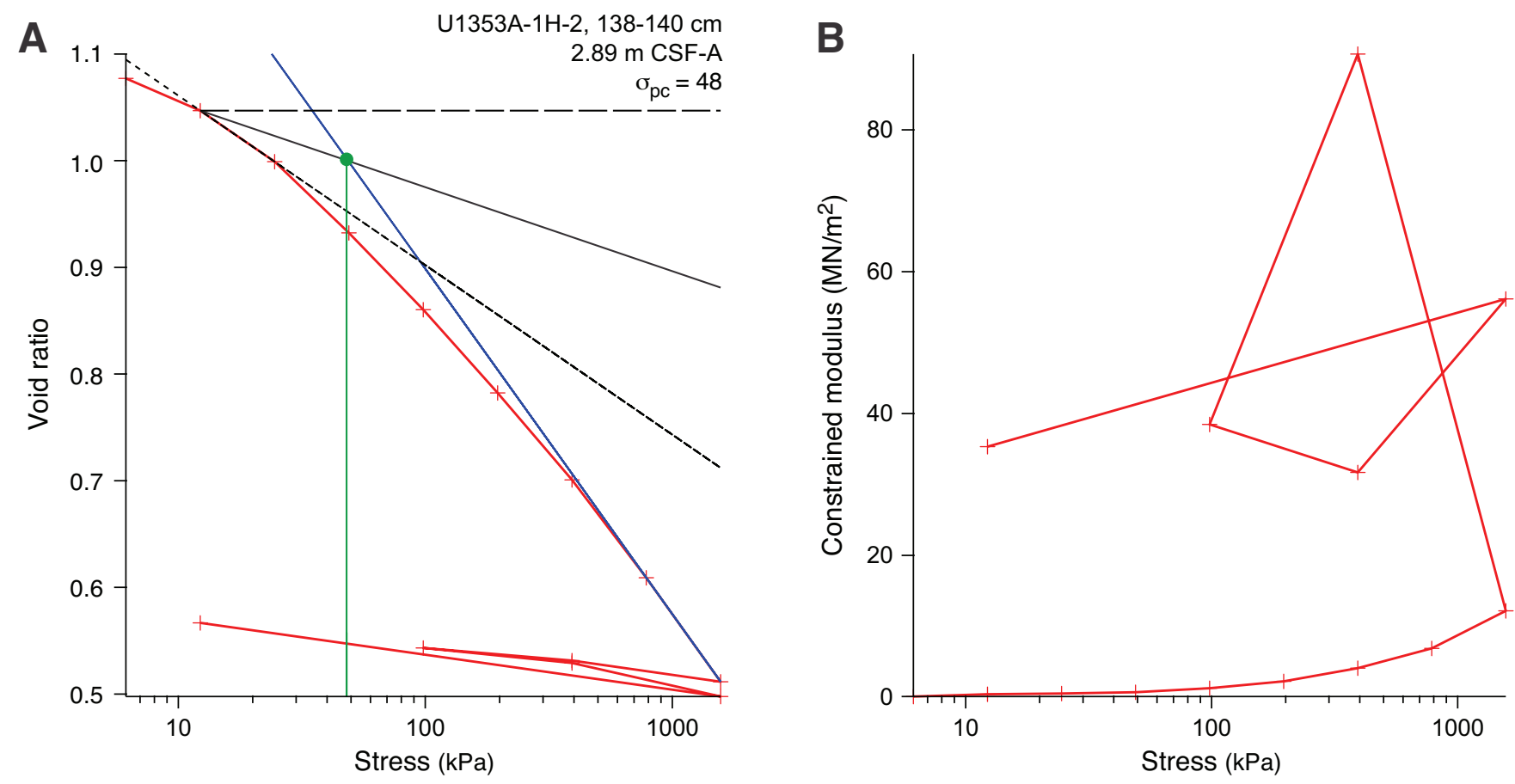
Figure F25. Results of uniaxial consolidation test (interval 317-U1353A-2H-2, 128-130 cm) represented by a semilogarithmic plot of (A) void ratio vs. vertical effective stress and (B) constrained modulus vs. vertical effective stress. Green dot = maximum past effective stress $\left(\sigma_{\mathrm{pc}}\right)$ derived by the graphical method of Casagrande (1936). $\sigma_{\mathrm{pc}}$ corresponds to the abscissa of the point of intersection between the backward projected virgin compression line (blue) and the bisecting line (black solid) between the horizontal line (black dashed) and the tangent (black dotted) at the point of maximum curvature of the consolidation curve (red).
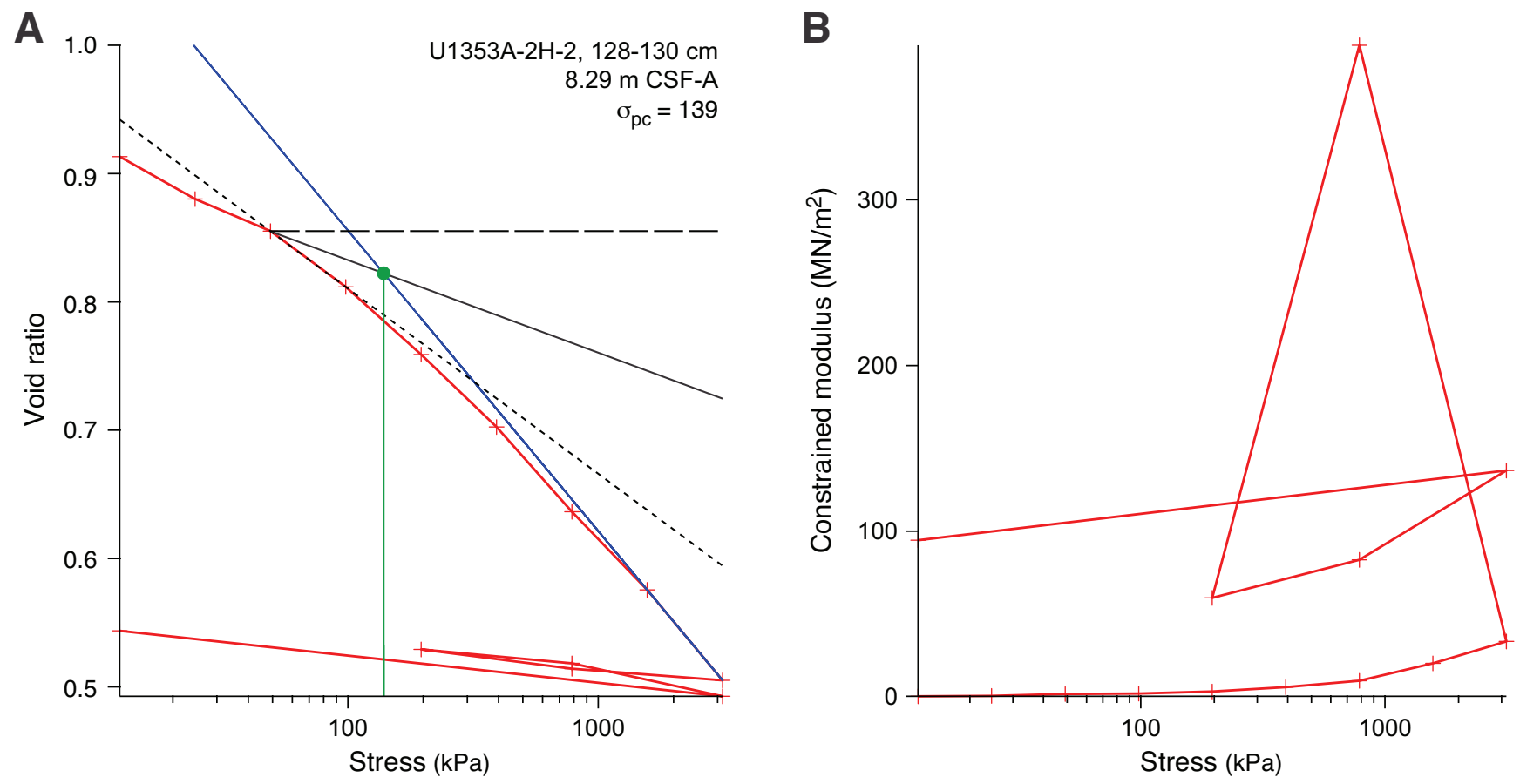
Figure F26. Results of uniaxial consolidation test (interval 317-U1353A-3H-3, 126-128 cm) represented by a semilogarithmic plot of (A) void ratio vs. vertical effective stress and (B) constrained modulus vs. vertical effective stress. Green dot = maximum past effective stress $\left(\sigma_{\mathrm{pc}}\right)$ derived by the graphical method of Casagrande (1936). $\sigma_{\mathrm{pc}}$ corresponds to the abscissa of the point of intersection between the backward projected virgin compression line (blue) and the bisecting line (black solid) between the horizontal line (black dashed) and the tangent (black dotted) at the point of maximum curvature of the consolidation curve (red).
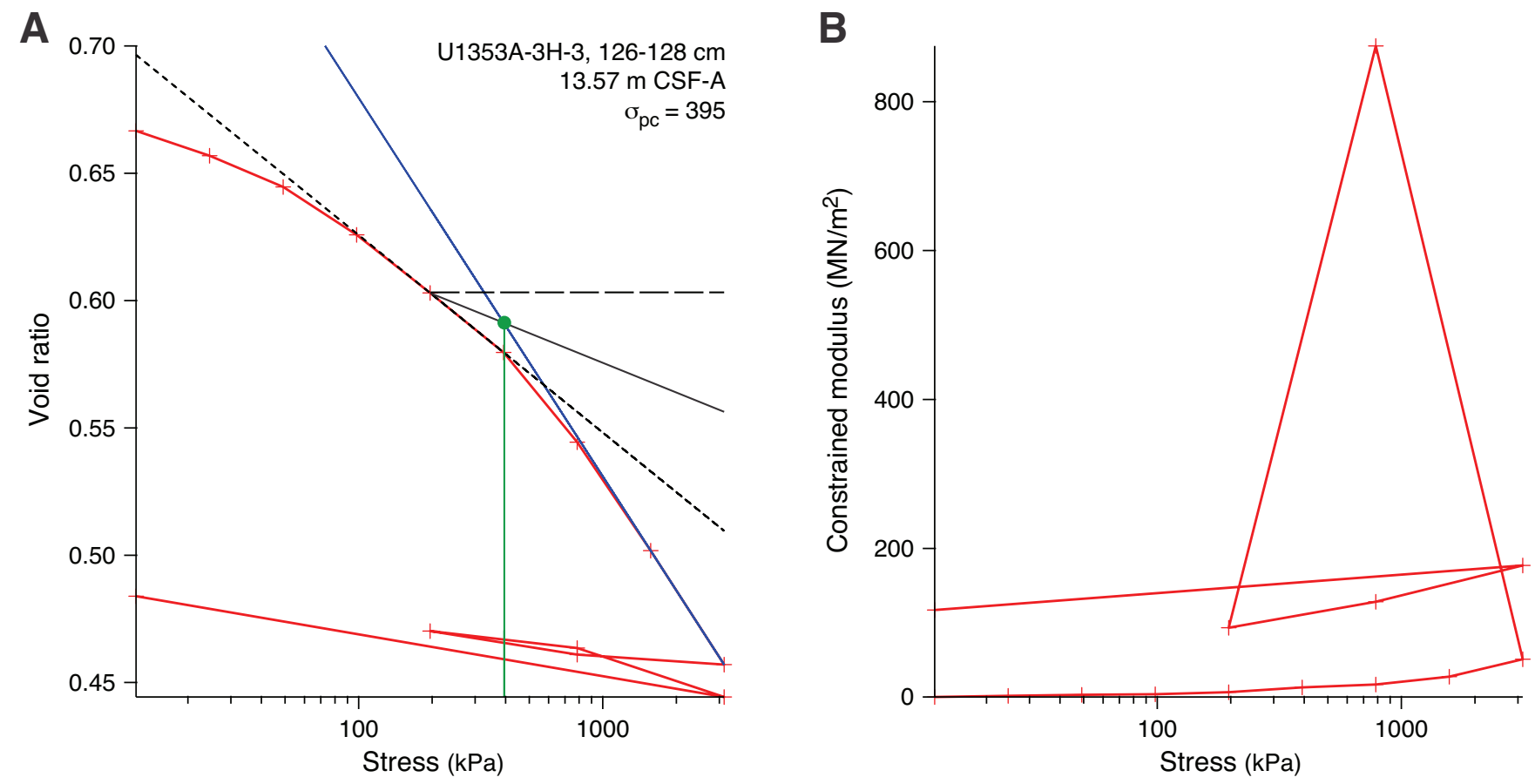
Figure F27. Results of uniaxial consolidation test (interval 317-U1353A-4H-4, 8-10 cm) represented by a semilogarithmic plot of (A) void ratio vs. vertical effective stress and (B) constrained modulus vs. vertical effective stress. Green dot $=$ maximum past effective stress $\left(\sigma_{\mathrm{pc}}\right)$ derived by the graphical method of Casagrande (1936). $\sigma_{\mathrm{pc}}$ corresponds to the abscissa of the point of intersection between the backward projected virgin compression line (blue) and the bisecting line (black solid) between the horizontal line (black dashed) and the tangent (black dotted) at the point of maximum curvature of the consolidation curve (red).
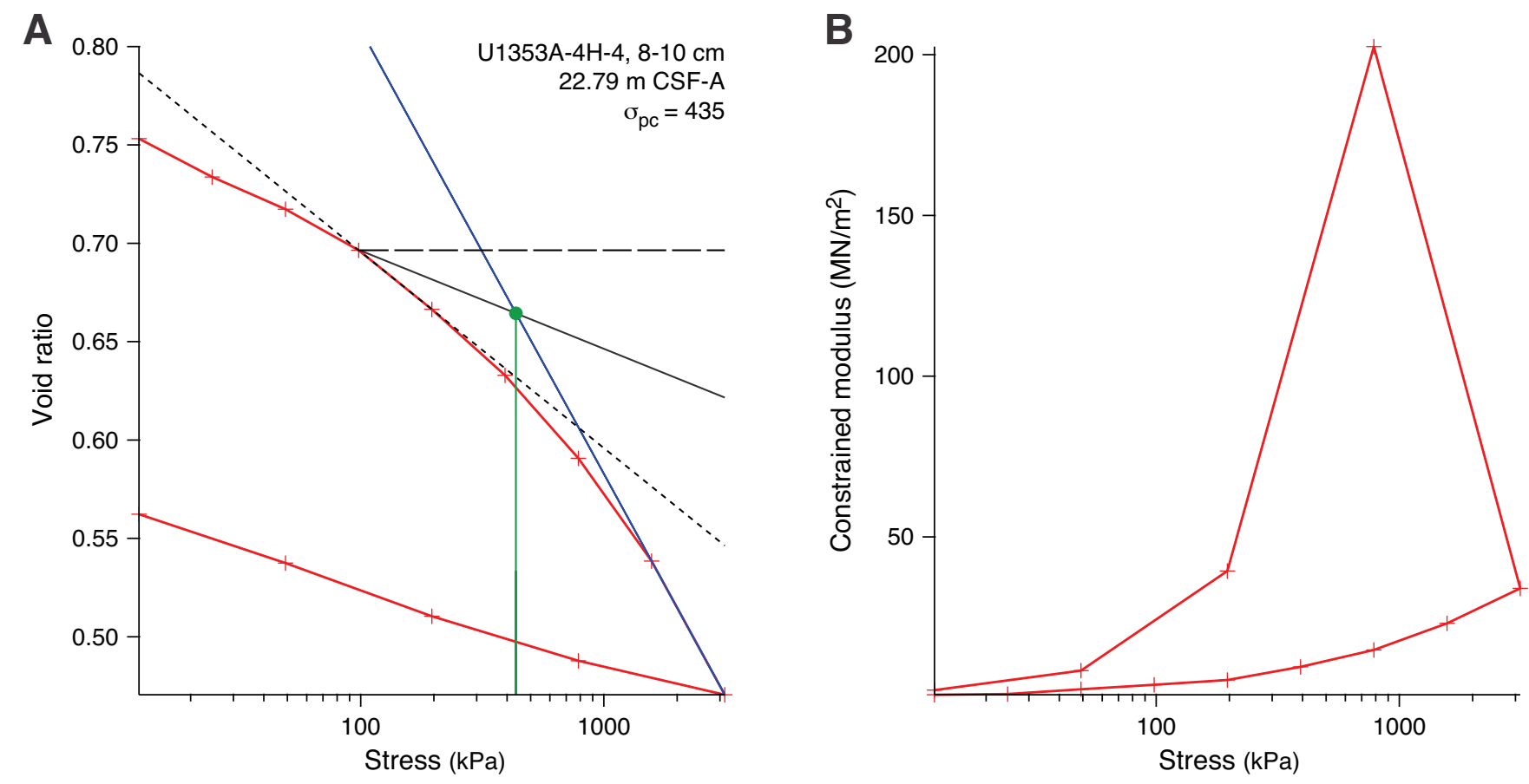
Figure F28. Results of uniaxial consolidation test (interval 317-U1353A-6H-4, 138-140 cm) represented by a semilogarithmic plot of (A) void ratio vs. vertical effective stress and (B) constrained modulus vs. vertical effective stress. Green dot = maximum past effective stress $\left(\sigma_{\mathrm{pc}}\right)$ derived by the graphical method of Casagrande (1936). $\sigma_{\mathrm{pc}}$ corresponds to the abscissa of the point of intersection between the backward projected virgin compression line (blue) and the bisecting line (black solid) between the horizontal line (black dashed) and the tangent (black dotted) at the point of maximum curvature of the consolidation curve (red).
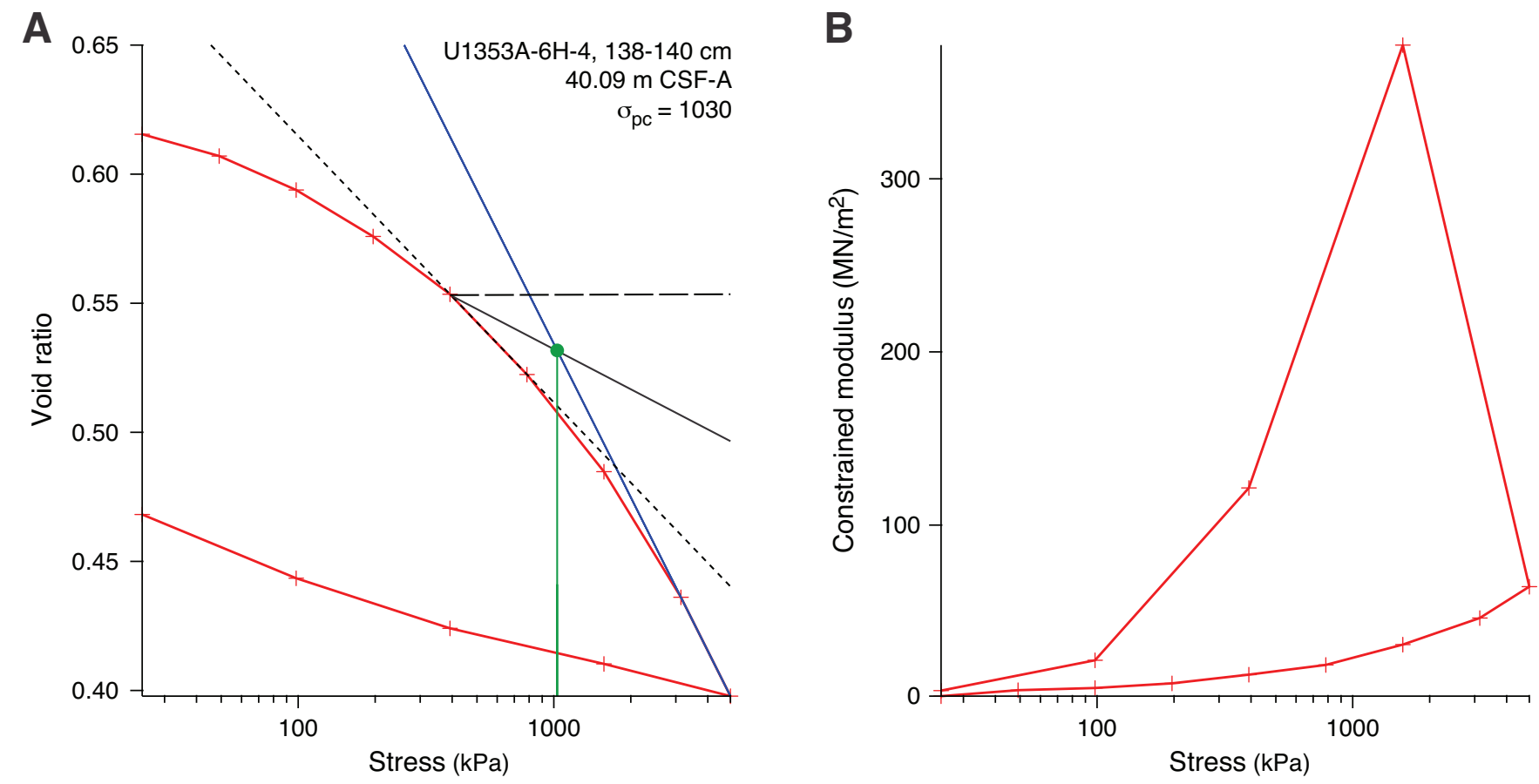
Figure F29. Results of uniaxial consolidation test (interval 317-U1353A-7H-4, 138-140 cm) represented by a semilogarithmic plot of (A) void ratio vs. vertical effective stress and (B) constrained modulus vs. vertical effective stress. Green dot = maximum past effective stress $\left(\sigma_{\mathrm{pc}}\right)$ derived by the graphical method of Casagrande (1936). $\sigma_{\mathrm{pc}}$ corresponds to the abscissa of the point of intersection between the backward projected virgin compression line (blue) and the bisecting line (black solid) between the horizontal line (black dashed) and the tangent (black dotted) at the point of maximum curvature of the consolidation curve (red).
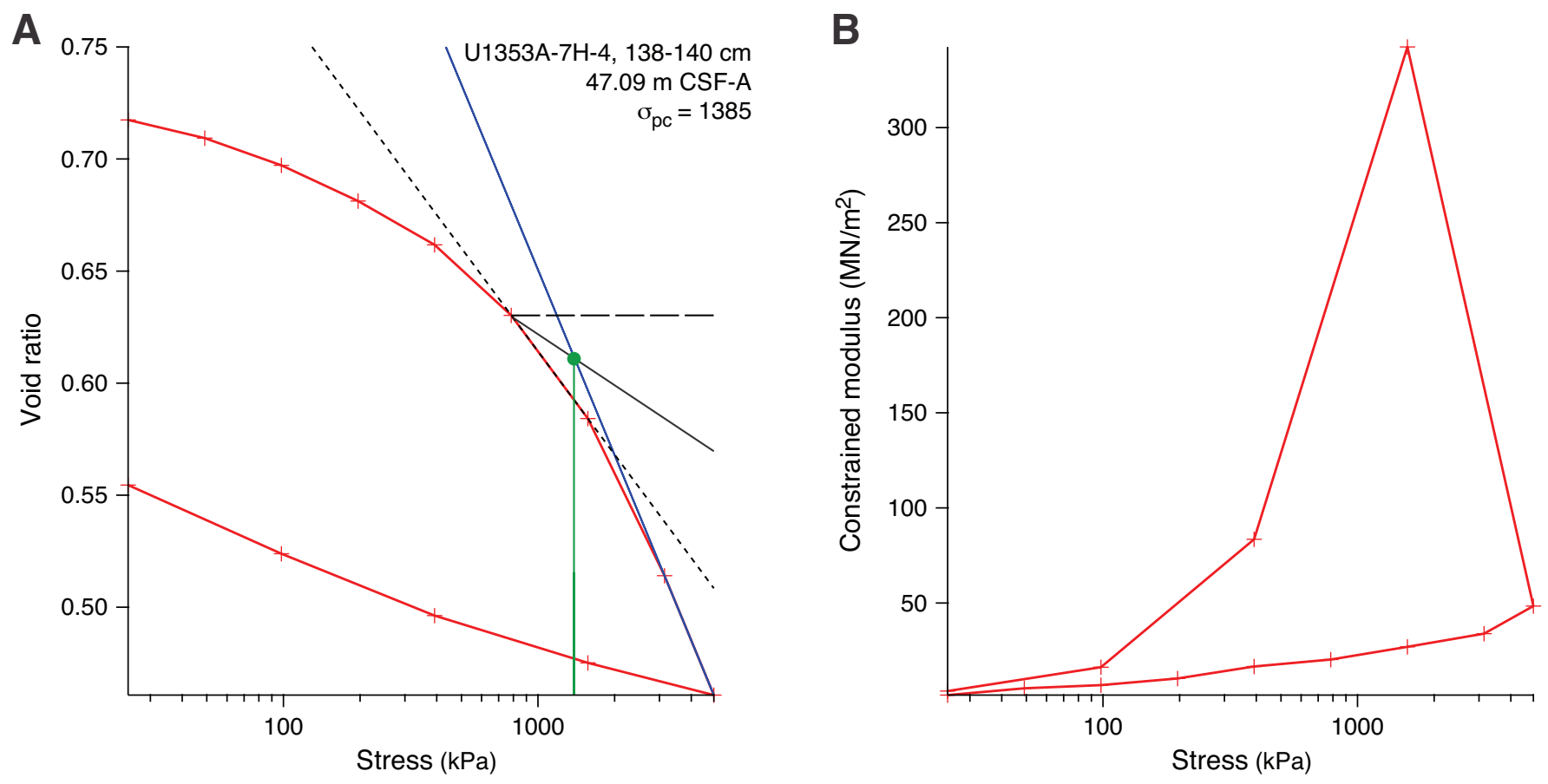
Figure F30. Results of uniaxial consolidation test (interval 317-U1353A-8H-4, 138-140 cm) represented by a semilogarithmic plot of (A) void ratio vs. vertical effective stress and (B) constrained modulus vs. vertical effective stress. Green dot = maximum past effective stress $\left(\sigma_{\mathrm{pc}}\right)$ derived by the graphical method of Casagrande (1936). $\sigma_{\mathrm{pc}}$ corresponds to the abscissa of the point of intersection between the backward projected virgin compression line (blue) and the bisecting line (black solid) between the horizontal line (black dashed) and the tangent (black dotted) at the point of maximum curvature of the consolidation curve (red).
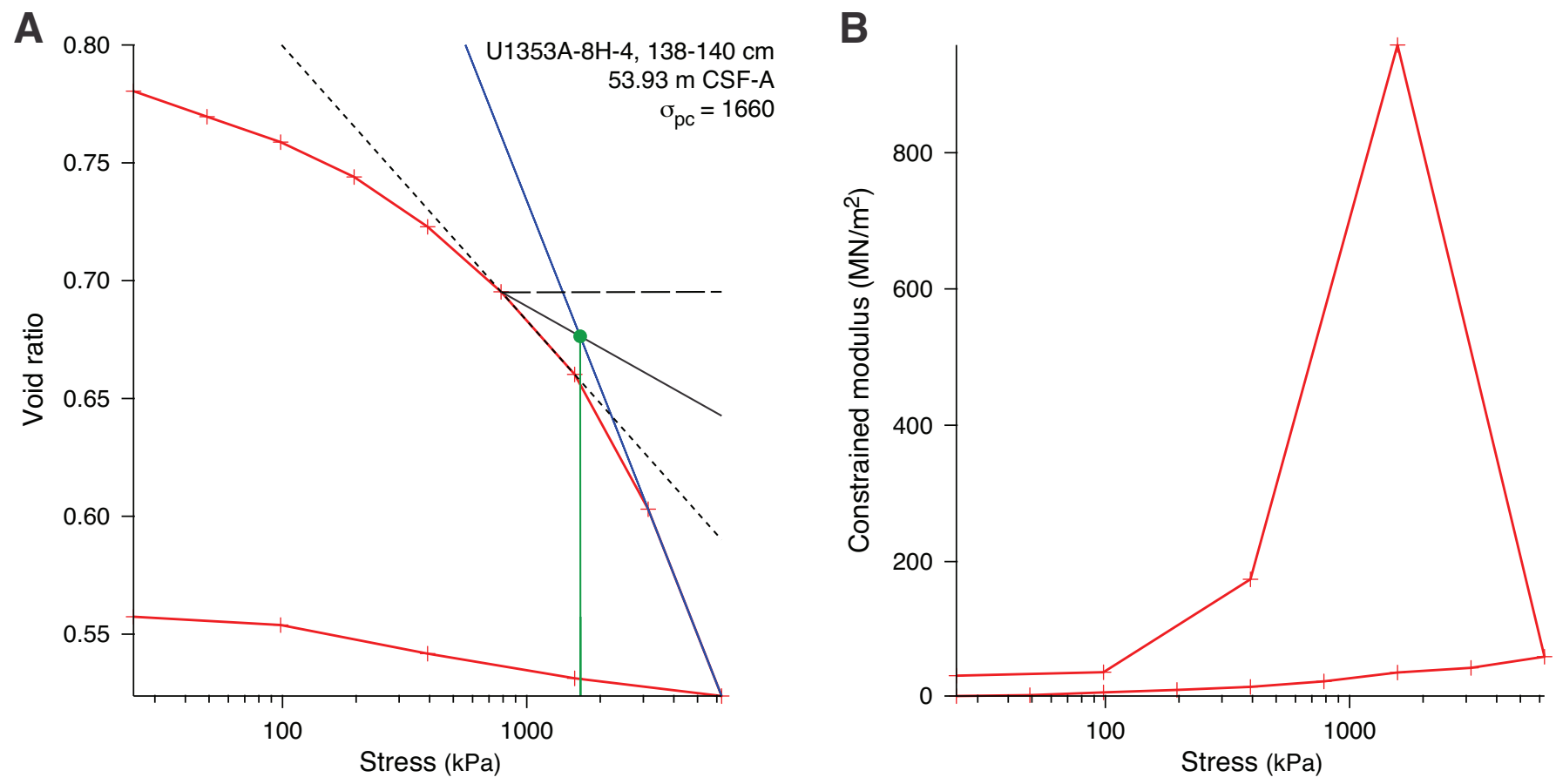
Figure F31. Results of uniaxial consolidation test (interval 317-U1354A-1H-2, 130-132 cm) represented by a semilogarithmic plot of (A) void ratio vs. vertical effective stress and (B) constrained modulus vs. vertical effective stress. Green dot = maximum past effective stress $\left(\sigma_{\mathrm{pc}}\right)$ derived by the graphical method of Casagrande (1936). $\sigma_{\mathrm{pc}}$ corresponds to the abscissa of the point of intersection between the backward projected virgin compression line (blue) and the bisecting line (black solid) between the horizontal line (black dashed) and the tangent (black dotted) at the point of maximum curvature of the consolidation curve (red).
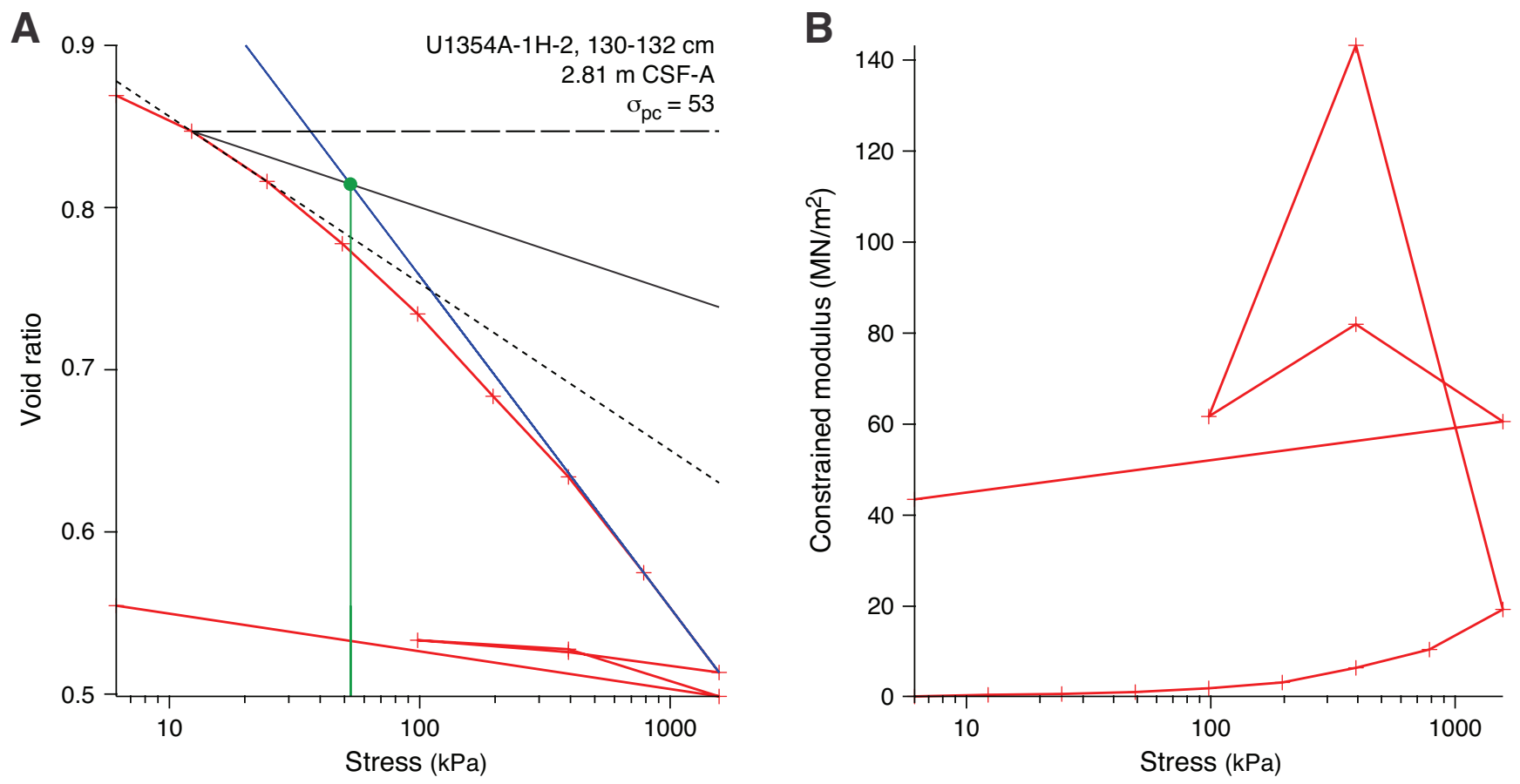
Figure F32. Results of uniaxial consolidation test (interval 317-U1354A-2H-4, 138-140 cm) represented by a semilogarithmic plot of (A) void ratio vs. vertical effective stress and (B) constrained modulus vs. vertical effective stress. Green dot = maximum past effective stress $\left(\sigma_{\mathrm{pc}}\right)$ derived by the graphical method of Casagrande (1936). $\sigma_{\mathrm{pc}}$ corresponds to the abscissa of the point of intersection between the backward projected virgin compression line (blue) and the bisecting line (black solid) between the horizontal line (black dashed) and the tangent (black dotted) at the point of maximum curvature of the consolidation curve (red).
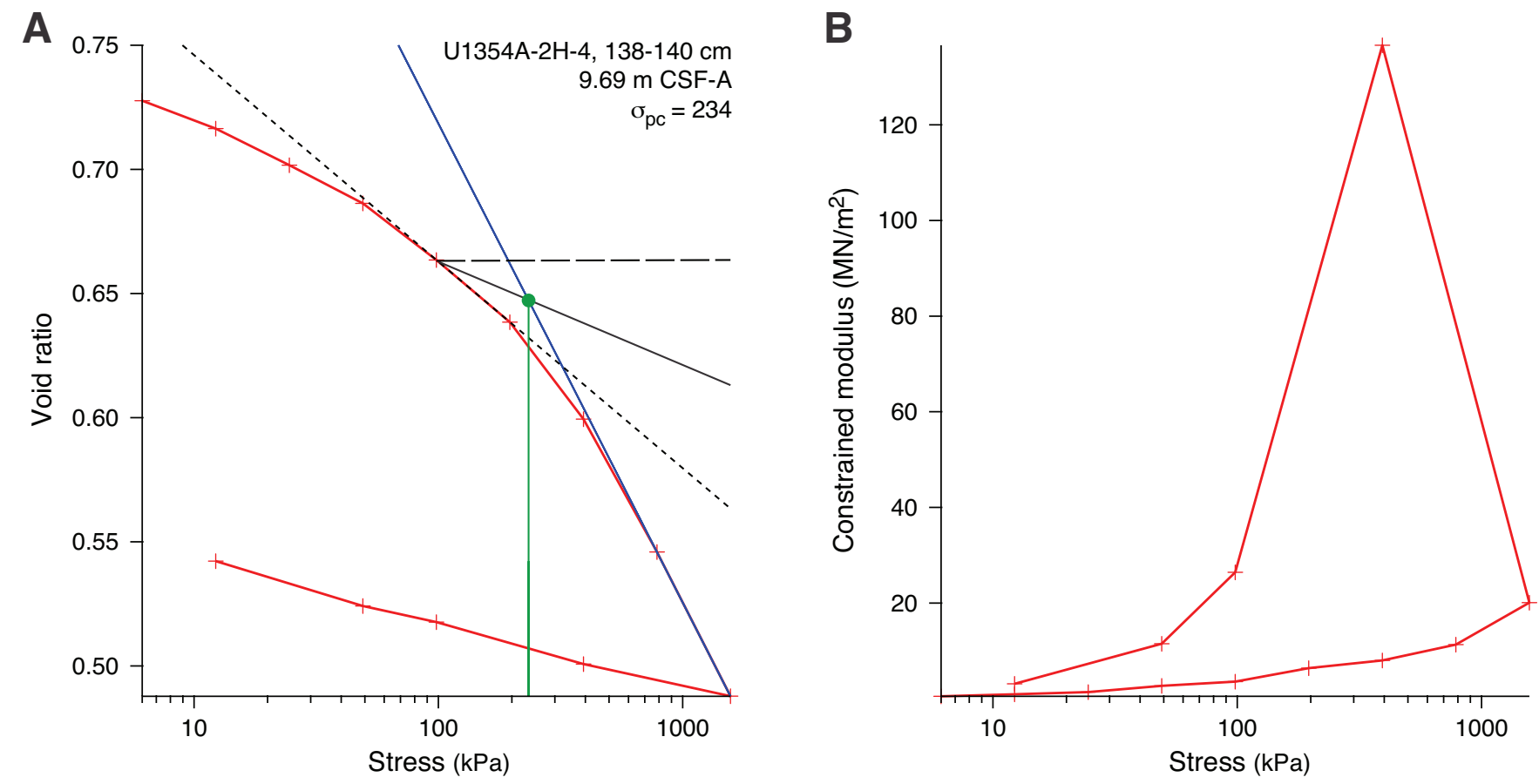
Figure F33. Results of uniaxial consolidation test (interval 317-U1354A-6H-3, 138-140 cm) represented by a semilogarithmic plot of (A) void ratio vs. vertical effective stress and (B) constrained modulus vs. vertical effective stress. Green dot = maximum past effective stress $\left(\sigma_{p c}\right)$ derived by the graphical method of Casagrande (1936). $\sigma_{\mathrm{pc}}$ corresponds to the abscissa of the point of intersection between the backward projected virgin compression line (blue) and the bisecting line (black solid) between the horizontal line (black dashed) and the tangent (black dotted) at the point of maximum curvature of the consolidation curve (red).
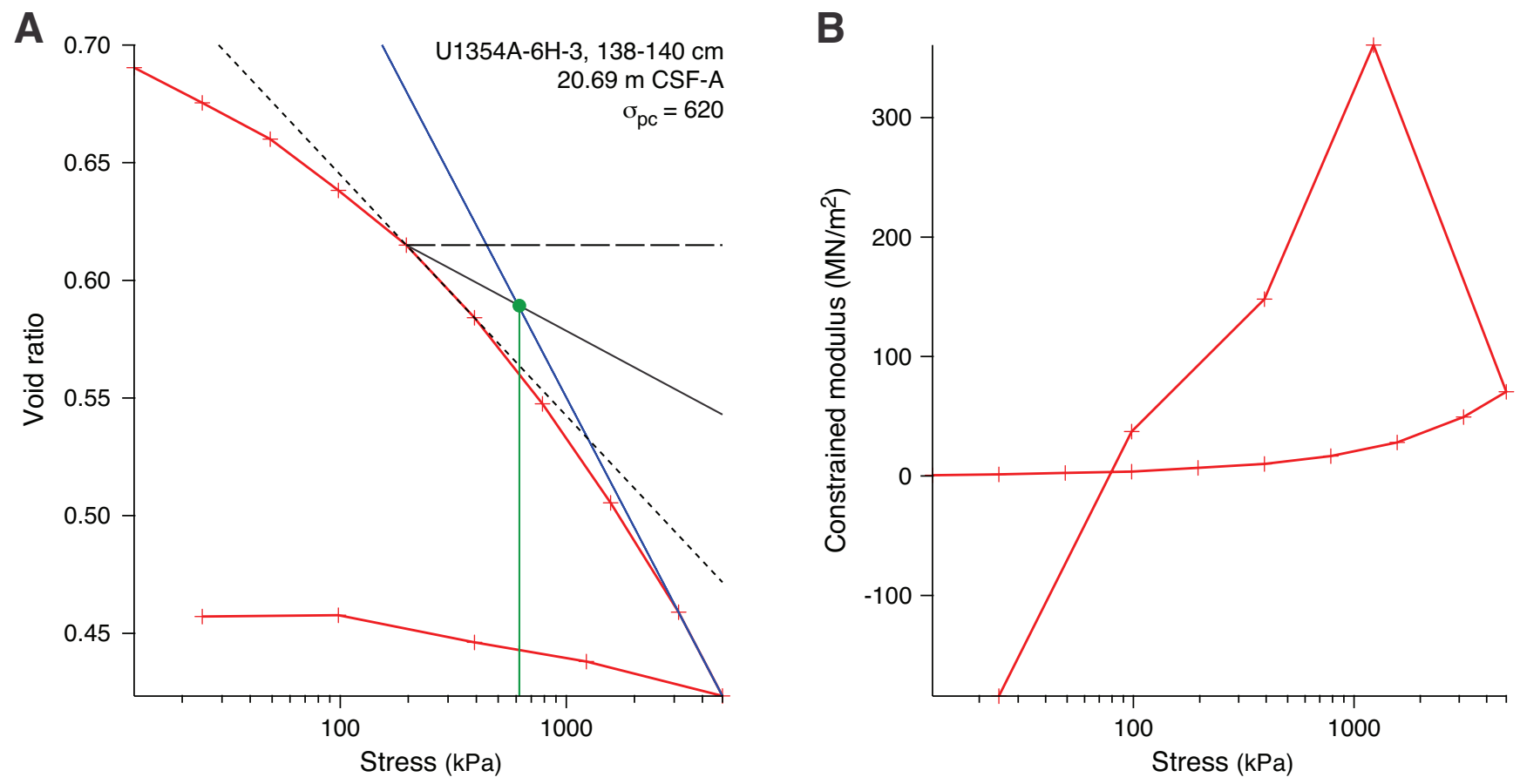
Figure F34. Results of uniaxial consolidation test (interval 317-U1354A-9H-4, 138-140 cm) represented by a semilogarithmic plot of (A) void ratio vs. vertical effective stress and (B) constrained modulus vs. vertical effective stress. Green dot = maximum past effective stress $\left(\sigma_{\mathrm{pc}}\right)$ derived by the graphical method of Casagrande (1936). $\sigma_{\mathrm{pc}}$ corresponds to the abscissa of the point of intersection between the backward projected virgin compression line (blue) and the bisecting line (black solid) between the horizontal line (black dashed) and the tangent (black dotted) at the point of maximum curvature of the consolidation curve (red).
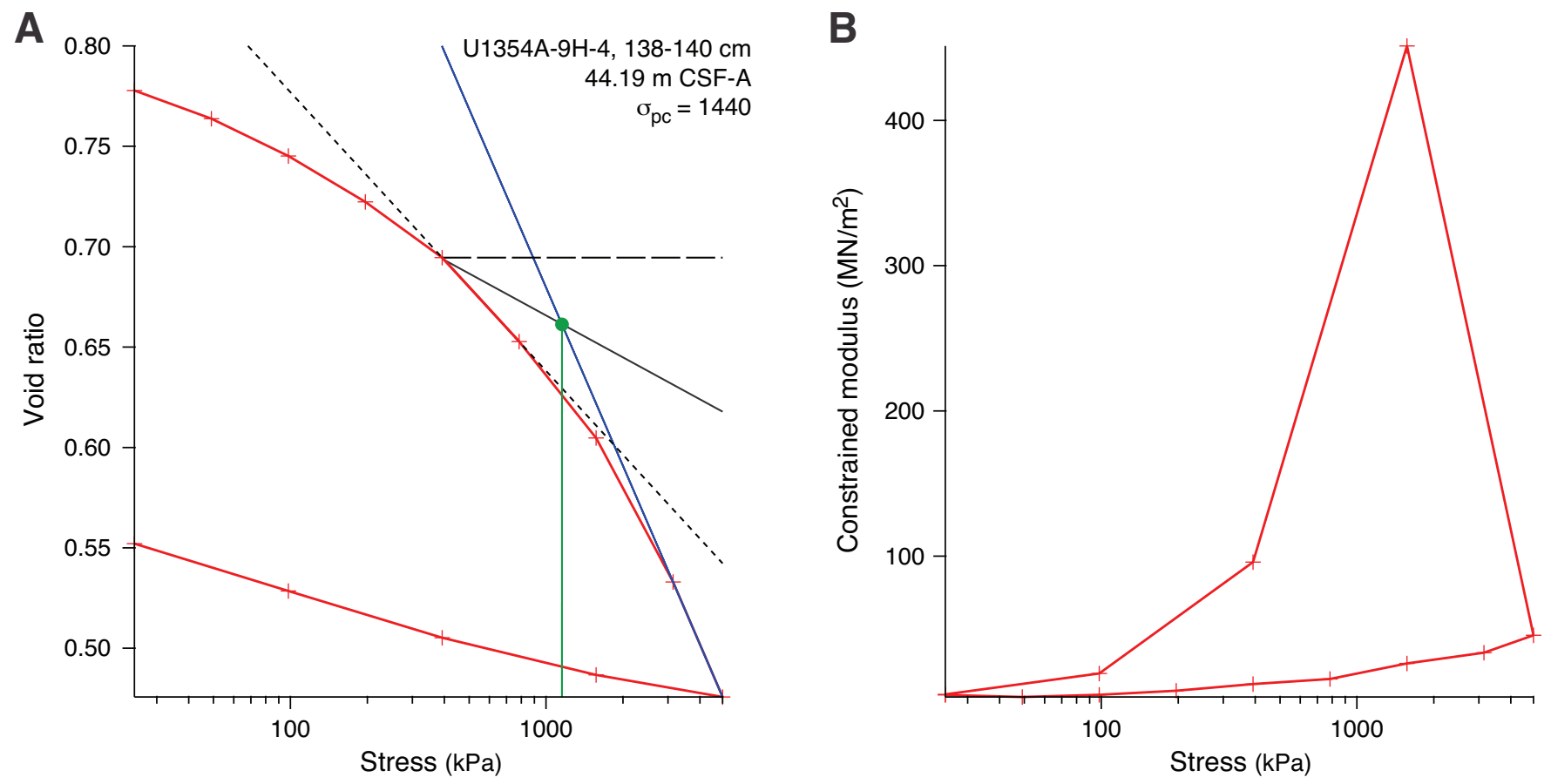
Figure F35. Results of uniaxial consolidation test (interval 317-U1354A-10H-4, 138-140 cm) represented by a semilogarithmic plot of (A) void ratio vs. vertical effective stress and (B) constrained modulus vs. vertical effective stress. Green dot = maximum past effective stress $\left(\sigma_{p c}\right)$ derived by the graphical method of Casagrande (1936). $\sigma_{\mathrm{pc}}$ corresponds to the abscissa of the point of intersection between the backward projected virgin compression line (blue) and the bisecting line (black solid) between the horizontal line (black dashed) and the tangent (black dotted) at the point of maximum curvature of the consolidation curve (red).
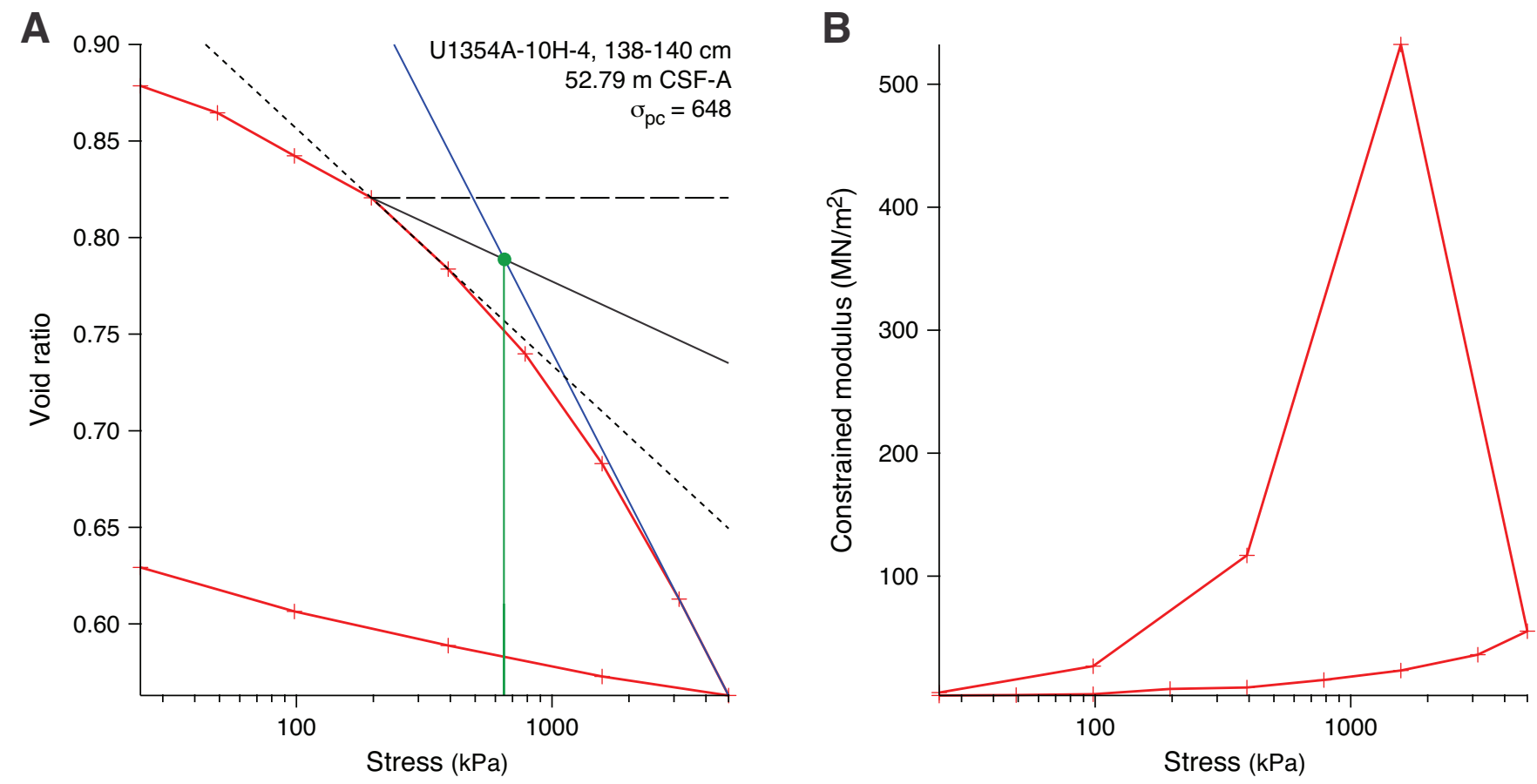
Figure F36. Results of uniaxial consolidation test (interval 317-U1354A-12H-4, 138-140 cm) represented by a semilogarithmic plot of (A) void ratio vs. vertical effective stress and (B) constrained modulus vs. vertical effective stress. Green dot = maximum past effective stress $\left(\sigma_{p c}\right)$ derived by the graphical method of Casagrande (1936). $\sigma_{\mathrm{pc}}$ corresponds to the abscissa of the point of intersection between the backward projected virgin compression line (blue) and the bisecting line (black solid) between the horizontal line (black dashed) and the tangent (black dotted) at the point of maximum curvature of the consolidation curve (red).
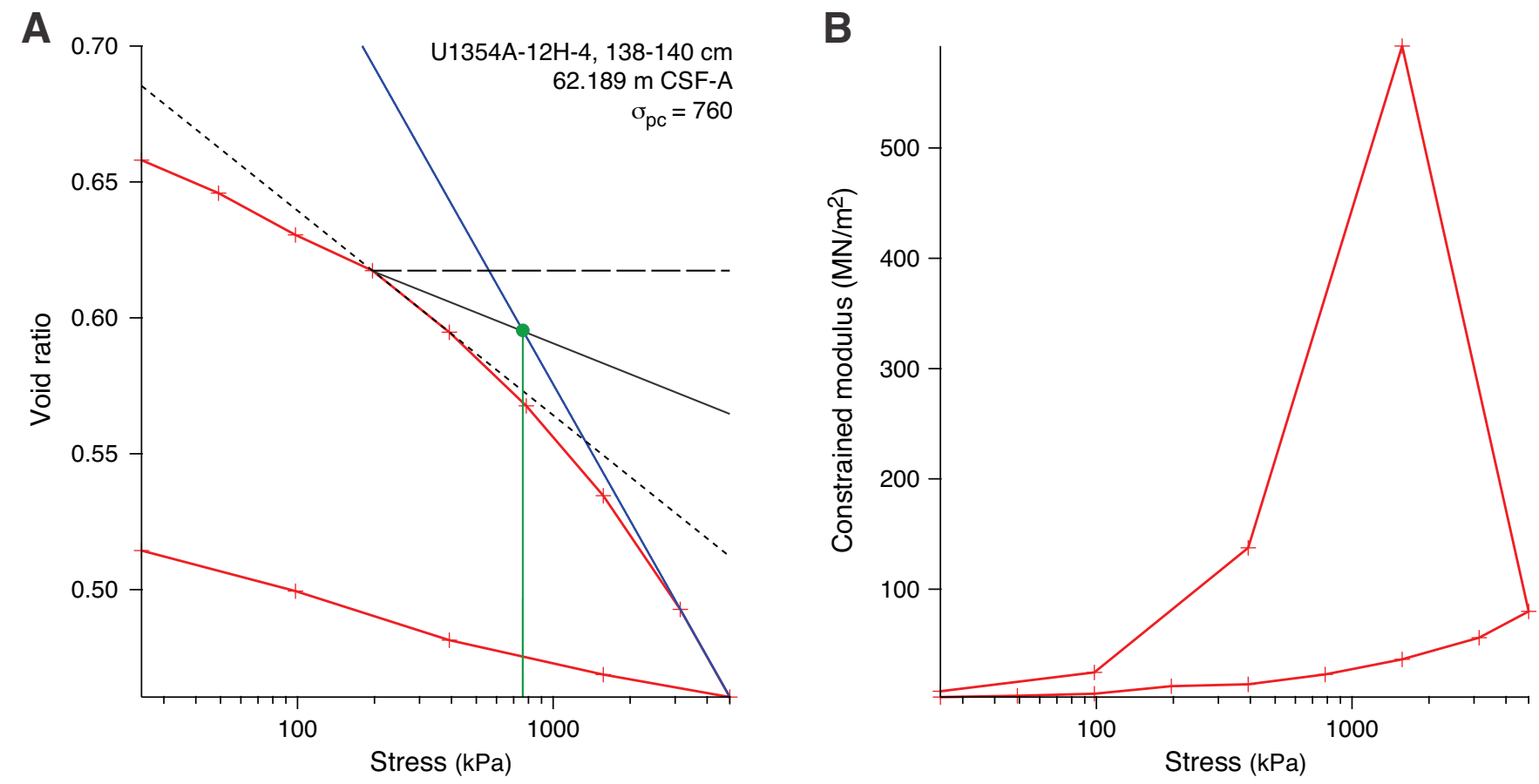
Figure F37. Results of uniaxial consolidation test (interval 317-U1354A-13H-4, 138-140 cm) represented by a semilogarithmic plot of (A) void ratio vs. vertical effective stress and (B) constrained modulus vs. vertical effective stress. Green dot = maximum past effective stress $\left(\sigma_{p c}\right)$ derived by the graphical method of Casagrande (1936). $\sigma_{\mathrm{pc}}$ corresponds to the abscissa of the point of intersection between the backward projected virgin compression line (blue) and the bisecting line (black solid) between the horizontal line (black dashed) and the tangent (black dotted) at the point of maximum curvature of the consolidation curve (red).
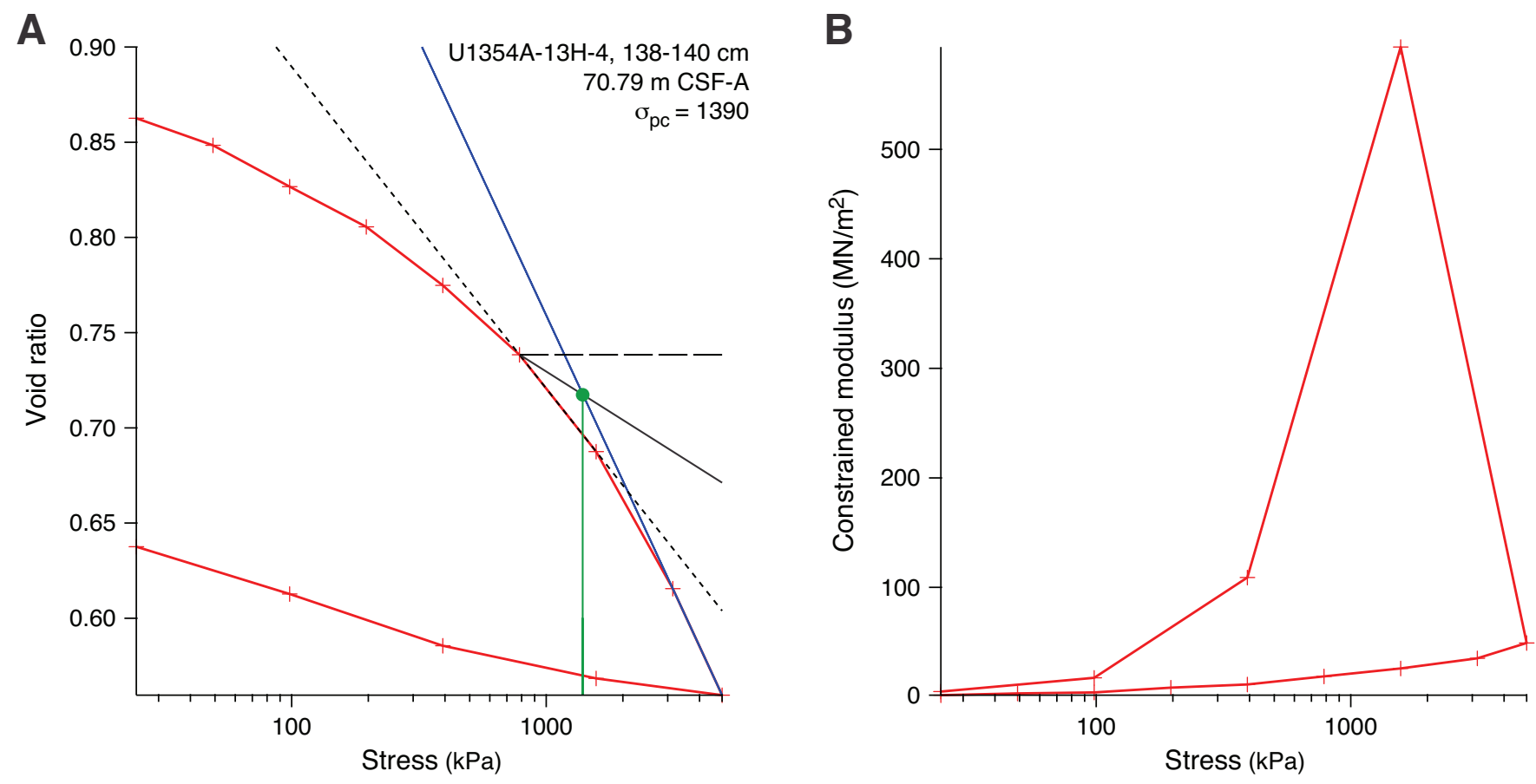
Figure F38. Results of uniaxial consolidation test (interval 317-U1354A-19H-2, 148-150 cm) represented by a semilogarithmic plot of (A) void ratio vs. vertical effective stress and (B) constrained modulus vs. vertical effective stress. Green dot = maximum past effective stress $\left(\sigma_{p c}\right)$ derived by the graphical method of Casagrande (1936). $\sigma_{p c}$ corresponds to the abscissa of the point of intersection between the backward projected virgin compression line (blue) and the bisecting line (black solid) between the horizontal line (black dashed) and the tangent (black dotted) at the point of maximum curvature of the consolidation curve (red).
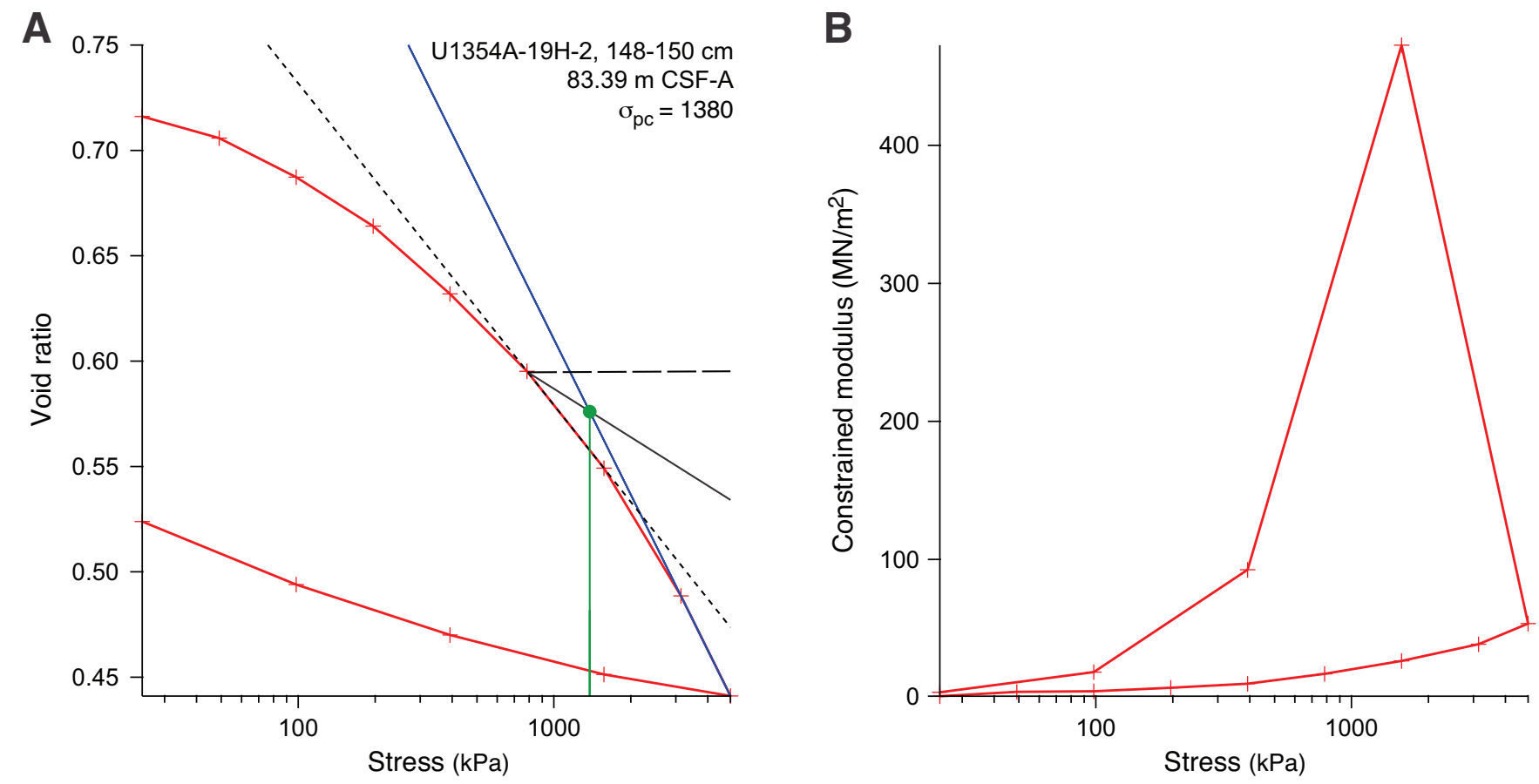
Figure F39. Comparison of maximum past effective overburden stress calculated by the graphical method of Casagrande (1936) vs. depth for Sites U1351-U1354.
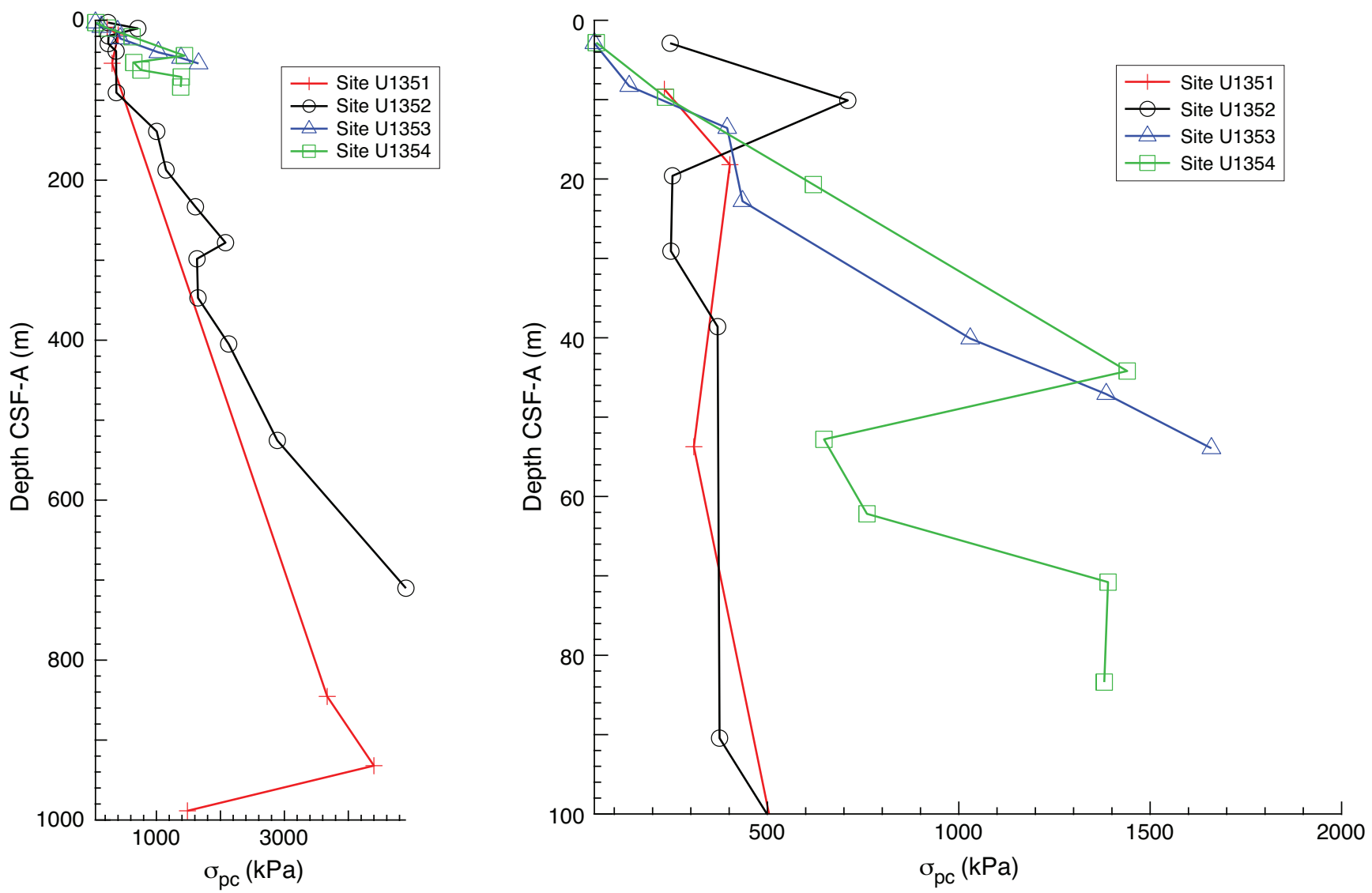
Table T1. Nomenclature and symbols used in this study, Expedition 317.

\begin{tabular}{|c|c|c|}
\hline Symbol & Definition & SI unit \\
\hline$A$ & Area of specimen & $\mathrm{cm}^{2}$ \\
\hline$C_{c}$ & Compression index & \\
\hline$d$ & Diameter of specimen & $\mathrm{cm}$ \\
\hline$e$ & Void ratio & \\
\hline$e_{\mathrm{i}}$ & Initial void ratio measured on specimen & \\
\hline$e_{\mathrm{pc}}$ & Void ratio at the intersection point measured on specimen & \\
\hline$\varepsilon$ & Strain rate & \\
\hline$E_{\mathrm{s}}$ & Constrained modulus & $\mathrm{MN} / \mathrm{m}^{2}$ \\
\hline$g$ & Gravity acceleration & $\mathrm{m} / \mathrm{s}^{2}$ \\
\hline$h$ & Height of specimen & $\mathrm{cm}$ \\
\hline$h_{\mathrm{i}}$ & Initial height of specimen & $\mathrm{cm}$ \\
\hline OCR & Overconsolidation ratio & \\
\hline$\rho_{\mathrm{b}}$ & Bulk density & $\mathrm{g} / \mathrm{cm}^{3}$ \\
\hline$\rho_{\mathrm{d}}$ & Dry bulk density & $\mathrm{g} / \mathrm{cm}^{3}$ \\
\hline$\rho_{\mathrm{pw}}$ & Pore water density & $\mathrm{g} / \mathrm{cm}^{3}$ \\
\hline$\sigma_{\mathrm{pc}}$ & Preconsolidation stress & $\mathrm{kPa}$ \\
\hline$\sigma_{v}^{\prime}$ & Vertical effective stress & $\mathrm{kPa}$ \\
\hline$\sigma_{\mathrm{vh}}^{\prime}$ & Vertical hydrostatic effective stress & $\mathrm{kPa}$ \\
\hline$\sigma_{\mathrm{vi}}^{\prime}$ & Initial vertical effective stress & $\mathrm{kPa}$ \\
\hline$\sigma_{\mathrm{vm}}^{\prime}$ & Maximum vertical effective stress applied on specimen & $\mathrm{kPa}$ \\
\hline$V_{\mathrm{b}}$ & Bulk volume of the specimen & $\mathrm{cm}^{3}$ \\
\hline$w_{\mathrm{d}}$ & Dry weight & g \\
\hline$w_{\mathrm{c}}$ & Water content & $\%$ \\
\hline$z_{\mathrm{s}}$ & Midpoint of depth interval of the sample & mbsf \\
\hline
\end{tabular}


Table T2. Oedometer test conditions, specimen properties, and results for samples from Sites U1351-U1354.

\begin{tabular}{|c|c|c|c|c|c|c|c|c|c|c|c|c|c|c|c|c|c|c|}
\hline \multicolumn{2}{|c|}{ Test information } & \multicolumn{5}{|c|}{ Specimen data } & \multicolumn{6}{|c|}{ Index properties } & \multicolumn{6}{|c|}{ Consolidation properties } \\
\hline $\begin{array}{l}\text { Core, section, } \\
\text { interval }(\mathrm{cm})\end{array}$ & $\begin{array}{c}\text { Depth } \\
\text { CSF-A (m) }\end{array}$ & $\begin{array}{c}A \\
\left(\mathrm{~cm}^{2}\right)\end{array}$ & $\begin{array}{c}d \\
(\mathrm{~cm})\end{array}$ & $\begin{array}{c}h_{\mathrm{i}} \\
(\mathrm{cm})\end{array}$ & $e_{\mathrm{i}}^{*}$ & $\begin{array}{l}\sigma_{\mathrm{vm}}^{\prime} \\
(\mathrm{kPa})\end{array}$ & $\begin{array}{c}w_{c} \\
(\%)^{*}\end{array}$ & $\frac{\rho_{b}}{\left(\mathrm{~g} / \mathrm{cm}^{3}\right)^{*}}$ & $\begin{array}{c}\rho_{\mathrm{b}} \\
\left(\mathrm{g} / \mathrm{cm}^{3}\right)^{\dagger}\end{array}$ & $\begin{array}{c}\rho_{b}-1 \\
c\left(g / \mathrm{cm}^{3}\right)^{\star}\end{array}$ & $\begin{array}{c}\rho_{\mathrm{b}}-1 \\
\mathrm{c}\left(\mathrm{g} / \mathrm{cm}^{3}\right)^{\dagger}\end{array}$ & $\frac{\rho_{\mathrm{d}}}{\left(\mathrm{g} / \mathrm{cm}^{3}\right)^{*}}$ & $e_{\mathrm{pc}}{ }^{*}$ & $\begin{array}{c}\sigma_{\mathrm{v}}^{\prime} \\
(\mathrm{kPa})\end{array}$ & $\begin{array}{c}\sigma_{\mathrm{pc}} \\
(\mathrm{kPa})\end{array}$ & $c_{c}$ & $\begin{array}{c}E_{\mathrm{s}} \\
\left(\mathrm{MN} / \mathrm{m}^{2}\right)\end{array}$ & OCR \\
\hline \multicolumn{19}{|l|}{ 317-U1351A- } \\
\hline $2 \mathrm{H}-4,148-150$ & 8.69 & 20.00 & 5.05 & 1.48 & 0.76 & $1,569.76$ & 0.26 & 1.89 & 1.85 & 0.89 & 0.85 & 1.51 & 0.61 & 75.75 & 231.00 & 0.21 & 18.16 & 3.05 \\
\hline $3 \mathrm{H}-4,148-150$ & 18.19 & 20.00 & 5.05 & 1.48 & 0.60 & $1,569.76$ & 0.24 & 2.05 & 1.93 & 1.05 & 0.93 & 1.65 & 0.53 & 186.39 & 402.00 & 0.15 & 25.51 & 2.16 \\
\hline \multicolumn{19}{|l|}{ 317-U1351B- } \\
\hline $8 \mathrm{H}-4,152-154$ & 53.73 & 20.00 & 5.05 & 1.48 & 0.75 & $1,569.76$ & 0.27 & 1.92 & 2.00 & 0.92 & 1.00 & 1.52 & 0.61 & 485.98 & 308.00 & 0.18 & 21.97 & 0.63 \\
\hline $97 X-3,148-150$ & 845.49 & 10.00 & 3.57 & 1.48 & 0.60 & $34,339.78$ & 0.14 & 1.89 & 2.03 & 0.89 & 1.03 & 1.66 & 0.51 & $7,422.99$ & $3,670.00$ & 0.27 & 308.98 & 0.49 \\
\hline $106 X-3,98-100$ & 931.99 & 10.00 & 3.57 & 1.48 & 0.41 & $32,868.07$ & 0.11 & 2.18 & 2.04 & 1.18 & 1.04 & 1.88 & 0.32 & $10,791.44$ & $4,400.00$ & 0.17 & 404.02 & 0.41 \\
\hline $112 X-2,148-150$ & 988.49 & 10.00 & 3.57 & 1.48 & 0.46 & $34,339.78$ & 0.11 & 2.02 & 2.04 & 1.02 & 1.04 & 1.82 & 0.37 & $9,873.34$ & $1,485.00$ & 0.15 & 510.36 & 0.15 \\
\hline \multicolumn{19}{|l|}{ 317-U1352A- } \\
\hline $1 \mathrm{H}-2,138-140$ & 2.89 & 20.00 & 5.05 & 1.48 & 0.71 & $4,905.52$ & 0.22 & 1.89 & 1.85 & 0.89 & 0.85 & 1.55 & 0.64 & 25.28 & 246.00 & 0.20 & 60.12 & 9.73 \\
\hline $2 \mathrm{H}-4,138-140$ & 10.09 & 20.00 & 5.05 & 1.48 & 0.58 & $4,905.52$ & 0.39 & 2.33 & 1.91 & 1.33 & 0.91 & 1.68 & 0.48 & 131.20 & 710.00 & 0.15 & 83.66 & 5.41 \\
\hline $3 \mathrm{H}-4,138-140$ & 19.59 & 20.00 & 5.05 & 1.48 & 0.46 & $3,139.53$ & 0.07 & 1.94 & 1.95 & 0.94 & 0.95 & 1.82 & 0.38 & 181.24 & 252.00 & 0.11 & 59.70 & 1.39 \\
\hline $4 \mathrm{H}-4,138-140$ & 29.09 & 20.00 & 5.05 & 1.48 & 0.76 & $3,139.53$ & 0.22 & 1.84 & 1.95 & 0.84 & 0.95 & 1.51 & 0.60 & 238.48 & 248.00 & 0.18 & 41.22 & 1.04 \\
\hline $5 \mathrm{H}-4,138-140$ & 38.59 & 20.00 & 5.05 & 1.48 & 0.71 & $3,139.53$ & 0.20 & 1.86 & 1.95 & 0.86 & 0.95 & 1.55 & 0.55 & 325.81 & 370.00 & 0.13 & 56.16 & 1.14 \\
\hline \multicolumn{19}{|l|}{ 317-U1352B- } \\
\hline $10 \mathrm{H}-5,148-150$ & 90.45 & 20.00 & 5.05 & 1.48 & 0.69 & $3,139.53$ & 0.22 & 1.91 & 1.97 & 0.91 & 0.97 & 1.56 & 0.61 & 807.19 & 375.00 & 0.18 & 40.13 & 0.46 \\
\hline $15 \mathrm{H}-5,148-150$ & 138.99 & 20.00 & 5.05 & 1.48 & 0.79 & $17,169.30$ & 0.19 & 1.76 & 1.97 & 0.76 & 0.97 & 1.48 & 0.69 & $1,040.85$ & $1,005.00$ & 0.28 & 156.92 & 0.97 \\
\hline $21 \mathrm{H}-5,148-150$ & 187.19 & 20.00 & 5.05 & 1.48 & 0.81 & $17,169.30$ & 0.23 & 1.80 & 1.97 & 0.80 & 0.97 & 1.46 & 0.72 & $1,464.99$ & $1,152.00$ & 0.31 & 146.63 & 0.79 \\
\hline $26 \mathrm{H}-4,148-150$ & 233.11 & 20.00 & 5.05 & 1.48 & 0.76 & $12,263.79$ & 0.22 & 1.83 & 1.97 & 0.83 & 0.97 & 1.50 & 0.64 & $1,906.91$ & $1,610.00$ & 0.31 & 89.54 & 0.84 \\
\hline $32 \mathrm{H}-4,143-145$ & 278.14 & 20.00 & 5.05 & 1.48 & 0.82 & $12,263.79$ & 0.21 & 1.76 & 1.97 & 0.76 & 0.97 & 1.45 & 0.67 & $2,082.24$ & $2,080.00$ & 0.30 & 96.46 & 1.00 \\
\hline $37 X-1,118-120$ & 298.19 & 20.00 & 5.05 & 1.48 & 0.73 & $12,263.79$ & 0.18 & 1.81 & 1.97 & 0.81 & 0.97 & 1.53 & 0.57 & $2,374.47$ & $1,635.00$ & 0.27 & 99.42 & 0.69 \\
\hline $42 X-4,148-150$ & 347.09 & 20.00 & 5.05 & 1.48 & 0.89 & $12,263.79$ & 0.23 & 1.72 & 1.97 & 0.72 & 0.97 & 1.40 & 0.68 & $2,457.40$ & $1,650.00$ & 0.30 & 94.66 & 0.67 \\
\hline $48 X-4,148-150$ & 404.69 & 20.00 & 5.05 & 1.48 & 0.67 & $16,678.75$ & 0.19 & 2.00 & 1.97 & 1.00 & 0.97 & 1.59 & 0.60 & $3,974.36$ & $2,130.00$ & 0.17 & 212.24 & 0.54 \\
\hline $61 X-2,82-84$ & 525.33 & 10.00 & 3.57 & 1.48 & 0.92 & $25,103.02$ & 0.21 & 1.67 & 1.98 & 0.67 & 0.98 & 1.38 & 0.74 & $3,444.62$ & $2,890.00$ & 0.39 & 143.05 & 0.84 \\
\hline $81 X-3,98-100$ & 710.09 & 20.00 & 5.05 & 1.48 & 0.14 & $34,320.54$ & 0.19 & 2.33 & 1.99 & 1.33 & 0.99 & 3.09 & 0.23 & $9,289.31$ & $4,900.00$ & 0.15 & 280.57 & 0.53 \\
\hline \multicolumn{19}{|l|}{ 317-U1353A- } \\
\hline $1 \mathrm{H}-2,138-140$ & 2.89 & 20.00 & 5.05 & 1.48 & 1.21 & $1,569.76$ & 0.28 & 1.53 & 1.72 & 0.53 & 0.72 & 1.20 & 1.02 & 15.00 & 48.00 & 0.32 & 12.17 & 3.20 \\
\hline $2 \mathrm{H}-2,128-130$ & 8.29 & 20.00 & 5.05 & 1.48 & 0.97 & $3,139.53$ & 0.25 & 1.68 & 1.77 & 0.68 & 0.77 & 1.34 & 0.83 & 55.56 & 139.00 & 0.23 & 33.50 & 2.50 \\
\hline $3 \mathrm{H}-3,126-128$ & 13.57 & 20.00 & 5.05 & 1.48 & 0.71 & $3,139.53$ & 0.22 & 1.90 & 1.82 & 0.90 & 0.82 & 1.55 & 0.59 & 119.24 & 395.00 & 0.15 & 51.10 & 3.31 \\
\hline $4 \mathrm{H}-4,8-10$ & 22.79 & 20.00 & 5.05 & 1.48 & 0.78 & $3,139.53$ & 0.26 & 1.88 & 1.87 & 0.88 & 0.87 & 1.49 & 0.68 & 197.55 & 435.00 & 0.23 & 33.95 & 2.20 \\
\hline $6 \mathrm{H}-4,138-140$ & 40.09 & 20.00 & 5.05 & 1.48 & 0.65 & $4,905.52$ & 0.26 & 2.03 & 1.91 & 1.03 & 0.91 & 1.61 & 0.54 & 405.08 & $1,030.00$ & 0.20 & 64.44 & 2.54 \\
\hline $7 \mathrm{H}-4,138-140$ & 47.09 & 20.00 & 5.05 & 1.48 & 0.72 & $4,905.52$ & 0.26 & 1.92 & 1.92 & 0.92 & 0.92 & 1.52 & 0.65 & 423.67 & $1,385.00$ & 0.27 & 48.45 & 3.27 \\
\hline $8 \mathrm{H}-4,138-140$ & 53.93 & 10.00 & 3.57 & 1.48 & 0.80 & $6,279.27$ & 0.24 & 1.83 & 1.92 & 0.83 & 0.92 & 1.47 & 0.68 & 438.36 & $1,660.00$ & 0.26 & 60.34 & 3.79 \\
\hline \multicolumn{19}{|l|}{ 317-U1354A- } \\
\hline $1 \mathrm{H}-2,130-132$ & 2.81 & 20.00 & 5.05 & 1.48 & 0.93 & $1,569.76$ & 0.24 & 1.70 & NA & 0.70 & NA & 1.37 & 0.83 & 19.27 & 53.00 & 0.20 & 19.30 & 2.75 \\
\hline $2 \mathrm{H}-4,138-140$ & 9.69 & 20.00 & 5.05 & 1.48 & 0.75 & $1,569.76$ & 0.25 & 1.90 & NA & 0.90 & NA & 1.52 & 0.67 & 85.62 & 234.00 & 0.19 & 20.11 & 2.73 \\
\hline $6 \mathrm{H}-3,138-140$ & 20.69 & 20.00 & 5.05 & 1.48 & 0.72 & $4,905.52$ & 0.20 & 1.85 & NA & 0.85 & NA & 1.54 & 0.63 & 171.60 & 620.00 & 0.18 & 70.58 & 3.61 \\
\hline $9 \mathrm{H}-4,138-140$ & 44.19 & 20.00 & 5.05 & 1.48 & 0.79 & $4,905.52$ & 0.25 & 1.86 & NA & 0.86 & NA & 1.48 & 0.67 & 372.67 & $1,440.00$ & 0.30 & 45.52 & 3.86 \\
\hline $10 \mathrm{H}-4,138-140$ & 52.79 & 20.00 & 5.05 & 1.48 & 0.89 & $4,905.52$ & 0.25 & 1.75 & NA & 0.75 & NA & 1.40 & 0.80 & 388.54 & 648.00 & 0.26 & 55.30 & 1.67 \\
\hline $12 \mathrm{H}-4,138-140$ & 62.19 & 20.00 & 5.05 & 1.48 & 0.68 & $4,905.52$ & 0.22 & 1.93 & NA & 0.93 & NA & 1.58 & 0.61 & 566.17 & 760.00 & 0.17 & 79.88 & 1.34 \\
\hline $13 \mathrm{H}-4,138-140$ & 70.79 & 20.00 & 5.05 & 1.48 & 0.89 & $4,905.52$ & 0.26 & 1.76 & NA & 0.76 & NA & 1.40 & 0.71 & 529.06 & $1,390.00$ & 0.29 & 49.21 & 2.63 \\
\hline $19 \mathrm{H}-2,148-150$ & 83.39 & 20.00 & 5.05 & 1.48 & 0.76 & $4,905.52$ & 0.21 & 1.81 & NA & 0.81 & NA & 1.50 & 0.57 & 663.92 & $1,380.00$ & 0.25 & 53.55 & 2.08 \\
\hline
\end{tabular}

$*$ = calculated from oedometer test, $\dagger=$ from shipboard moisture and density data for interval closest to the sample. NA = not applicable. See Table T1 for symbol definitions. 
Table T3. Quantification of sample disturbance using ratings criteria from Lunne et al. (1997), Sites U1351U1354.

\begin{tabular}{|c|c|c|c|c|}
\hline \multicolumn{2}{|c|}{ Test information } & \multirow{2}{*}{\multicolumn{3}{|c|}{ Rating }} \\
\hline \multirow{2}{*}{$\begin{array}{l}\text { Core, section, } \\
\text { interval }(\mathrm{cm})\end{array}$} & \multirow{2}{*}{$\begin{array}{c}\text { Depth } \\
\text { CSF-A (m) }\end{array}$} & & & \\
\hline & & $\Delta e$ & $\Delta e / e_{\mathrm{i}}$ & Criteria \\
\hline \multicolumn{5}{|l|}{ 317-U1351A- } \\
\hline $2 \mathrm{H}-4,148-150$ & 8.69 & 0.15 & 0.20 & Very poor \\
\hline $3 \mathrm{H}-4,148-150$ & 18.19 & 0.07 & 0.11 & Poor \\
\hline \multicolumn{5}{|l|}{ 317-U1351B- } \\
\hline $8 \mathrm{H}-4,152-154$ & 53.73 & 0.14 & 0.19 & Very poor \\
\hline $97 X-3,148-150$ & 845.49 & 0.09 & 0.16 & Very poor \\
\hline $106 X-3,98-100$ & 931.99 & 0.09 & 0.23 & Very poor \\
\hline $112 X-2,148-150$ & 988.49 & 0.08 & 0.18 & Very poor \\
\hline \multicolumn{5}{|l|}{ 317-U1352A- } \\
\hline $1 \mathrm{H}-2,138-140$ & 2.89 & 0.07 & 0.10 & Poor \\
\hline $2 \mathrm{H}-4,138-140$ & 10.09 & 0.10 & 0.17 & Very poor \\
\hline $3 \mathrm{H}-4,138-140$ & 19.59 & 0.08 & 0.17 & Very poor \\
\hline $4 \mathrm{H}-4,138-140$ & 29.09 & 0.15 & 0.20 & Very poor \\
\hline $5 \mathrm{H}-4,138-140$ & 38.59 & 0.16 & 0.22 & Very poor \\
\hline \multicolumn{5}{|l|}{ 317-U1352B- } \\
\hline $10 \mathrm{H}-5,148-150$ & 90.45 & 0.08 & 0.12 & Poor \\
\hline $15 \mathrm{H}-5,148-150$ & 138.99 & 0.10 & 0.12 & Poor \\
\hline $21 \mathrm{H}-5,148-150$ & 187.19 & 0.09 & 0.11 & Poor \\
\hline $26 \mathrm{H}-4,148-150$ & 233.11 & 0.12 & 0.16 & Very poor \\
\hline $32 \mathrm{H}-4,143-145$ & 278.14 & 0.15 & 0.19 & Very poor \\
\hline $37 X-1,118-120$ & 298.19 & 0.16 & 0.22 & Very poor \\
\hline $42 X-4,148-150$ & 347.09 & 0.22 & 0.24 & Very poor \\
\hline $48 X-4,148-150$ & 404.69 & 0.06 & 0.10 & Fair \\
\hline $61 X-2,82-84$ & 525.33 & 0.18 & 0.20 & Very poor \\
\hline \multicolumn{5}{|l|}{ 317-U1353A- } \\
\hline $1 \mathrm{H}-2,138-140$ & 2.89 & 0.19 & 0.16 & Very poor \\
\hline $2 \mathrm{H}-2,128-130$ & 8.29 & 0.14 & 0.14 & Poor \\
\hline $3 \mathrm{H}-3,126-128$ & 13.57 & 0.12 & 0.17 & Very poor \\
\hline $4 \mathrm{H}-4,8-10$ & 22.79 & 0.10 & 0.12 & Poor \\
\hline $6 \mathrm{H}-4,138-140$ & 40.09 & 0.11 & 0.17 & Very poor \\
\hline 7H-4, 138-140 & 47.09 & 0.07 & 0.10 & Poor \\
\hline $8 \mathrm{H}-4,138-140$ & 53.93 & 0.12 & 0.15 & Very poor \\
\hline \multicolumn{5}{|l|}{ 317-U1354A- } \\
\hline $1 \mathrm{H}-2,130-132$ & 2.81 & 0.10 & 0.11 & Poor \\
\hline $2 \mathrm{H}-4,138-140$ & 9.69 & 0.07 & 0.10 & Poor \\
\hline $6 \mathrm{H}-3,138-140$ & 20.69 & 0.10 & 0.13 & Poor \\
\hline $9 \mathrm{H}-4,138-140$ & 44.19 & 0.11 & 0.14 & Poor \\
\hline $10 \mathrm{H}-4,138-140$ & 52.79 & 0.09 & 0.10 & Poor \\
\hline $12 \mathrm{H}-4,138-140$ & 62.19 & 0.07 & 0.10 & Poor \\
\hline $13 \mathrm{H}-4,138-140$ & 70.79 & 0.18 & 0.20 & Very poor \\
\hline $19 \mathrm{H}-2,148-150$ & 83.39 & 0.19 & 0.25 & Very poor \\
\hline
\end{tabular}

